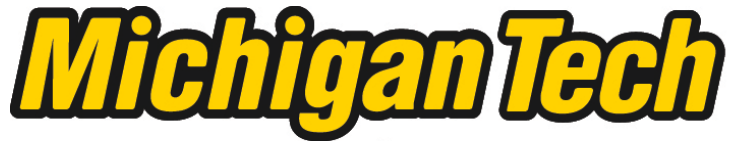 \\ Michigan Technological University Create the Future Digital Commons @ Michigan Tech
}

\section{Twelve factors influencing sustainable recycling of municipal solid waste in developing countries}

Alexis Manda Troschinetz

Michigan Technological University

Follow this and additional works at: https://digitalcommons.mtu.edu/etds

Part of the Civil and Environmental Engineering Commons

Copyright 2005 Alexis Manda Troschinetz

\section{Recommended Citation}

Troschinetz, Alexis Manda, "Twelve factors influencing sustainable recycling of municipal solid waste in developing countries ", Master's Thesis, Michigan Technological University, 2005.

https://doi.org/10.37099/mtu.dc.etds/277

Follow this and additional works at: https://digitalcommons.mtu.edu/etds

3 Part of the Civil and Environmental Engineering Commons 


\title{
TWELVE FACTORS INFLUENCING SUSTAINABLE RECYCLING OF MUNICIPAL SOLID WASTE IN DEVELOPING COUNTRIES
}

\author{
By \\ ALEXIS MANDA TROSCHINETZ \\ A THESIS \\ Submitted in partial fulfillment of the requirements \\ for the degree of \\ MASTER OF SCIENCE IN ENVIRONMENTAL ENGINEERING \\ MICHIGAN TECHNOLOGICAL UNIVERSITY \\ 2005
}

Copyright $(\mathbb{C}$ Alexis M. Troschinetz 2005 
This thesis, "Twelve factors influencing sustainable recycling of municipal solid waste in developing countries," is hereby approved in partial fulfillment of the requirements for the Degree of MASTER OF SCIENCE IN ENVIRONMENTAL ENGINEERING.

\section{DEPARTMENT or PROGRAM:}

Civil and Environmental Engineering

-Signatures-

Thesis Advisor:

Dr. James R. Mihelcic

Department Chair:

Dr. Neil J. Hutzler

Date: 


\section{Abstract}

Sustainable management of solid waste is a global concern, as exemplified by the United Nations Millennium Development Goals (MDG) that 191 member states support. The seventh MDG indirectly advocates for municipal solid waste management (MSWM) by aiming to ensure environmental sustainability into countries' policies and programs and reverse negative environmental impact. Proper MSWM will likely result in relieving poverty, reducing child mortality, improving maternal health, and preventing disease, which are MDG goals one, four, five, and six, respectively (UNMDG, 2005).

Solid waste production is increasing worldwide as the global society strives to obtain a decent quality of life. Several means exist in which the amount of solid waste going to a landfill can be reduced, such as incineration with energy production, composting of organic wastes, and material recovery through recycling, which are all considered sustainable methods by which to manage MSW. In the developing world, composting is already a widely-accepted method to reduce waste fated for the landfill, and incineration for energy recovery can be a costly capital investment for most communities. Therefore, this research focuses on recycling as a solution to the municipal solid waste production problem while considering the three dimensions of sustainability environment, society, and economy.

First, twenty-three developing country case studies were quantitatively and qualitatively examined for aspects of municipal solid waste management. The municipal solid waste (MSW) generation and recovery rates, as well as the composition were compiled and assessed. The average MSW generation rate was $0.77 \mathrm{~kg} /$ person/day, with recovery rates varying from $5-40 \%$. The waste streams of nineteen of these case studies consisted of $0-70 \%$ recyclable material and $17-80 \%$ organic material. 
All twenty-three case studies were analyzed qualitatively by identifying any barriers or incentives to recycling, which justified the creation of twelve factors influencing sustainable municipal solid waste management (MSWM) in developing countries. The presence of regulations, enforcement of laws, and use of incentive schemes constitutes the first factor, Government Policy. Cost of MSWM operations, the budget allocated to MSWM by local to national governments, as well as the stability and reliability of funds comprise the Government Finances factor influencing recycling in the third world.

Many case studies indicated that understanding features of a waste stream such as the generation and recovery rates and composition is the first measure in determining proper management solutions, which forms the third factor Waste Characterization. The presence and efficiency of waste collection and segregation by scavengers, municipalities, or private contractors was commonly addressed by the case studies, which justified Waste Collection and Segregation as the fourth factor.

Having knowledge of MSWM and an understanding of the linkages between human behavior, waste handling, and health/sanitation/environment comprise the Household Education factor. Individuals' income influencing waste handling behavior (e.g., reuse, recycling, and illegal dumping), presence of waste collection/disposal fees, and willingness to pay by residents were seen as one of the biggest incentives to recycling, which justified them being combined into the Household Economics factor.

The MSWM Administration factor was formed following several references to the presence and effectiveness of private and/or public management of waste through collection, recovery, and disposal influencing recycling activity. Although the MSWM Personnel Education factor was only recognized by six of the twenty-two case studies, the lack of trained laborers and skilled professionals in MSWM positions was a barrier to sustainable MSWM in every case but one. The presence and effectiveness of a comprehensive, integrative, long-term MSWM strategy was highly encouraged by every case study that addressed the tenth factor, MSWM Plan. 
Although seemingly a subset of private MSWM administration, the existence and profitability of market systems relying on recycled-material throughput, involvement of small businesses, middlemen, and large industries/exporters is deserving of the factor Local Recycled-Material Market. Availability and effective use of technology and/or human workforce and the safety considerations of each were recurrent barriers and incentives to recycling to warrant the Technological and Human Resources factor. The Land Availability factor takes into consideration land attributes such as terrain, ownership, and development which can often times dictate MSWM.

Understanding the relationships among the twelve factors influencing recycling in developing countries, made apparent the collaborative nature required of sustainable MSWM. Factors requiring the greatest collaborative inputs include waste collection and segregation, MSWM plan, and local recycled-material market. Aligning each factor to the societal, environmental, and economic dimensions of sustainability revealed the motives behind the institutions contributing to each factor. A correlation between stakeholder involvement and sustainability existed, as supported by the fact that the only three factors driven by all three dimensions of sustainability were the same three that required the greatest collaboration with other factors.

With increasing urbanization, advocating for improved health for all through the MDG, and changing consumption patterns resulting in increasing and more complex waste streams, the utilization of the collaboration web offered by this research is ever needed in the developing world. Through its use, the institutions associated with each of the twelve factors can achieve a better understanding of the collaboration necessary and beneficial for more sustainable MSWM. 


\section{ACKNOWLEDGEMENTS}

First and foremost, I would like to extend gratitude to my advisor, Dr. Jim Mihelcic, for not only all of his support of this research, but for his contributions to my academic, professional, and personal development over the past six years. Thanks to Jim's genuine support and encouragement, I have had a unique and fulfilling graduate education experience. His confidence in my work and trust of my character truly inspired me to keep going when I doubted myself and my abilities.

My advising committee has been of much intellectual support and motivation as well with this project. Dr. David Watkins helped me to attempt a new direction of this research. Dr. Kurt Paterson was particularly advantageous to this research by helping me recognize the practical utility of its final outcome. Dr. Hugh Gorman beneficially shed a non-engineering light to the research and provided honest opinions. Thank you.

I would like to deeply thank my close friends and family. Benjamin Arcand, my dearest partner, has watched me grow in so many aspects since my start at Michigan Tech. I am grateful for his patience, love, understanding, and support, all of which have been dispensed unconditionally. Shalini Suryanarayana, my dear friend, has supported me personally through long giggle-filled, dog admiring times together, professionally by encouraging and challenging me during our time as co-chairs of the Environmental Sustainability Committee. Thank you so much to Shal and Ben for showing support above and beyond by attending my defense.

I feel that my experiences on the WERC Senior Design and MTU Caterpillar Research Teams truly taught me how to conduct research thoroughly and create a useful 'product.' Thank you to all the folks associated with these two teams, and especially those affording me those opportunities.

Last, but certainly not least, I'd like to thank the following funding sources that most literally afforded me the opportunity to pursue this graduate degree: Caterpillar, Air and Waste Management Association, Dr. Pati and Soumitri Reddy Graduate Fellowship, and the Century II National Academy of Engineering Fellowship. 


\section{TABLE OF CONTENTS}

LIST OF TABLES ............................................................................................... vii

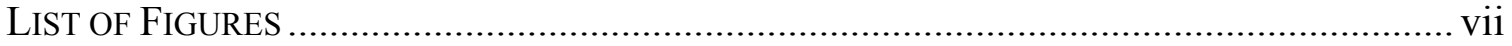

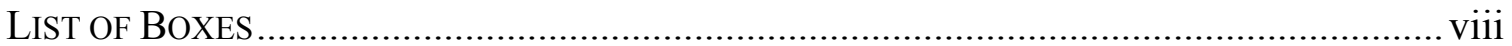

LIST OF ACRONYMS .......................................................................................... viii

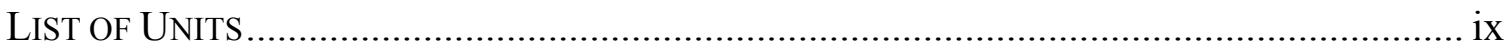

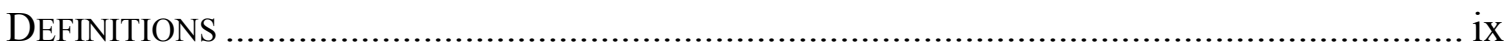

CHAPtER ONE Municipal Solid Waste MANAgEMENT: A Global Priority? .......... 1

CHAPTER TWO DeVeloped Countries' Municipal Solid Waste ManaGement ..... 7

2.1 Municipal Solid Waste Generation, Composition, and Recovery ......................... 7

2.1.1 United States of America ............................................................................. 7

2.1.2 European Union: Western Countries......................................................... 10

2.1.3 Organization for Economic Co-operation and Development ....................... 13

2.2 Review of Recycling Research in Developed Countries ................................... 15

CHAPTER THREE Developing COUnTRIES’ Municipal Solid Waste MngmnT....... 20

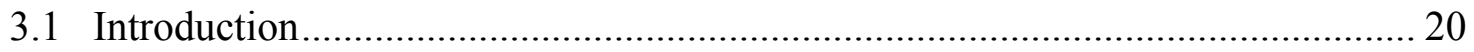

3.2 Material Studied: Global Recycling Initiatives............................................. 23

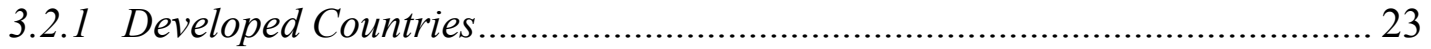

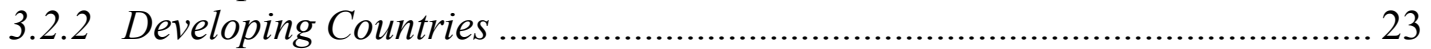

3.2.3 Terminology of country classification ..................................................... 25

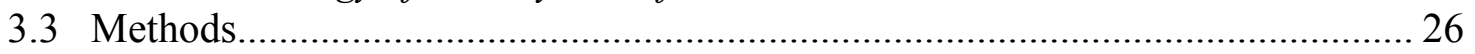

3.3.1 Selection of Country Case Studies ............................................................ 26

3.3.2 Quantitative Data: MSW Generation, Composition, Recovery ..................... 28

3.3.3 Qualitative Data: Incentives and Barriers to Recycling............................. 28

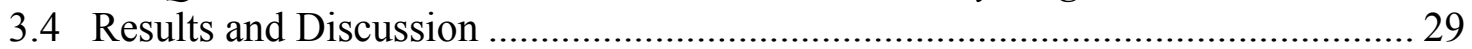

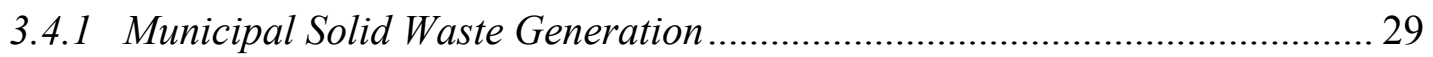

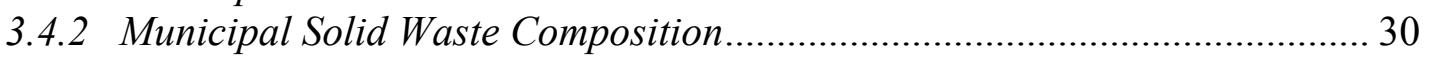

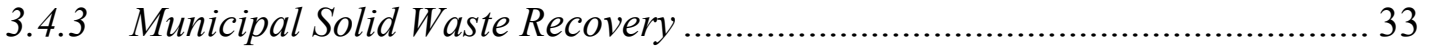

3.4.4 Incentives and Barriers to Recycling: Twelve MSWM Factors .................... 35

1) Government Policy ........................................................................................ 39

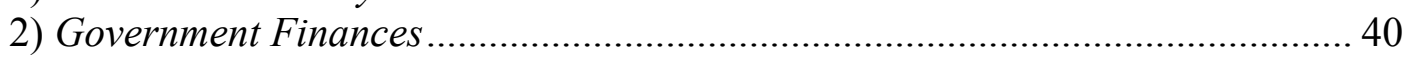

3) Waste Characterization ............................................................................. 41

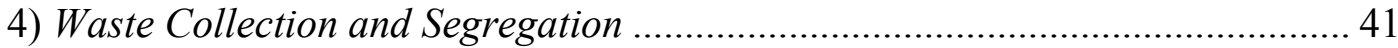

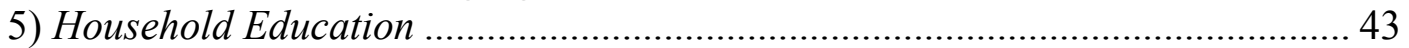

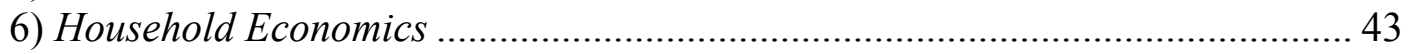

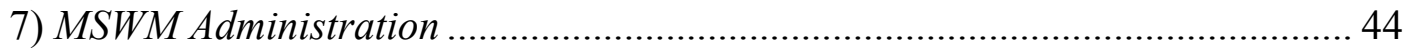

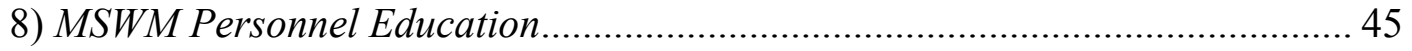

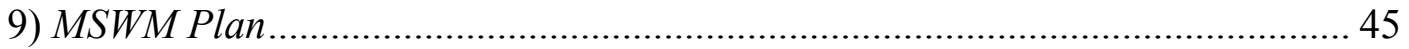




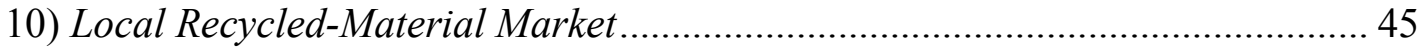

11) Technological and Human Resources ........................................................... 46

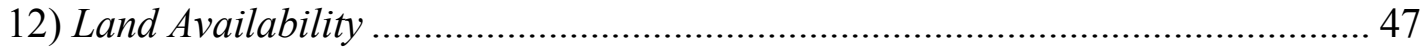

3.4.5 Validation of Twelve Factors Influencing Recycling................................... 47

3.4.6 Relation of Twelve Factors to Big Picture Indicators ................................. 48

3.4.7 Stakeholder Involvement and Sustainability ............................................ 49

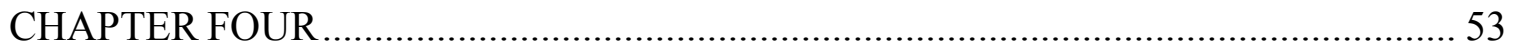

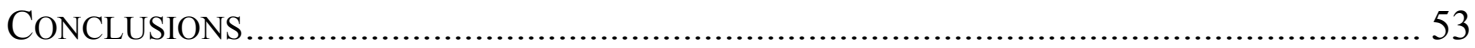

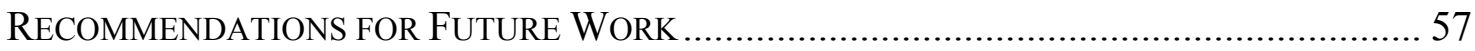

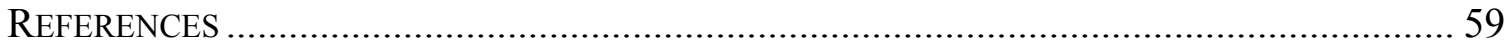

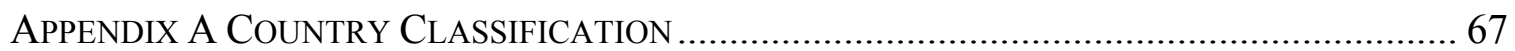

APPENDIX B SUPPLEMENTAL DEVELOPED COUNTRY RESEARCH ...................................... 72

APPENDIX C JUSTIFICATION FOR BARRIER AND INCENTIVE DESIGNATIONS .................... 75

APPENDIX D SCAVENGERS IN DEVELOPING WORLD MSWM ......................................... 104

APPENDIX E DETAILED DEVELOPING COUNTRY QUANTITATIVE DATA........................... 108

APPENDIX F DETAILED EXPLANATION OF FACTOR RELATIONSHIPS ............................... 110

APPENDIX G DATA ON SOCIAL, ENVIRONMENTAL, AND ECONOMIC INDICATORS ........... 115

APPENDIX H DEFINITIONS OF SOCIAL, ENVIRONMENTAL, AND ECONOMIC INDICATORS . 125 


\section{LIST OF TABLES}

Table 2.1: Comparison of developed countries' municipal solid waste generation, recovery, and discard rates............................... 15

Table 3.1: Various county classification terminology ........................ 25

Table 3.2: Socio-economic standing, national data type and data source for the twenty-three selected case studies on MSWM in the developing world......... 27

Table 3.3: Range of composition of municipal solid waste for nineteen of the

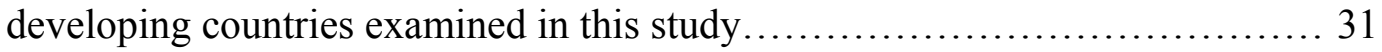

Table 3.4: Municipal solid waste recovery in thirteen developing countries......... 34

Table 3.5: Barriers and incentives to recycling in twenty-two developing countries amount to twelve factors influencing sustainable MSWM........... 37

Table 3.6: Summarized descriptions of twelve factors influencing recycling as an element of sustainable MSWM in developing countries................. 38

\section{LIST OF FIGURES}

Figure 2.1: Waste composition by percentage per material category for the

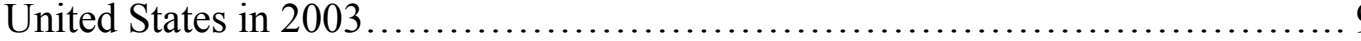

Figure 2.2: Composition of waste generated overlaid with composition of waste recovered by percentage per category for the United States in $2003 \ldots \ldots \ldots$. 9

Figure 2.3: Average waste composition by percentage wet mass per category for eighteen Western European Union countries during 1998-2001............ 12

Figure 2.4: Average waste composition by percentage wet mass per category for thirteen Candidate European Union countries during 1998-2001............ 12

Figure 2.5: Comparison of per capita daily waste generation rates for OECD countries in 2000

Figure 2.6: Comparison of glass and paper recycling rates for OECD countries in 2000

Figure 3.1: Urban and rural population (millions) plotted against time (years)..... 21

Figure 3.2: Municipal solid waste generation rates for twenty-three developing countries

Figure 3.3: Average composition of nineteen developing countries' municipal solid waste presented as percentage by weight

Figure 3.4: Comparison of MSW composition of developed countries (United States and those in the European Union) against the average of nineteen developing countries (LDC).

Figure 3.5: Collaboration web illustrating the necessary (solid line) and beneficial (dash line) relationships among the twelve factors influencing recycling in developing countries 


\section{LIST OF BOXES}

Box 3.1 The Brazilian Recycling Commitment............................. 35

Box 3.2 Garbage Banks..................................................... 40

Box 3.3 Scavengers................................................ 42

\section{LIST OF ACRONYMS}

B

Cempre

CIA

$\mathrm{DC}$

EU

Eurostat

GDP

GEO

I

IETC

IGO

IMF

ISWA

LDC

LLDC

MDG

MSW

MSWM

$\mathrm{N}$

OECD

PPP

RE

SPC

UN-HABITAT

UNDESA

UNEP

UNESCO

UNMDG

US

USEPA

WHO

$\mathrm{Y}$
Barrier to recycling

Compromiso Empresarial para Reciclagem

(the Brazilian Recycling Commitment)

Central Intelligence Agency

Developed Country

European Union

Statistical Office of the European Communities

Gross Domestic Product

Global Environment Outlook

Incentive to recycling

International Environmental Technology Centre

International Government Organization

International Monetary Fund

International Solid Waste Association

Less Developed Country

Least Developed Country

Millennium Development Goals

Municipal Solid Waste

Municipal Solid Waste Management

No

Organization for Economic Co-operation and Development

Purchasing Power Parity

Recycling Efficiency

Sustainable production and consumption

United Nations Human Settlements Programme

United Nations Department of Economic and Social Affairs

United Nations Environment Programme

United Nations Educational, Scientific, Cultural Organization

United Nations Millennium Development Goals

United States of America

United States Environmental Protection Agency

World Health Organization

Yes 


\section{LIST OF UNITS}

$\begin{array}{ll}\text { CNY } & \text { China Yuan Renminbi (currency) [1USD=8.1CNY] } \\ \text { kpd } & \text { kilograms per person per day } \\ \text { lbs } & \text { Pounds } \\ \text { MNT } & \text { Mongolian Tugrik (currency) [1USD=1,120MNT] } \\ \text { ppd } & \text { pounds per person per day } \\ \text { RMB } & \text { Renminbi = "people's currency" } \\ \text { THB } & \text { Thai Bhat (Thailand's currency) [1USD=41.4THB] } \\ \text { USD } & \text { United States Dollars (currency) } \\ \text { yuan } & \text { China currency }\end{array}$

\section{DEFINITIONS}

Barrier or Incentive (B or I): A specific MSWM operation that either prohibits or encourages recycling in developing countries.

Developed Country (DC): As defined by the Central Intelligence Agency's (CIA) World Factbook, a nation with greater than 10,000 USD gross domestic product per capita. See Appendix A for a detailed definition and listing of these countries as of June 2005.

Beneficial Relationship: Collaboration between two factors, or MSWM operations, that improves efficiency of recycling activities in developing countries.

Factor: Refers to the twelve factors developed in this study. A factor is essentially a MSWM operation that contributes to recycling activities in developing countries.

Gross Domestic Product (GDP), Purchasing Power Parity (PPP): Total annual output from a country's economy, converted to current international dollars using Purchasing Power Parity (PPP) rates. GDP is the total market value of all final goods and services produced in a country in a given year, equal to total consumer, investment and government spending. Dollar figures for GDP are converted to international dollars using purchasing power parity (PPP) rates. An international dollar adjusted for PPP has the same purchasing power over GDP as a U.S. dollar in the United States and buys an equivalent amount of goods or services irrespective of the country. PPP rates provide a standard measure allowing comparisons of real price levels between countries, just as conventional price indexes allow comparison of real values over time. Values are in current dollars and are not adjusted for inflation (WRI, 2005). 
Incentive or Barrier (I or B): A specific MSWM operation that either prohibits or encourages recycling in developing countries.

Least Developed Country (LLDC): As defined by the CIA's World Factbook, a nation with less than 1,000 USD gross domestic product per capita. See Appendix A for a detailed definition and listing of these countries as of June 2005.

Less Developed Country (LDC): As defined by the CIA's World Factbook, a nation with less than 5,000 USD gross domestic product per capita. See Appendix A for a detailed definition and listing of these countries as of June 2005.

Municipal Solid Waste (MSW): Waste generated in households, commercial establishments, institutions, and businesses. Includes used paper, discarded cans and bottles, food scraps, yard trimmings, and other items. Not Included: industrial process wastes, agricultural wastes, mining wastes, and sewage sludge. Also referred to as garbage, trash, refuse, litter, solid waste, rubbish.

Municipal Solid Waste Management (MSWM): Conscious and active systematic waste handling activities which provide for collection, source separation, storage, transport, treatment/processing (e.g., material or energy recovery), and disposal. Aims to improve human health and local aesthetics, and reduce human impact on the environment.

Necessary Relationship: Collaboration between two factors, or MSWM operations, that needs to be in place in order to recycling to occur in developing countries.

Sustainability: The design of human and industrial systems to ensure that humankind's use of natural resources and cycles do not lead to diminished quality of life due either to losses in future economic opportunities or to adverse impacts on social conditions, human health and the environment (Mihelcic, et al. 2003).

Sustainable MSWM: Utilization of waste handling techniques, whether one method or a combination of methods, to divert the maximum possible waste fraction from landfills in order to extend their life span. Sustainable MSWM techniques include, but are not limited to: reduction, reutilization, material recovery (composting), and incineration with energy recovery (UNDESA, 2005 and Fehr et al., 2000). Essentially, sustainable MSWM is to manage waste in manners that uphold the definition of sustainability stated above. 


\section{CHAPTER ONE}

\section{Municipal Solid Waste MANagement:}

\section{A Global Priority?}

At the United Nations Conference on Environment and Development in Rio de Janeiro, Brazil in 1992, 178 governments agreed that more sustainable municipal solid waste management was needed in both developed and developing nations. Chapter 21 of Agenda 21, the Rio Declaration on Environment and Development, outlines the environmentally sound management of solid wastes through the following hierarchy of program areas: 1) minimizing wastes; 2) maximizing environmentally sound waste reuse and recycling; 3) promoting environmentally sound waste disposal and treatment; and 4) extending waste service coverage (UNDESA, 2005).

"Sustainability is defined here as the design of human and industrial systems to ensure that humankind's use of natural resources and cycles do not lead to diminished quality of life due either to losses in future economic opportunities or to adverse impacts on social conditions, human health and the environment."

- Mihelcic et al. (2003)

Eight years later, though not as specifically addressed in Agenda 21, sustainable management of solid waste is still a global concern, as exemplified by the United Nations Millennium Development Goals (MDG) that 191 member states support. The seventh MDG indirectly advocates for municipal solid waste management (MSWM) by aiming to ensure environmental sustainability into countries' policies and programs and reverse negative environmental impact. Proper MSWM will likely result in relieving poverty, reducing child mortality, improving maternal health, and preventing disease, which are MDG goals one, four, five, and six, respectively (UNMDG, 2005). An organized and effective MSWM plan will provide jobs that are clearly defined and necessary. Collecting, transporting, and treating garbage in an environmentally-sound manner will 
remove the very substance present in inhabitants' living and working spaces causing health problems and protect the soil and water resources people need for food production and drinking water.

A review of several international government organizations (IGOs) and one professional society demonstrates the effort put toward sustainable MSWM at the global level. Many of these organizations have a primary mission of relieving poverty, improving drinking water sources, or dissolving corrupt governments, and have recognized the direct relation of these greater issues to MSWM. Every organization researched embraces the importance of MSWM planning through a major publication, whether it is in the form of a guidebook or training manual. The following paragraphs highlight each organization's involvement with respect to MSWM and recycling.

United Nations Educational, Scientific, Cultural Organization (UNESCO), an IGO working "to contribute to peace and security by promoting collaboration among nations through education, science and culture," documents a Training Course in Sustainable Development and Management of Municipal Infrastructures and Services for Managers and Decision-Makers from Eastern Europe. UNESCO also conducted an international meeting focused on creating new synergies for recycling information technology equipment. Lastly, it is noted that UNESCO advocates that MSW may be a useful, sustainable energy source for small-island, developing countries (UNESCO, 2005).

United Nations Environment Programme (UNEP) "promotes environmental understanding and increases public knowledge about environmental factors and problems of future generations." Through its International Environmental Technology Centre (IETC), the 3R Platform has been launched to provide the direction and tools necessary for developing countries in the Asia-Pacific Region to implement sustainable production and consumption (SPC) activities (UNEP-IETC, 2005). Two SPC projects already taking place incorporate ideas of the life-cycle approach and eco-towns, respectively, with both projects emphasizing material reuse and recycle. UNEP also collaborated with the 
International Solid Waste Association (ISWA) to produce a MSWM planning booklet called Waste Management Planning, An Environmentally Sound Approach for Sustainable Urban Waste Management: An Introductory Guide for Decision-makers (UNEP and ISWA, 2004).

The ISWA is an international, non-profit organization with a mission "to promote and develop professional solid waste management world-wide." Aside from the MSWM planning booklet jointly produced with UNEP, ISWA also publishes two well-respected journals Waste Management World and Waste Management and Research. ISWA also cooperates with the World Health Organization (WHO) and UNEP to create and promote training, seminar, and workshop material on health care wastes and landfills, recycling, and hazardous wastes, respectively. ISWA has several 'working groups' that consist of experts striving to study in-depth specific MSW issues (e.g.; in 2004, such a group reported on various collection schemes utilized in nine different countries). Specifically of interest to this research are the ISWA position papers on the Prevention and Recycling of Wastes and the Definitions of Waste Recycling and Recovery (ISWA, 2005).

While the WHO's goal is "the attainment by all peoples of the highest possible level of health," WHO specifically recognizes poor MSW management as a health problem. WHO has created eight informational booklets on waste topics such as solid waste and health, waste incineration and landfill, waste minimization, and hazardous waste (WHO, 2005a). It is evident that WHO accounts for waste created by its efforts from its published book Safe Management of Waste from Health Care Activities with a chapter detailing minimization, recycling, and reuse of health care wastes (Prüss et al., 1999), and the investigation and support of recycling the plastic portion of syringes (WHO, 2005b). The WHO also advocates tracking data about waste generation and fate (i.e., recycling, disposal, etc.), as well as how to perform a waste characterization study in its document Information Management for Municipal Solid Waste Management Services (WHO, 2005c). 
"In most developing countries, solid waste is disposed in open dumpsites with waste pickers. These inadequate municipal solid waste management systems cause environmental and public health problems. Since the mid-1980s, WHO has been supporting countries to strengthen their national capacity in municipal solid waste management."

- World Health Organization (WHO, 2005c)

The European Commission holds responsibility for proposing legislation to Parliament and the Council, administering and implementing Community policies, enforcing Community law (jointly with the Court of Justice), and negotiating international agreements. European Union (EU) legislation requires MSWM planning, and accordingly, the Commission has created a guidance booklet called Preparing a Waste Management Plan: A methodological guidance note. In 1999, the Commission hosted the first EU conference on MSWM planning with the aim to exchange the necessary information to encourage greater coverage of MSWM plans throughout the EU. Five years later, an Integrated Waste Management \& Life Cycle Assessment Workshop and Conference furthered more sustainable uses of resources, waste prevention and recycling, which inadvertently minimizes environmental impacts associated with waste generation and resource use, while promoting economic growth and improved quality of life (Europa, 2005).

United Nations Human Settlements Programme (UN-HABITAT) has been "mandated by the UN General Assembly to promote socially and environmentally sustainable towns and cities with the goal of providing adequate shelter for all." Several case studies of UN-HABITAT projects illustrate such effort with respect to MSWM specifically. One project in Sri Lanka utilizes micro-enterprises to promote solid waste management; the waste collection center generates income with a percentage of profits from the resale of recyclable items funding community development projects (UNHABITAT, 2005a). In Afghanistan, a UN-HABITAT project aims to initiate a solid waste collection strategy, health and hygiene education, and a recycling and composting program (UN-HABITAT, 2005b). These project examples and others utilize the UNHABITAT's Conceptual Framework for Municipal Solid Waste Management In LowIncome Countries, which considers the political/institutional, social/cultural, financial/economic, and technical aspects (Schübeler, 1996). 
The World Bank Group's mission is "to fight poverty and improve the living standards of people in the developing world" by providing loans, policy advice, technical assistance, and knowledge sharing services to low and middle income countries. An inter-agency solid waste collaborative working group formed in the 1990s to further strategic MSWM planning (World Bank, 2005), and in 2003, a Practical Guidebook on Strategic Planning in Municipal Waste Management was published which supports this effort (Kobus, 2003). The Bank prefers to fund projects that include elements of strategic planning, social assessment, and public participation in MSWM. The World Bank also promotes financially assessing the different MSWM options through its "Waste Collection Planning Tool: Cost Analysis of Collection Options” (World Bank, 2005).

Although the aforementioned organizations are making incredible strides toward improving MSWM, several account that their efforts are not enough. The European Commission comments that "today, almost 25 years after the adoption of the Framework Directive, the situation within the EU regarding waste management continues to be unsatisfactory" (Europa, 2005), which may largely be due to other, more immediate issues taking priority over MSWM. Also, many of the organizations discussed above focus their efforts on developing countries, because it is in these countries where MSWM requires the most attention. Developed countries are gaining proficiency at MSWM at a much higher rate than developing countries due to the availability of financial and technological resources.

"Solid waste is an inevitable by-product of human activities. In the past, this was not a major problem because almost everything was reused or recycled and whatever remained was taken care of by nature."

-United Nations Environment Programme (UNEP, 2001e)

Further investigation of MSWM in developing countries is needed to ensure health and safety of all global citizens and to protect the environment from which all humans seek resources. Therefore, the overall goal of this research is to study recycling as one possible solution to the municipal solid waste management problem of the developing world while embracing the ideal of sustainability. Known information on MSWM in developing countries will be synthesized, and knowledge on the sustainability 
of MSWM in developing countries will be further developed. The following four specific objectives are pursued in order to accomplish this goal:

1) Compile and present municipal solid waste generation and recovery rates globally, including the composition of the waste stream.

2) Summarize previous recycling research both in the first and third world.

3) Analyze case studies on developing countries to identify barriers against or incentives toward recycling, which will justify the creation of key factors that influence sustainable MSWM.

4) Relate the factors created in objective three to understand the collaborative nature required of sustainable MSWM, and align the factors to social, environmental, and economic dimensions, which will make apparent any correlations between stakeholder involvement and sustainability.

The remaining chapters of this thesis will provide detail on each of the above stated objectives, while emphasizing the overall goal of the research. Chapter Two presents the MSW generation and recovery rates, including composition, for the United States, the European Union, and the member states of the Organization for Economic Cooperation and Development (OECD), as well as highlights the works of others with respect to analyzing attitudes and behavior on waste recycling. Chapter Two thus discusses municipal solid waste and recycling in the developed world. Chapter Three presents the following main findings of this research, which came to fruition through extensive literature review: identification of barriers and incentives to recycling in developing nations, creation of twelve factors influencing sustainable MSWM with direct respect to recycling, comprehension of relationships among the twelve factors through the creation of a 'collaboration web,' and correlation of sustainability dimensions inherent within each factor to an overarching MSWM theme stakeholder involvement. Chapter Four summarizes the major findings of this research and provides recommendations for future work on this topic. 


\section{CHAPTER TWO}

\section{DEVELOPED COUNTRIES'}

\section{Municipal Solid Waste Management}

This research uses the well-accepted definition of developed countries as nations with a gross domestic product per capita greater than 10,000 USD (CIA, 2004), but also considers the International Monetary Fund's designation of countries as either advanced economies, countries in transition, or developing countries. The former is based solely upon an economic attribute of a country, whereas the latter considers the economic as well as social climate. Due to their privileged socio-economic status, developed countries not only have successfully implemented municipal solid waste management (MSWM) plans, but resource recovery programs are plentiful as well. Developed countries also possess mature databases containing municipal solid waste (MSW) generation rates, composition, and recovery rates. In this section, such values will be compared and discussed for the United States of America (US), the Western Countries of the European Union (EU), and the member states of the Organization of Economic Co-operation and Development (OECD). Due to data availability, composition of waste for the OECD will not be presented. Following the data assessment, a condensed overview of recycling research in developed countries will be discussed.

\subsection{Municipal Solid Waste Generation, Composition, and Recovery}

\subsubsection{United States of America}

The US Environmental Protection Agency (USEPA) recently documented waste generation, composition, and recovery for the entire nation in the report Municipal Solid Waste in the United States: Facts and Figures 2003 (USEPA, 2003). This report represents the latest version of this database that has been evolving for over 20 years. 
USEPA utilized the material flow method to characterize American waste, which is based on production data (by weight) of the products and materials in the waste stream. This technique uses data gathered from industry and businesses, as well as data from the Department of Commerce, the U.S. Census Bureau, and waste characterizations and surveys performed by governments, industry, or the press. A mass balance approach estimates tons of materials and products generated, recycled, or discarded. MSW generation data is estimated by adjusting production data by weight with the import and export figures of the United States, any diversions from MSW (e.g.: plastic and paperboard that are classified as construction and demolition debris), and different allowances are made for the average lifetimes of different products.

For the estimation of MSW, the USEPA includes wastes such as product packaging, newspapers, office and classroom papers, bottles and cans, boxes, wood pallets, food scraps, grass clippings, clothing, furniture, appliances, automobile tires, consumer electronics, and batteries. The MSW sources include waste from homes, institutions (e.g.: schools and prisons), commercial sources (e.g.: restaurants and small businesses), and occasional industrial contributions. MSW does not however include hazardous waste. The MSW waste is separated into the following categories: Paper and Paperboard, Yard Trimmings, Food Scraps, Plastics, Metals (Steel, Aluminum, Other Nonferrous), Wood, Glass, Textiles, Rubber and Leather, Other, and Miscellaneous Inorganic Material. Not being able to account for product residues combined with other items in MSW (usually containers) is one problem associated with the materials flow method. These residues include, for example, food left in a jar, detergent left in a box or bottle, and dried paint in a can. Some household hazardous wastes, (e.g., pesticide left in a can) are also included among these product residues. Material flow is the preferred method when characterizing MSW on a regional or national scale.

USEPA (2003) reported Americans generating a total of 236 million tons of MSW in one year, which equates to $4.58 \mathrm{lbs}$ waste per person per day (ppd) (2.08 kpd). Figure 2.1 illustrates the compositional breakdown of the MSW. The largest constituents of the American waste stream are paper, organic material, and plastics. Figure 2.2 
displays the composition of material recovery for each waste category. Paper, organic material, and metal are the three waste types most recovered. Americans recover 30.6\% of waste generated which equals $1.40 \mathrm{ppd}$ (0.64 kpd) (USEPA, 2003).

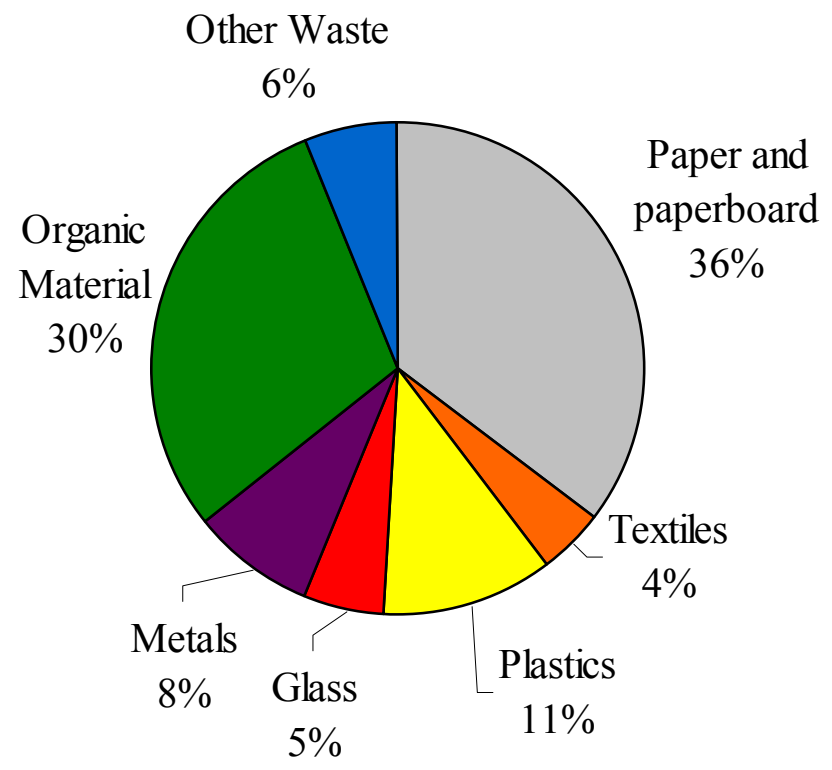

Figure 2.1: Waste composition by percentage per material category for the United States in 2003 (USEPA, 2003).

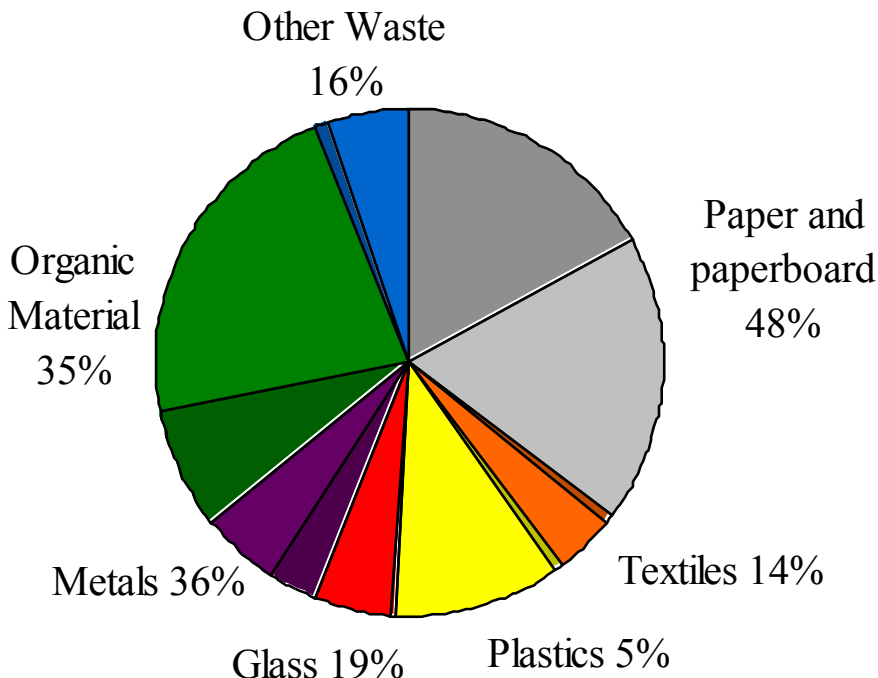

Figure 2.2: Composition of waste generated overlaid with composition of waste recovered by percentage per category for the United States in 2003. The percentages noted are the recycled portions of a given category (e.g.; for organic material, 35\% recovered relative to the $30 \%$ generated, or $10.5 \%$ recovered absolute) (USEPA, 2003). 
In a study on packaging waste generation and recycling in the United States (US) versus eighteen other developed countries, it was found that the US utilizes more packaging that any other country, recycles less of it, and pursues weaker policy measures than those considered in other countries.

- McCarthy (1993)

\subsubsection{European Union: Western Countries}

In 2003, the European Union reported on waste generation rates, composition, and recovery rates in Waste Generated and Treated in Europe: 1998-2001 (Eurostat, 2003). This data includes statistics on 18 Western European countries and 13 Candidate Countries. The 18 Western European countries consist of Norway, Switzerland, Iceland, and the 15 European Union Member States, all of which are developed countries. The 15 EU Member States are Belgium, Denmark, Germany, Greece, France, Ireland, Italy, Luxembourg, Netherlands, Austria, Portugal, Finland, Spain, Sweden, and United Kingdom. The 13 Candidate countries (in Eastern Europe) are Bulgaria, Cyprus, Czech Republic, Estonia, Hungary, Latvia, Lithuania, Malta, Poland, Romania, Slovakia, Slovenia, and Turkey, all of which are developing countries except Malta and Turkey ${ }^{1}$.

Data were gathered by the Organization for Economic Co-operation and Development (OECD) and the Statistical Office of the European Communities (Eurostat) through the "Questionnaire on the State of the Environment" administered to all the Western and Candidate EU countries. This questionnaire has been performed since 1988, and it still shows that data availability is insufficient from every country in order to present an accurate overview of the EU's waste generation, composition, and recovery. Therefore, the values provided by the report were interpreted with care.

Most EU countries utilize the site specific methodology for characterizing a waste stream. Site specific methodology involves collecting a sample of waste, sorting the waste by established categories, and weighing each category sample. This method needs to be repeated over a period of time for best results. Site specific studies offer a more

\footnotetext{
${ }^{1}$ In 2004, the European Union Commission accepted all 13 Candidate countries into the European Union, and for this reason, both the Western (all developed countries) and Candidate (mostly developing countries) countries are discussed in this chapter even though the focus of Chapter Two is MSWM in developed countries.
} 
accurate assessment of MSW generation \& composition, and the more localized a study, the easier it is to conduct a site specific study. Estimates were not figured for countries that did not provide waste generation and recovery data, which may suggest that the values provided for the Western European countries and the Candidate countries are less than the actual waste generation rates. Waste in the EU report refers to any material that no longer has a use (i.e., no material transformed for use in the market). This waste could be generated during material extraction, processing of raw material into intermediate forms for production, creating the final product, and during the product use.

The EU virtually requests reporting of all wastes through the questionnaire, and then once all data is gathered, the OECD and Eurostat categorize the data as to which is household waste (i.e., MSW), hazardous waste, agricultural wastes, and industrial wastes. Although data is scarce for many countries, the data provided on MSW is the most reliable in terms of quantity and quality. MSW is defined by Eurostat and OECD as waste collected by or on behalf of the municipalities, which includes households, commerce and trade, small businesses, office buildings and institutions such as schools, hospitals, government buildings, etc. The definition also includes waste generated by private sectors (businesses and non-profit organizations) and rural areas that are not serviced by the municipalities. Municipal sewage and construction and demolition waste are not included as MSW. Unfortunately, not all countries adhere to this definition of MSW, which contributes to some of the overall inaccuracy of the EU data. The MSW waste is separated into the following categories: Paper and Paperboard, Textiles, Plastics, Glass, Metals, Organic Material, Bulky Waste, and Other Waste.

Eurostat (2003) reported the Western countries generating 210 million tons of MSW annually, and the Candidate countries annually producing only 60 million tons of MSW. These regional values equate to $3.32 \mathrm{ppd}(1.51 \mathrm{kpd})$ and $2.16 \mathrm{ppd}(0.98 \mathrm{kpd})$ for the Western and Candidate countries, respectively. Figures 2.3 and 2.4 show the composition of European MSW for both the Western and Candidate countries, respectively. Note the difference in the organic material and paper components of the MSW between the Western and Candidate countries (42\% in Candidate and $27 \%$ in 
Western countries). Comparable graphs to Figure 2.2, which illustrated the portion of each waste category recovered for the United States, could not be created due to lack of data. However, it can be noted that the Western countries of the EU have an annual recovery rate of $18 \%$, which equates to $0.6 \mathrm{ppd}(0.27 \mathrm{kpd})$ (Eurostat, 2003) compared to $1.4 \mathrm{ppd}(0.64 \mathrm{kpd})$ recovered material in the US (USEPA, 2003). Again, due to insufficient data, a similar statistic for the Candidate countries could not be presented.

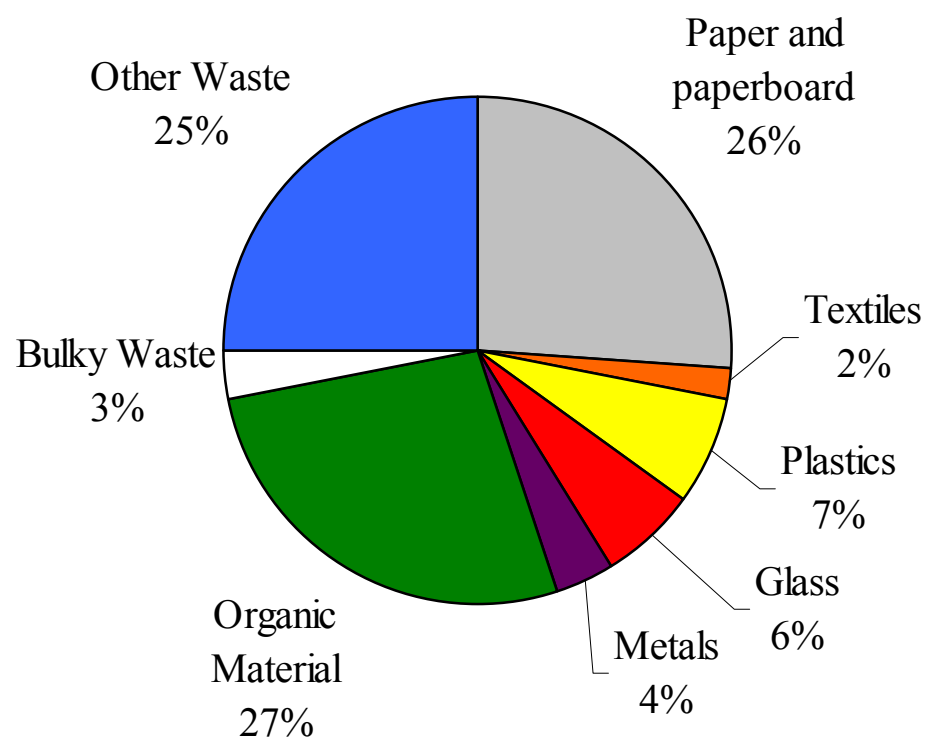

Figure 2.3: Average waste composition by percentage wet mass per category for eighteen Western European Union countries during 1998-2001 (Eurostat, 2003).

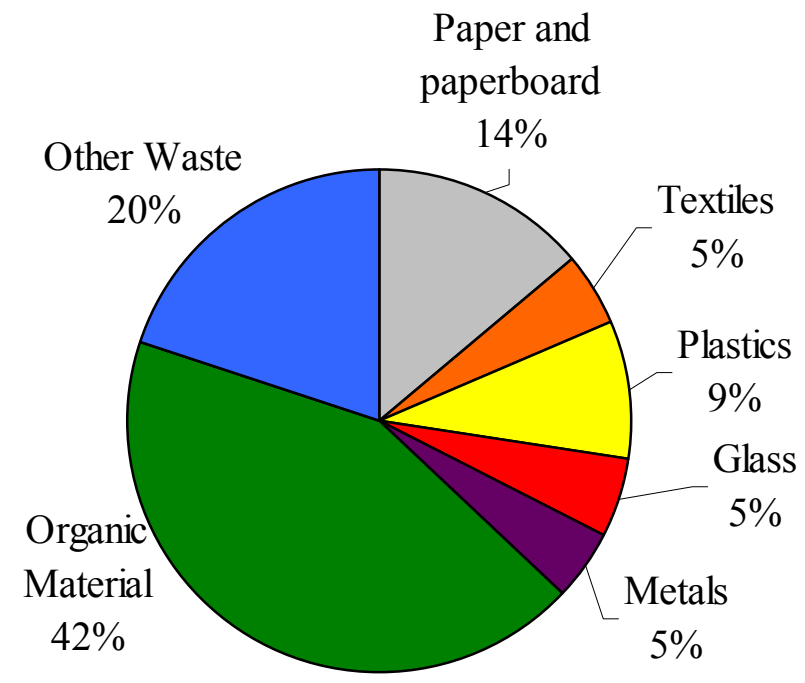

Figure 2.4: Average waste composition by percentage wet mass per category for thirteen Candidate countries of the European Union during 1998-2001 (Eurostat, 2003). 
A study on recycling behavior in fifteen countries of the European Union found that the greatest determinant of recycling is participation in environmental organizations due to the strong correlation between the two behaviors.

- Guerin et al. (2001)

\subsubsection{Organization for Economic Co-operation and Development}

The member states of the Organization for Economic Co-operation and Development (OECD) may be another source for comparison of developed country MSW generation and recovery rates. Data for the OECD is provided in a different format than the US and EU data, as a result of gathering information from a database that does not contain a detailed composition of the waste. The United Nations Environment Programme's Global Environment Outlook (GEO) 3 Data Portal (2005) offered MSW generation rates per capita and material recovery rates for paper and glass. Figure 2.5 offers an evaluation of the waste generated per person per day in each OECD country, except New Zealand (data not available). Citizens of the United States had the highest waste generation rate in 2000 at $4.58 \mathrm{ppd}(2.08 \mathrm{kpd})$, whereas Mexicans generated the least waste at $1.87 \mathrm{ppd}(0.85 \mathrm{kpd})$ (UNEP, 2005a).

Figure 2.6 illustrates glass and paper recycling rates for all OECD members, except Czech Republic, Iceland, Luxembourg, and Slovak Republic (data not available). Switzerland recycled the most glass at $91 \%$ and Mexico the least at $13 \%$. Germany recycled the most paper at 70\% and Mexico the least at 7\%. Overall, Finland had the highest rate of glass and paper recycling, whereas Mexico had the least (UNEP, 2005a).

As part of this research, the average percent of glass and paper recycling, glass recycling solely, and paper recycling solely were plotted against MSW generation to check for any relationship. No correlation was found to exist between waste recovery and generation rate for the thirty developed countries in the OECD. Figures B.1, B.2, and B.3 illustrate this conclusion in Appendix B - Supplemental Developed Country Research. 


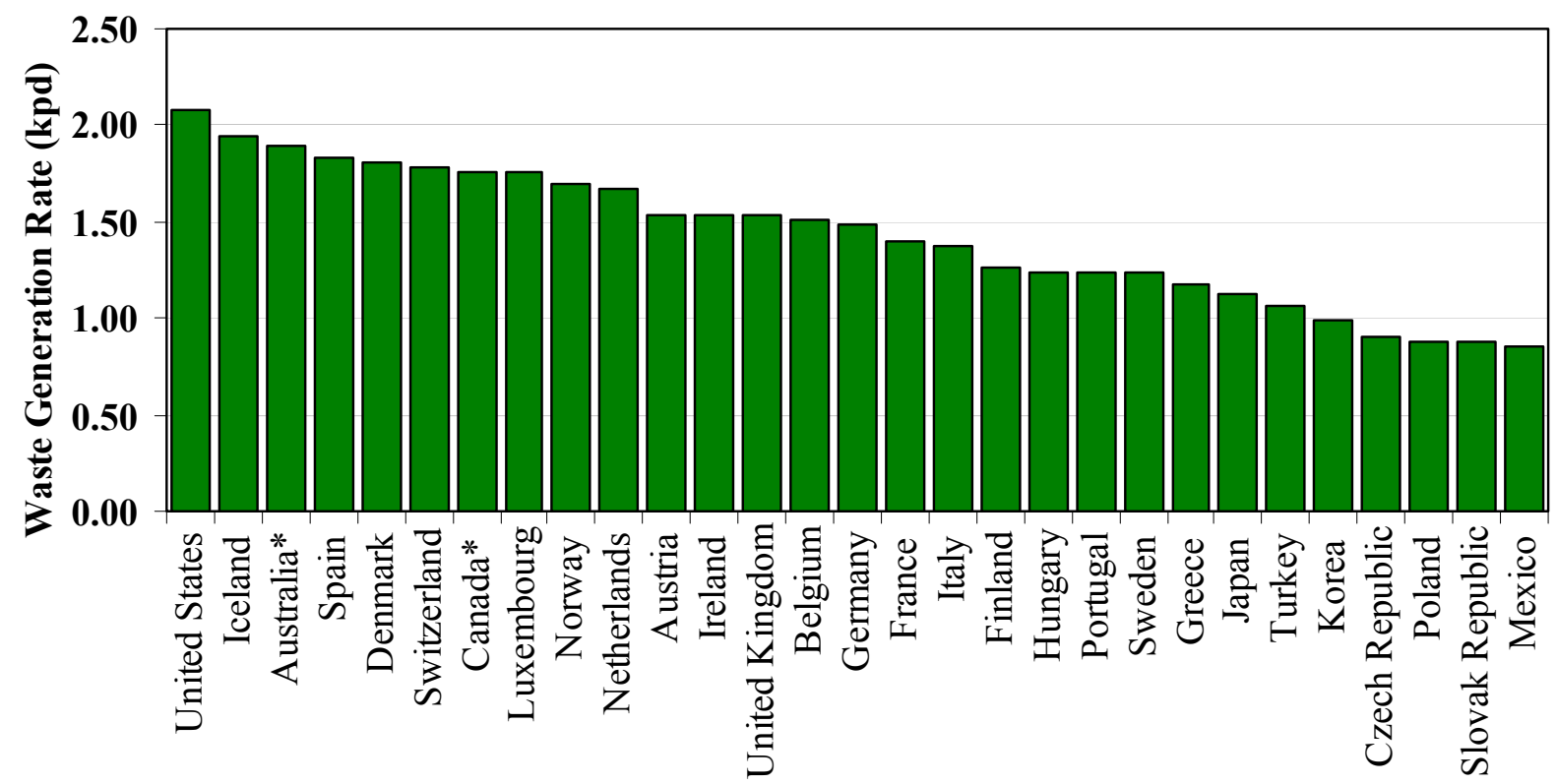

OECD Member States

Figure 2.5: Comparison of per capita daily waste generation rates for OECD countries in 2000. Asterisk (*) accompanying country name denotes 1999 data (UNEP, 2005a).

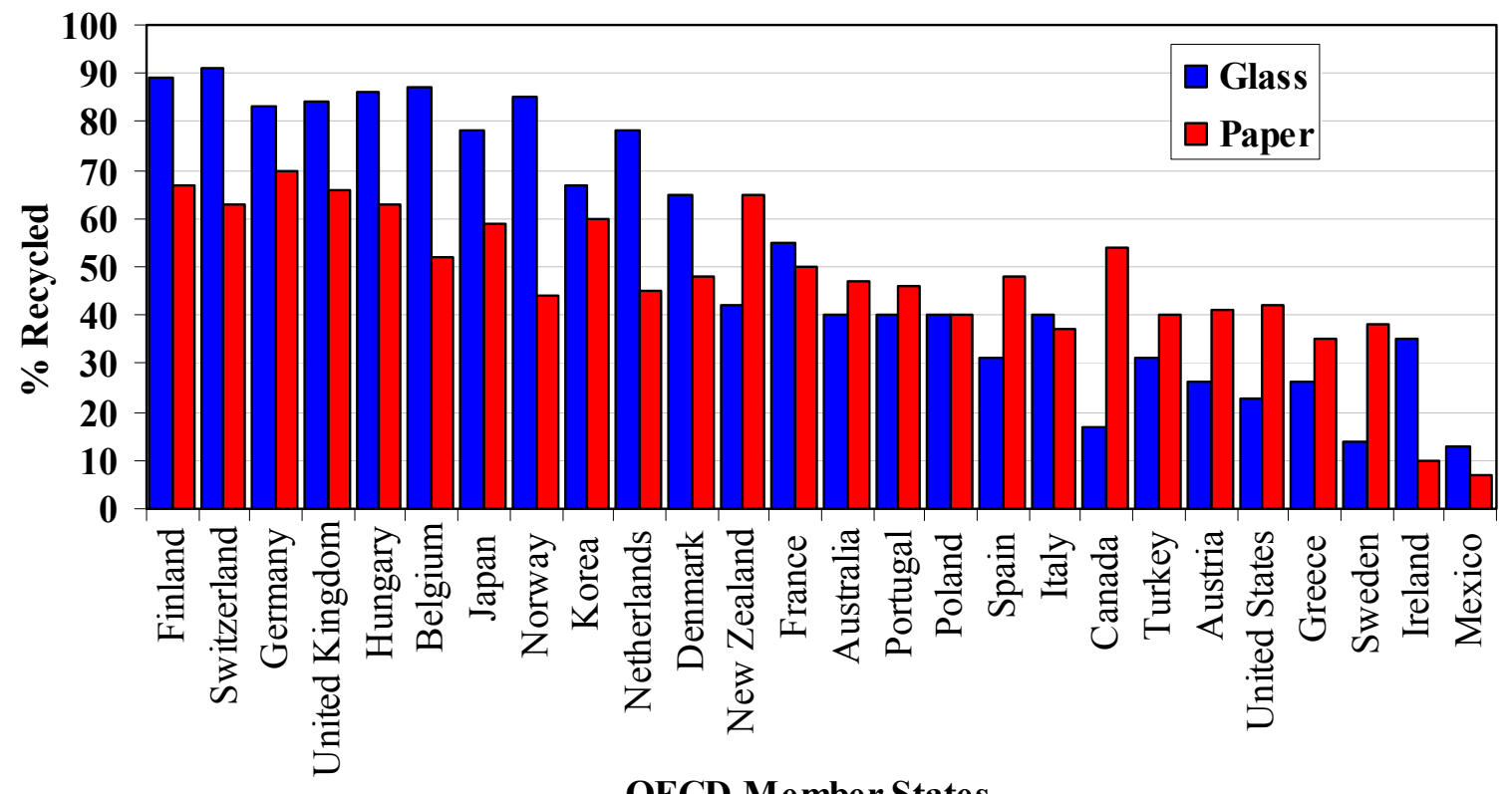

Figure 2.6: Comparison of glass and paper recycling rates for OECD countries in 2000 . Countries ordered by greatest to least combined glass and paper recycling. Data for years other than 2000 include: 1992 Canada glass; 1996 Canada paper; 1997 Norway paper and Poland glass; 1998 Austria glass; and 1999 Portugal paper, United States paper glass, and Sweden glass (UNEP, 2005a). 
Table 2.1 summarizes the generation and recovery rates, as well as presents final discard rates, for the following developed countries: US, those in the EU, and those members of the OECD. The discard rate is the amount of municipal solid waste remaining after recovery of any materials (i.e., waste for landfill or incineration). It is important to note that while the US generates $38 \%$ more waste than the EU, the US also recovers almost twice as much material as the EU (30.6\% versus $18.0 \%$, respectively). However, such a relatively high recovery rate does not result in the Americans discarding less than Europeans overall, because the final US discard rate is still $16 \%$ greater than the EU (1.44 kpd in the US versus $1.24 \mathrm{kpd}$ in the EU).

Table 2.1: Comparison of developed countries' municipal solid waste generation, recovery, and discard rates.

\begin{tabular}{cccc}
\hline Country(ies) & $\begin{array}{c}\text { Generation } \\
\text { Rate }(\boldsymbol{k p d})\end{array}$ & $\begin{array}{c}\text { Recovery } \\
\text { Rate (\%) }\end{array}$ & $\begin{array}{c}\text { Discard } \\
\text { Rate (kpd) }\end{array}$ \\
\hline Western Countries of European Union & 1.51 & 18.0 & 1.24 \\
United States & 2.08 & 30.6 & 1.44 \\
Member States of OECD & 1.43 & $\sim 50^{1}$ & $\mathrm{~N} / \mathrm{A}^{1}$ \\
\hline
\end{tabular}

${ }^{1}$ The OECD MSW Recovery Rate is for paper and glass recovery rates only. It does not consider any other recovered material. Therefore, a MSW Discard Rate for the OECD is not provided.

The thirty member countries of the OECD average a MSW generation rate of 1.43 kpd, which falls below both the EU and US averages. This may be due merely to the number of countries being averaged having a wider spread of socio-economic status. Factors such as socio-economic and others correlate to MSW generation and recovery rate, as will be discussed below.

\subsection{Review of Recycling Research in Developed Countries}

Aside from the analysis of individual and groups of countries' municipal solid waste generation and recovery rates, an extensive amount of research about the underlying reasons contributing to such waste production and treatment has been performed by others. Efforts made in engineering, mathematics, social sciences, economics, and other fields contribute to behaviors that influence municipal solid waste management as a whole by creating tools and models, analyzing policy, and understanding human tendencies, to name a few. 
The creation of analysis tools offers a more tangible method to understanding and predicting municipal solid waste generation and recovery. Daskalopoulos et al. (1998) created a model that accurately estimates future municipal solid waste (MSW) generation using a correlation to gross domestic product; the model was tested with European Union and United States of America MSW data (Daskalopoulos et al., 1998). A more practical approach to municipal solid waste management was introduced by Barlishen and Baetz (1995) through a prototype decision support system, as opposed to mathematical models, which combines knowledge-based systems with spreadsheet models to better support decision-making and planning of recycling and composting programs and facilities (Barlishen and Baetz, 1995).

Much research aims to understand how policy can act as a catalyst to decrease waste generation and increase material recovery. In a study on policy that aims to minimize municipal solid waste and divert it from landfills in the US, Taylor (2000) concluded the three main influential policy types are command-and-control, socialpsychological incentives, and economic incentives, and that the latter two function best at shaping positive attitudes and behavior about waste generation and disposal (Taylor, 2000). Shinkuma (2003) investigated the following three policies affecting the economics of material recycling in more developed countries: unit pricing with an advance disposal fee, a deposit-refund system, and a producer take-back requirement (Shinkuma, 2003).

Many efforts are put forth in the social sciences to understand waste recycling behavior with the utilization of Aizen's well-accepted theory of planned behavior which includes an assessment of attitudes, social norms, and behavioral control. McCarty and Shrum (1994) discussed how environmental values have no direct relationship with recycling behaviors, but that values have an influence on attitudes which then have a direct correlation to the behavior (McCarty and Shrum, 1994). Following a national study of environmentalism among Americans, Steel (1996) found a correlation between attitude and self-reported behavior with respect to recycling, as well as females behaving more environmentally-responsible than males, especially among the elderly (Steel, 1996). 
Chan (1998) concluded that more publicity messages promoting recycling should be utilized to influence behavior in a study of voluntary waste recycling in Hong Kong (a developed part of China) to predict behavioral intention and actual behavior (Chan, 1998). Again, Werner and Makela (1998) link attitudes with behavior by explaining how people persist at a perceived boring, mundane task like recycling by cognitively transforming the behavior as satisfactory and pleasurable (Werner and Makela, 1998).

It may be easier to manage the linkages between attitudes and behavior with a small, homogenous population, and therefore, much research utilizes campus communities as sample populations. Kelly et al. (2005) examined the attitudes and behavior of campus members toward recycling at a New Zealand university, and noted a strong relationship between self-reported behavior and the following three attributes: attitudes toward recycling, campus occupation, and location of work on campus. Also offered with this study is an extensive overview of work by others on recycling attitudes and behavior of campus communities (Kelly et al., 2005). With the use of a structural equation model, Hartig et al. (2001) tested if restorative experiences in nature, such as hiking or camping, influence environmentally-responsible behavior, and found that for twenty-three percent of participants in a university student survey, this is true (Hartig et al., 2001). At Pennsylvania State University, Thapa (1999) challenged the connection between environmentalist attitudes and behavior as his study resulted in undergraduate students expressing sympathy for the state of the environment, but rarely acting on these concerns through environmentally responsible behavior aside from recycling (Thapa, 1999).

A research niche beyond understanding attitudes and behaviors towards recycling and municipal solid waste generation is that of finding relationships to factors influencing such behavior. Kishino et al. (1998) compared environmentally-responsible consumption and recycling behavior in Germany and Japan. German households are required to pay for waste collection and have higher recycling rates in general than Japanese households, which is consistent with the recycling rates shown in Figure 2.6 (Kishino et al., 1999). As an elaboration of Kishino's research just mentioned, Hanyu et al. (2000) link 
recycling behavior and consumption in a toilet paper case study in Japan. Two of the four major findings were 1) recycling behavior was not directly related to consumption patterns of recycled paper, but rather knowledge of the waste collection and payment system, and 2) most people do not realize that consuming recycled products is a major component of any material recycling (Hanyu et al., 2000).

"Women engage more than men in private, home-based environmental behaviors in contrast with more public activities involving politics. Women in our study were more likely than men to recycle household products. This was the only behavior where women reported more activity than men."

- Johnson et al. (2004)

Johnson et al. (2004) investigated the differences in environmental belief and behavior among various ethnicities. In the United States, African-Americans and foreign-born Latinos held fewer environmental beliefs than Caucasians, and the environmentalism of Asian-American and domestic-born Latinos was most similar to Caucasians, where as African-Americans were least similar. Also, females, younger persons, and persons with liberal political orientation were consistently identified as predictors of environmental concern and behavior (Johnson et al., 2004).

In investigating self-reported recycling and waste reduction behavior, Ebreo and Vining (2004) found that one's concern for the future directly related to recycling behavior, and that no correlation existed between one's behavior of recycling waste versus minimizing waste (Ebreo and Vining, 2004). Hornik et al. (1995) concluded that the following facilitators and incentives act as predictors for recycling: consumer knowledge, commitment to recycling, monetary rewards, social influence, and frequency of collection (Hornik et al., 1995). While investigating factors that influence municipal solid waste generation in the southeastern United States, Hockett et al. (1995) found that the per capita retail sales of eating establishments had the greatest effect on waste generation (Hockett et al., 1995). Meaning, the more citizens spent on eating out at restaurants, a greater amount of waste was generated, which is most likely due to people not eating all the food provided in a restaurant meal and the establishment having to throw away these leftovers. Medina (1997) found that the relationship between municipal solid waste generation and income varies with respect to the developmental 
stage of a nation (Medina, 1997). As a country develops, its waste generation rate increases; whereas, a weak correlation exists between income and waste generation for middle and upper-income countries, and a decrease in waste generation is seen for the wealthiest countries (Medina, 1997).

In developed countries, curbside recycling programs are very prevalent, which offers yet another research niche for identifying factors that affect recycling. Owens et al. (2000) conducted a small-scale case study to correlate recycling efficiency (RE) of residents participating in a curbside recycling program in Georgia, United States. It was noted that residents either did not recycle at all $(0 \% \mathrm{RE})$ or heavily recycled $(75-100 \%$ $\mathrm{RE}$ ), and that strong correlations were seen between RE and annual household income, home-ownership status, and level of education attained by the lead recycler (Owens et al., 2000). Also, access to curbside recycling programs showed nearly 50\% participation rate as opposed to the $25 \%$ participation in community recycling center drop-off of material, and factors such as access, shopping behaviors, age, family size, and income acted as predictors of recycling behavior (Domina and Koch, 2002) (Domina and Koch, 2002). Noehammer and Byer (1997) examined design variables of curbside recycling programs to assess the affects on participation rate, and found that no single set of design variables result in the ideal program, but rather a variety of combinations are successful and that costs, needs, and goals of the community should be factors highly considered (Noehammer and Byer, 1997).

As demonstrated by the previous section, a large amount of research has been focused on developed countries' municipal solid waste generation and recovery, as well as the linkages to behavior affecting these two parameters. With nearly $80 \%$ of the nations on the globe classified as 'developing' (CIA, 2004), similar investigations of the third world should heighten understanding of the MSWM issues and point to solutions that embrace a more sustainable approach to MSWM. 


\section{CHAPTER THREE}

\section{DEVELOPING COUNTRIES'}

\section{Municipal Solid Waste Management}

This chapter presents the main findings of this research on recycling as a form of sustainable solid waste management in the developing world. It is written in a manner such that it is nearly ready for submission to the Resources, Conservation and Recycling journal. Therefore, some of the key points presented in the first two chapters will be restated in this chapter.

\subsection{Introduction}

One hundred ninety-one countries believe that the United Nations Millennium Development Goals of ensuring environmental sustainability policies and programs, relieving poverty, reducing child mortality, improving maternal health, and preventing disease (goals seven, one, four, five, and six, respectively) should be met by the anticipated target date 2015 (UNMDG, 2005). Meanwhile, population continues to escalate with projections nearing 7.2 billion by 2015 (UNEP, 2005a). Accompanying this trend, as shown in Figure 3.1, rapid urbanization is occurring as a result of general population increase, as well as rural-to-urban migration by people seeking employment opportunities.

"Although urbanization in itself is not necessarily a problem as it promotes economic activities and alleviates pressure on land resources, haphazard and unplanned urban growth generally invites many environmental problems such as public space and river bank encroachment, air and water pollution, and solid waste generation."

- United Nations Environment Programme (UNEP, 2001e)

Both urbanization and pursuit of higher quality of life will lead to the global society producing increased amounts of solid waste, especially in developing countries. 
In fact, urbanization is one of the critical global trends shaping the future with an estimated two-thirds of the world's people living in cities by 2025. In addition, more than 150,000 people are being added to urban populations in developing countries every day (UNDESA, 2004). A study in India showed increases of $49 \%$ for population and $67 \%$ for municipal solid waste in the same time period (UNEP, 2001c). With nearly $80 \%$ of the nations on the globe classified as 'developing' (CIA, 2004), similar trends in other third world countries heighten concern of municipal solid waste management (MSWM) and require more sustainable solutions.

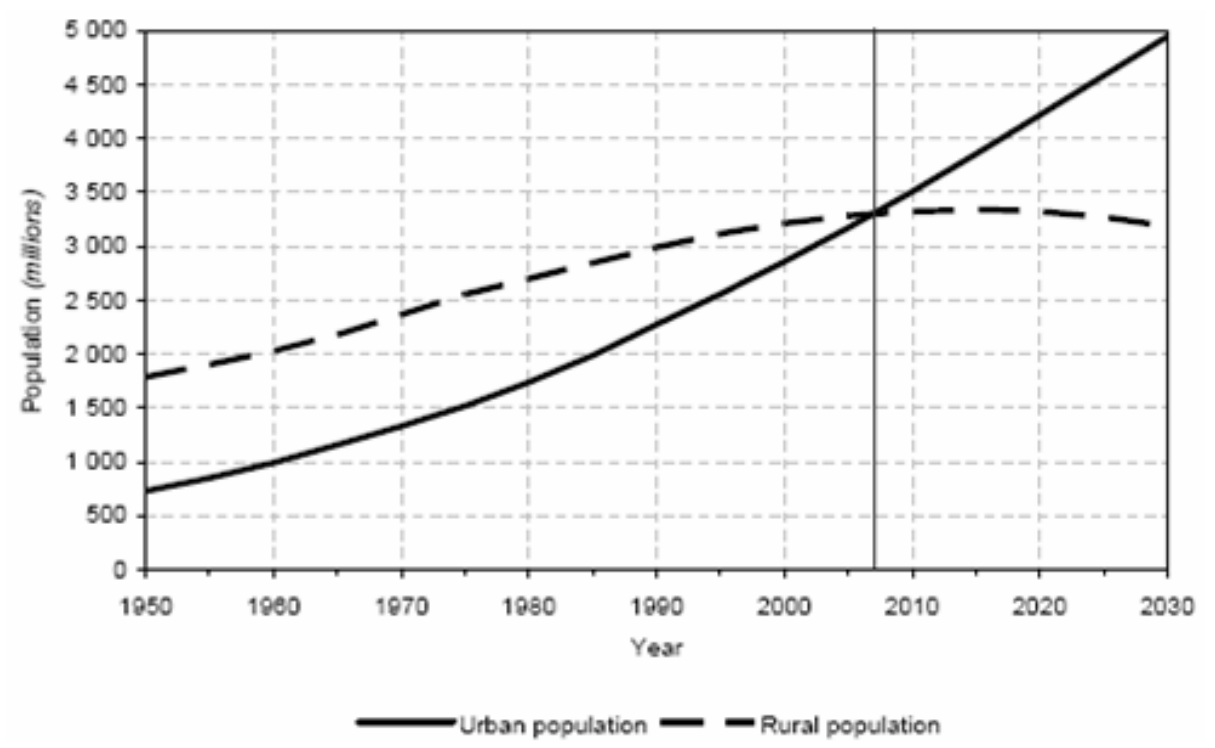

Figure 3.1: Urban and rural population in millions plotted against time in years illustrates urban population exceeding rural population in 2007.

Why investigate municipal solid waste only? Municipal waste, when defined as containing residential waste, can make up nearly $80 \%$ of the average waste stream. Also, municipal solid waste has the most complexity in composition.

-Weng and Nie (2001)

Several technological means exist to divert solid waste typically destined for a landfill, such as incineration with energy production, composting of organic wastes, and material recovery through recycling, which all are considered sustainable methods by which to manage MSW. However, with waste streams comprised of $55 \%$ or greater organic matter in developing countries, composting is already a widely-accepted method to reduce waste fated for the landfill. Also, incineration for energy recovery can be a costly capital investment for most communities in the developing world, pose societal 
and environmental health risks if misused (e.g.: burning toxic wastes causes harmful air pollution), and shows a less positive energy balance than transforming material via recycling (Oliveira and Rosa, 2003).

Developed countries have sophisticated recycling programs and mature MSW databases, and extensive research has been conducted on topics such as psychological motivations to recycling, correlations of generation and recovery rates to socio-economic aspects like income and education, and prediction modeling of recycling behavior. Similar research is sparse with respect to developing countries. In developing countries recycling and MSWM research utilize practical approaches to define societal, environmental, and economic issues causing MSW problems, assess site specific MSW characteristics, and analyze the operations directly associated to MSWM for efficiency and effectiveness.

Therefore, this research focuses on recycling as a sustainable solution to municipal solid waste management issues in the third world, considering elements such as stakeholder involvement and the environmental, social, and economic pressures on MSWM. Here, sustainable MSWM does not lead to diminished quality of life due to forgone economic opportunities or adverse effects on social conditions, human health, and the environment (Mihelcic et al., 2003). Case studies on twenty-three developing countries supply the data analyzed in this research with emphasis on urban and peri-urban areas rather than rural areas.

First, the municipal solid waste (MSW) generation and recovery rates, as well as the composition will be presented for twenty-three developing countries. Following identification of any barriers or incentives to recycling for these case studies, twelve factors influencing sustainable municipal solid waste management (MSWM) in developing countries will be presented and discussed. Thereafter, relationships among these factors will be distinguished in order to understand the collaborative nature required of sustainable MSWM, while aligning them to the societal, environmental, and economic dimensions of sustainability. 


\subsection{Material Studied: Global Recycling Initiatives}

\subsubsection{Developed Countries}

A definite contrast exists between the discussion of research on recycling in developed and developing countries. Developed countries possess heavily industrialized recycling activities that are more or less removed from the daily life of a citizen. Therefore, research on waste recycling in the developed world focuses on technical applications such as models and tools (Daskalopoulos et al., 1998; Barlishen and Baetz, 1994); policy analysis such as command-and-control, and social-psychological and economic incentives (Taylor, 2000); and, extensively, psychological and socio-economic influences on human behaviors. Psychological research efforts include assessments of attitudes toward recycling (McCarty and Shrum, 1994; Steel, 1996; Kelly et al., 2005; Thapa, 1999; Werner and Makela, 1998), and perceived versus actual behavior (Steel, 1996; Chan, 1998; Kelly et al., 2005). Socio-economic factors correlated with recycling include consumption patterns (Kishino, et al. 1998; Hanyu et al., 2000; Domina and Koch, 2002), education (Hornik et al., 1995; Hanyu et al., 2000; Owens et al., 2000), gender (Johnson et al., 2004; Steel, 1996), age (Johnson et al., 2004; Domina and Koch, 2002), and income (Owens et al., 2000; Domina and Koch, 2002).

\subsubsection{Developing Countries}

Research on waste recycling in the developing world places less emphasis on understanding the indirect motives of one's behavior, but more heavily on the practical, direct factors influencing the institutions and elements associated with MSWM. The only work done that seems most similar to research conducted in developed countries were on Mexico and China. During a study of reuse and recycling behavior in Mexico, CorralVerdugo (1997) observed that competencies were the best predictors of actual behavior, whereas beliefs were more indicative of perception of behavior or desired behavior. In the case of recycling, one was more likely to recycle waste when fully understanding the proper way and the reasons to do it as opposed to one simply desiring to recycle. 
In a study of recycling behavior in Wuhan, China's fifth largest city, Li (2003) found that gender, age, and household income were three factors most influential to the activity of recycling. Particularly, elderly females responsible for the household duties of low-income families were most likely to recycle ( $\mathrm{Li}, 2003)$. In exploring the relationship between environmental knowledge and action, factors influencing environmental behavior, and the ways to motivate environmental attitudes and behavior, Harvie and Jaques (2003) learned that residents of China, a developing nation, possess greater knowledge of environmental issues and are more willing to participate in activities like recycling than citizens of the United States of America, a developed country (Harvie and Jaques, 2003).

While it is noteworthy that this type of research is occurring with regard to developing countries, it is also important to mention here that both Mexico and China are experiencing economic and social development that is uncharacteristic of third world countries. In China, more developed regions, like Hong Kong and other coastal cities, may positively influence the activities in the developing interior regions. The socioeconomic transition taking place in Mexico is made apparent by the International Monetary Fund classifying it as a developing country, when its gross domestic product defines it as a developed country (CIA, 2004). Since China and Mexico are transitioning into developed countries, it is not surprising that these two countries have research conducted on themes closely resembling research in developed countries.

Conversely, extensive research has been performed on practical, direct aspects influencing the institutions and elements associated with MSWM, such as identifying waste problems and their causes, quantifying waste characteristics, and analyzing waste operations. For example, a survey conducted in Nairobi, Kenya assessed citizenry knowledge and attitudes about factors contributing to improper management of waste, as well as gathered possible solutions to these issues. Ninety-three percent of the respondents reported solid waste as a problem, less than thirty percent felt that the little amount of recycling was a problem, and approximately forty percent suggested recycling be formalized and encouraged, as well as that industrialists should invest in recycling (Mwanthi et al., 1997). 


\subsubsection{Terminology of country classification}

Several terms are utilized by various organizations to classify the approximately 190 nations on this planet. Table 3.1 offers a summary of these terms.

Table 3.1: Various county classification terminology.

\begin{tabular}{ccc}
\hline Third World & Second World & First World \\
Less Developed & & \\
Country (LDC) & $\mathrm{n} / \mathrm{a}$ & $\begin{array}{c}\text { Developed } \\
\text { Country (DC) } \\
\text { Least Developed }\end{array}$ \\
Country (LLDC) & & \\
Developing & Country in & Advanced \\
Country & Transition & Economy \\
Non-market & $\mathrm{n} / \mathrm{a}$ & Market Society \\
Society & Industrializing & Industrialized \\
Non-industrialized & Nation & Nation \\
Nation & & \\
\hline
\end{tabular}

The second and third sets of terminology in Table 3.1 were utilized for classifying the case studies in this research. These terminologies may not meld well with the ideals of sustainable development and sustainability, but they are well-accepted and established terms. Explicitly said, the terminology used to categorize a given country is not paralleled to the sustainability of the country in general or its MSWM specifically. Meaning, just because a country is termed "developed," by no means indicates that it has developed sustainably nor does it signify that it is most sustainable or more sustainable than "developing" countries. The bottom two definitions in Table 3.1 better recognizes the status of a country with terminology more aligned with sustainability. 


\subsection{Methods}

\subsubsection{Selection of Country Case Studies}

Selection of the case studies was based on the following two criteria: 1) the country has a socio-economic status of "developing" as designated by the International Monetary Fund (IMF) or economic status of "less developed" as based on a country's gross domestic product (GDP), and 2) availability of national data. Detailed definitions and a listing of countries associated with the terms "developing" and "less developed" can be found in Appendix A-Country Classification. Prior to employing the selection criteria, thirty-one case studies were gathered from a variety of sources including research journal articles and international government organizations' reports. Two case studies, Malta and Singapore, actually fulfilled the first criteria, but were removed due to displaying too many developed country characteristics. For instance, both countries have gross domestic products an order of magnitude higher than the other countries selected for the study.

Based on the second criteria, case studies on Ghana, Nigeria, Pakistan, Tanzania, Vanuatu, and South Africa were disqualified for the study due to insufficient national data. Some case studies contain data that is considered national data by the source itself, whereas others have data for only a portion of the population. If a country case study contained waste characterization data for ten percent or greater of the national population, then data were considered representative of national data and the case study was included in the research. Table 3.2 offers a listing of the twenty-three selected case studies and the information utilized to determine inclusion in the study, as well as the source(s) of data.

As Table 3.2 shows, the categories based on GDP and IMF classification are not consistent with one another, and for this reason, a country could meet the criteria under either status and still be considered for this study. Also, data type and source are not necessarily correlated; a diversity of combinations exists. 
Table 3.2: Socio-economic standing, national data type and data source for the twentythree selected case studies on MSWM in the developing world.

\begin{tabular}{|c|c|c|c|c|}
\hline \multirow[b]{2}{*}{ Country } & \multicolumn{2}{|c|}{$\begin{array}{c}\text { Socio-economic } \\
\text { standing defined by: }\end{array}$} & \multirow[b]{2}{*}{ National Data ${ }^{3}$} & \multirow[b]{2}{*}{ Source $^{4}$} \\
\hline & $G D P^{I}$ & $I M F^{2}$ & & \\
\hline Bhutan & LLDC & developing & actual & UNEP, 2001b \\
\hline Botswana & LLDC & developing & representative & Bolaane and Ali, 2001 \\
\hline Brazil & LDC & developing & representative & $\begin{array}{l}\text { Wells, } 1994 \\
\text { Fehr, } 2000\end{array}$ \\
\hline China & LDC & developing & actual & Wang and Nie, 2001 \\
\hline Guyana & LDC & developing & representative & Závodská, 2003 \\
\hline India & LDC & developing & actual & UNEP, 2001c \\
\hline Indonesia & LDC & developing & representative & World Bank, 2003a \\
\hline Iran & LDC & developing & representative & Abduli, 1995 \\
\hline Jamaica & LDC & developing & actual & Pendley, 2005 \\
\hline Lao & LLDC & developing & actual & UNEP, 2001d \\
\hline Lebanon & LDC & developing & representative & Nuwayhid et al., 1996 \\
\hline Malaysia & $\mathrm{LDC}$ & developing & actual & Kathirvale et al., 2003 \\
\hline Maldives & LLDC & developing & representative & UNEP, 2002 \\
\hline Mauritius & LDC & developing & actual & Mohee, 2002 \\
\hline Mexico & $\mathrm{DC}$ & developing & Actual & $\begin{array}{l}\text { Buenrostro and } \\
\text { Bocco, } 2003\end{array}$ \\
\hline Mongolia & LDC & in transition & representative & World Bank, 2004 \\
\hline Nepal & LLDC & developing & Actual & UNEP, 2001e \\
\hline Philippines & LDC & developing & Actual & World Bank, 2001 \\
\hline Sri Lanka & LDC & developing & Actual & UNEP, 2001f \\
\hline Thailand & LDC & developing & representative & $\begin{array}{l}\text { UNEP, 2001a and } \\
\text { World Bank, 2003b }\end{array}$ \\
\hline Turkey & $\mathrm{DC}$ & developing & Actual & Metin et al., 2003 \\
\hline Turkmenistan & LDC & in transition & Actual & UNEP, 2005b \\
\hline Vietnam & LDC & developing & representative & UNEP, 2001g \\
\hline \multicolumn{5}{|l|}{ Notes: } \\
\hline \multicolumn{5}{|c|}{${ }^{1}$ Definition based on per capita gross domestic product (GDP): Developed Country (DC) has per capit } \\
\hline \multicolumn{5}{|c|}{ GDP $>\$ 10,000$ USD; Less Developed Country $($ LDC) $<\$ 5,000 ;$ Least Developed Country (LLDC) } \\
\hline \multirow{2}{*}{\multicolumn{5}{|c|}{$\begin{array}{l}\$ 1,000 . \text { Countries with } \$ 5,000<\text { per capita GDP }<\$ 10,000 \text { are categorized based on other factors. } \\
{ }^{2} \text { Definition based on the International Monetary Fund's discretion. }\end{array}$}} \\
\hline & & & d's discretion. & \\
\hline \multicolumn{5}{|c|}{${ }^{3}$ Actual: national data cited by source. Representative: data for $>10 \%$ of population. } \\
\hline \multicolumn{5}{|c|}{$\begin{array}{l}{ }^{4} \text { UNEP and World Bank are international non-government organizations offering national reports on solic } \\
\text { waste and other environmental issues. Surname indicates data were derived from a journal article }\end{array}$} \\
\hline
\end{tabular}




\subsubsection{Quantitative Data: MSW Generation, Composition, Recovery}

The primary purpose of the second selection criteria relating to reliable national data was to ensure that data being analyzed for the generation and recovery rates, as well as the composition, were indicative of the MSW characteristics of the nation as a whole. The definition and method by which to quantify and classify municipal solid waste varies among the case studies, and different case studies offered varying amounts of data. For instance, some case studies have data for all three variables of generation, composition, and recovery, whereas others may only have data for one or two of these attributes. Case study waste compositions were conformed to the classification utilized by the European Union (Eurostat, 2003). In this study, a country was defined as having substantial recycling efforts if the case study showed material recovery rates of five percent or higher of the waste generated. Those countries with less than five percent recycling on a national level were considered as having a negligible amount of recycling, and are not included in the assessment of the quantitative recovery rates.

\subsubsection{Qualitative Data: Incentives and Barriers to Recycling}

The sources accompanying each country case study in Table 3.2 were examined to identify barriers and incentives to recycling, which, in this study, are considered to function as factors influencing sustainable MSWM in developing countries. The factors themselves were created as they became apparent in the literature. Then, the factors were subjectively assigned as incentives or barriers to recycling by interpretation of statements made in the literature. Exact verbiage from the sources supporting such choices has been documented in Appendix C - Justification for Barrier and Incentive Designations, and some in Appendix D - The Role of Scavengers in Developing World MSWM. Again, varying numbers of factors and the amount of detail supporting each factor were supplied by each source. 


\subsection{Results and Discussion}

\subsubsection{Municipal Solid Waste Generation}

Figure 3.2 presents the MSW generation rates for all of the twenty-three cases studies. Table E.1 in Appendix E - Detailed Developing Country Quantitative Data provides additional data relevant to the MSW generation rates, such as the year of data collection and the percentage of population represented for case studies without actual national data.

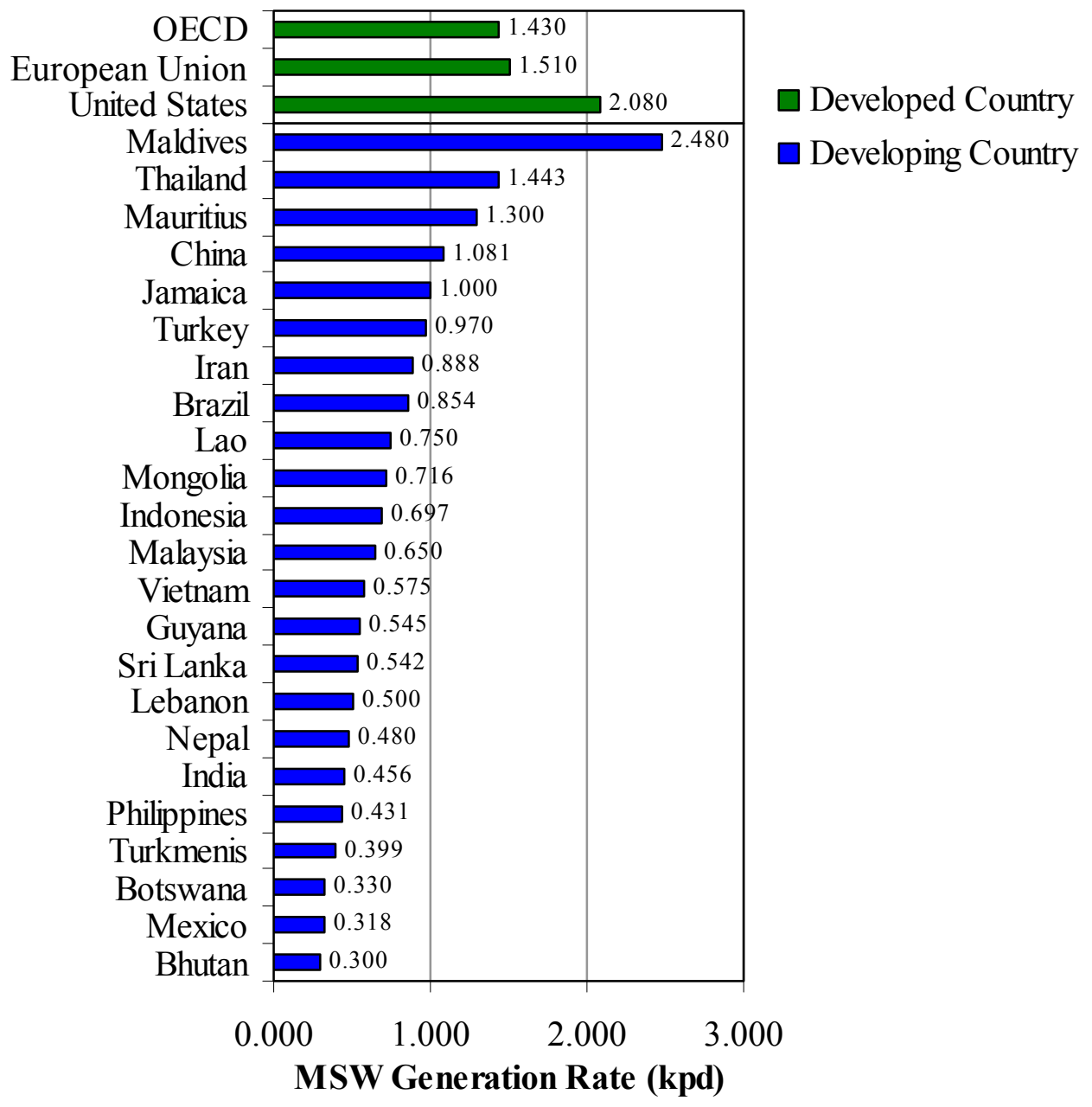

Figure 3.2: Municipal solid waste generation rates for twenty-three developing countries.

Figure 3.2 shows Maldives having the highest MSW generation rate due to its greatest economic activity being tourism (UNEP, 2002), and it is an exception to the range of 0.3-1.44 kg/person/day (kpd). Bhutan, Botswana, and Mexico generate the least amount of MSW on a per capita basis at approximately $0.3 \mathrm{kpd}$. In contrast, developed 
countries typically generate 1.43 to $2.08 \mathrm{kpd}$. The range of generation rates in this study is of no surprise, as the case studies vary greatly with respect to attributes like gross domestic product (GDP) (1,400 current international dollars of GDP as purchasing power parity (PPP) per capita in Bhutan to 11,258 current international dollars PPP per capita in Mauritius for 2003) and developmental stage (as shown in Table 3.2) (WRI, 2005; CIA, 2005; CIA, 2004).

The relationship between municipal solid waste generation and income varies with respect to the developmental stage of a nation (Medina, 1997). Medina (1997) found that as a country develops, its waste generation rate increases. Whereas, a weak correlation exists between income and waste generation for middle and upper-income countries, and a decrease in waste generation is seen for the wealthiest countries (Medina, 1997).

The quantity of waste generated in developing countries is directly affected by several different elements. The lifestyle (Fehr et al., 2000) that is usually associated with certain incomes can influence consumption rates and patterns (World Bank, 2003a). The number of people in household has shown a correlation to per capita waste generation as the greater number of people in a given household results in less waste generation per person per day (Bolaane and Ali, 2004). Socio-economic development and the degree of industrialization influence waste generation rates by generally affecting income and consumption patterns (World Bank, 2001). Climate and seasonal changes impact waste generation by having an effect on the amount of organic material generated as a waste product of preparing fresh foods in the seasons or climates that allow (World Bank, 2001).

\subsubsection{Municipal Solid Waste Composition}

Table 3.3 provides the spread of composition for each material in the waste stream for all case studies except four. Table E.2 in Appendix E-Detailed Developing Country Quantitative Data offers composition data for all nineteen countries with numerical data, as well as qualitative data for Indonesia and Turkmenistan. The Bhutan 
and Maldives case studies did not provide waste composition data. Figure 3.3 portrays the average MSW composition for the nineteen developing countries studied. The various composition classification schemes were fit to the categories used by the European Union, minus the bulky waste category. The category 'other waste' includes ash, stone, ceramic, and slag, as well as other undefined materials, and 'organic material' include bones, shells, leather, and wood. All other category names are reflective of the materials classified under them. However, this average composition should be interpreted carefully because of the wide array of material composition among several different case studies.

Table 3.3: Range of composition of municipal solid waste generated by households in nineteen of the developing countries examined in this study.

\begin{tabular}{cr}
\hline MSW Composition & Percentage by Weight \\
\hline Paper and paperboard & $5.6-25.0$ \\
Textiles & $0.0-6.4$ \\
Plastics & $3.3-30.0$ \\
Glass & $0.0-12.5$ \\
Metals & $0.7-12.5$ \\
Organic Material & $17.0-80.0$ \\
Other Waste & $0.0-40.6$ \\
\hline
\end{tabular}

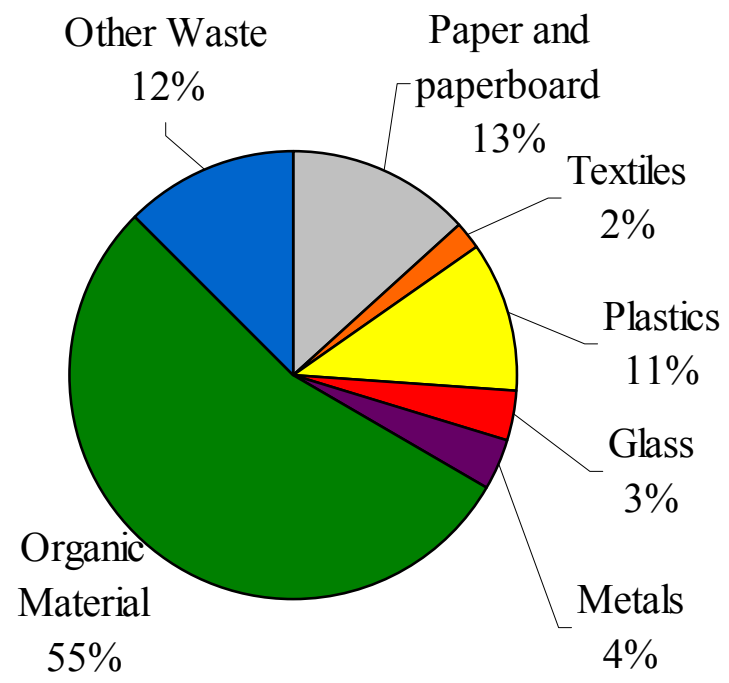

Figure 3.3: Average composition of nineteen developing countries' municipal solid waste presented as percentage by weight. 
The average $55 \%$ organic material of the nineteen case study countries (see Figure 3.3) is consistent with others' studies on MSW in developing countries (Blight and Mbande, 1996). Again, due to the diverse case studies, a wide array of waste composition is evidenced by the percentage ranges shown in Table 3.3. Seasonal effects, income level (Wells, 1994), domestic fuel supply (Wang and Nie, 2001 and Metin et al., 2003), geography, living standards, and climate (World Bank, 2003a; Buenrostro and Bocco, 2003) all affect the MSW composition.

For instance, a greater portion of MSW classified as 'other waste' depends upon the domestic fuel supply used; wood and coal result in large portion of inert matter, whereas gas has negligible amounts of solid residue (Wang and Nie, 2001 and Metin et al., 2003). Some experts claim that high-income households generate more inorganic material from packaging waste, whereas low-income households produce more organic material from preparing food from base ingredients, while others believe that highincome households may generate the same amount of organic material because they can afford servants to prepare fresh, unpackaged food (Wells, 1994). Also, more organic material from fruit occurs summer (Wells, 1994).

Figure 3.4 graphically communicates the difference between MSW composition in developed countries (US and EU) versus developing countries (LDC). On average, developed countries' waste stream comprises half as much organic material, twice the portion of paper and cardboard, and similar fractions of glass and plastic. 


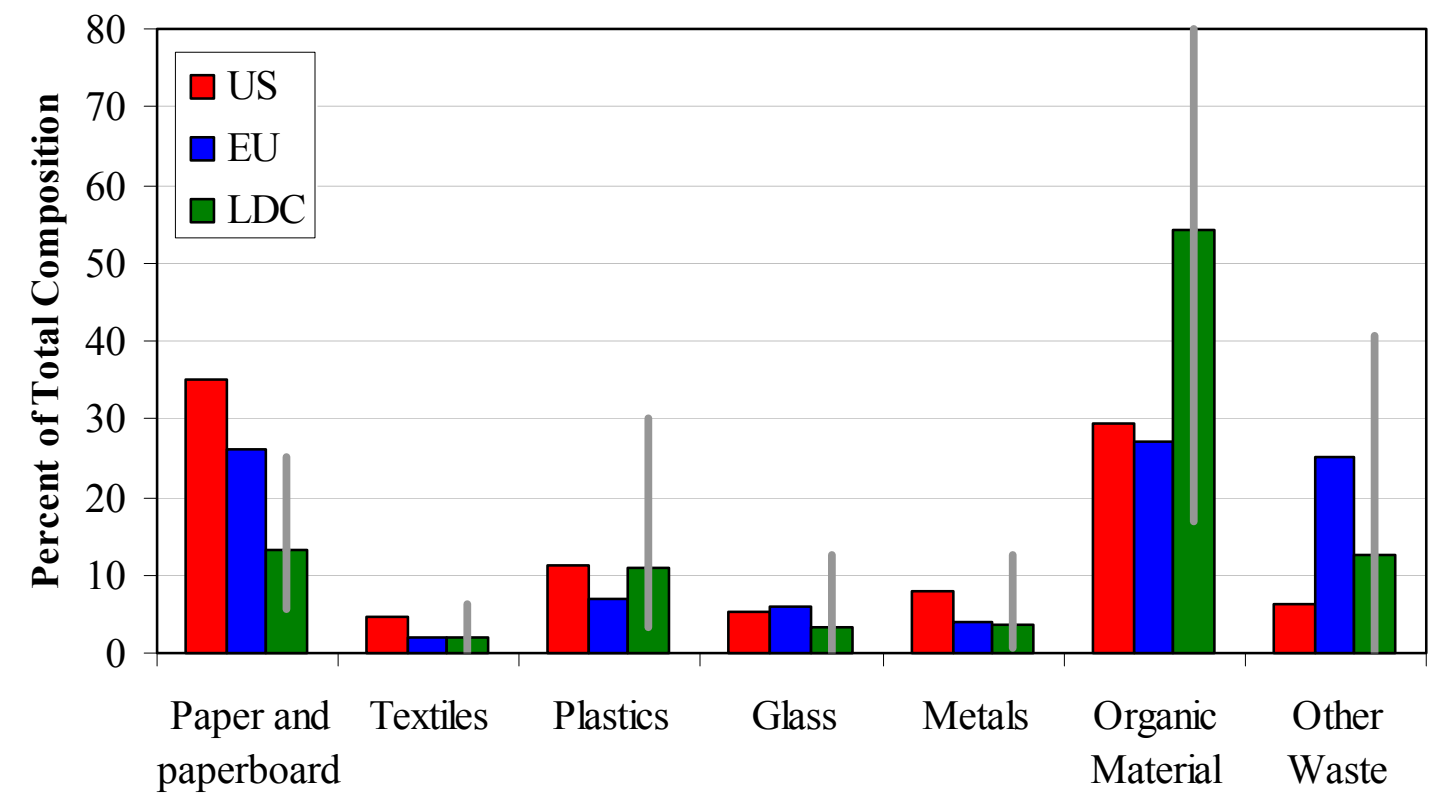

Figure 3.4: Comparison of MSW composition of developed countries (United States and those in the European Union) against the average of nineteen developing countries (LDC). Vertical bars provide the range of composition of each material type for the developing countries only. (USEPA, 2003; Eurostat, 2003; see sources in Table 3.1)

\subsubsection{Municipal Solid Waste Recovery}

Table 3.4 provides what waste recovery data were made available through the literature examination. When available, percentage of material recovery is provided; otherwise, the occurrence of material recovery is noted with a diamond symbol ( $\downarrow$ ). Mongolia is not shown in Table 3.4, but has significant recycling activities as evidenced by scavengers comprising ten percent of the capital city's population and a women's federation that operates household collection of recyclables via their "blue bag" campaign (World Bank, 2004). Mexico provided a national material recovery rate of $0.68 \%$, which fell well below the five percent recovery rate inclusion criteria (Buenrostro and Bocco, 2003). 
Table 3.4: Municipal solid waste recovery in thirteen developing countries. Quantitative recovery rates are shown as percentages. Diamond symbol $(\diamond)$ qualitatively signifies substantial recycling activity occurs either overall or for a particular material.

\begin{tabular}{|c|c|c|c|c|c|}
\hline \multirow[b]{2}{*}{ Country } & \multicolumn{5}{|c|}{ MSW Recovery (\%) } \\
\hline & Overall & Paper & Plastic & Glass & Metal \\
\hline Botswana & $\diamond$ & & 90 & & 65 \\
\hline Brazil & 41 & 30 & $20^{1}$ & $20^{2}$ & $49^{3}$ \\
\hline China & $7-10$ & $\diamond$ & & & $\bullet$ \\
\hline Guyana & $\diamond$ & & & $\diamond^{2}$ & $\diamond$ \\
\hline India & $\diamond$ & & $\diamond$ & & \\
\hline Indonesia & $\diamond$ & $\diamond$ & $\diamond$ & $\diamond$ & $\diamond$ \\
\hline Iran & $\diamond$ & $\diamond$ & $\diamond$ & & \\
\hline Nepal & 5 & & & & \\
\hline Philippines & 13 & $\diamond$ & $\diamond$ & $\diamond$ & 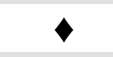 \\
\hline Sri Lanka & $\bullet$ & $\bullet$ & $\bullet$ & $\diamond$ & $\bullet$ \\
\hline Thailand & 15 & 28 & 14 & 18 & 39 \\
\hline Turkey & $\bullet$ & 36 & 30 & 25 & 30 \\
\hline Vietnam & $13-20$ & $\bullet$ & $\diamond$ & $\bullet$ & $\bullet$ \\
\hline \multicolumn{6}{|c|}{ Notes: } \\
\hline \multicolumn{6}{|c|}{${ }^{1}$ Recovery of plastic beverage bottles only. } \\
\hline \multicolumn{6}{|c|}{${ }^{2}$ Recovery of containers only. } \\
\hline${ }^{3}$ Recovery of als & cans only. & & & & \\
\hline
\end{tabular}

Due to data availability, the information provided in Table 3.4 varies widely with respect to the degree of detail. Table 3.4's main purpose is to justify the classification of each country as either recycling or not. Table 3.4 shows Brazil and Turkey having the highest material recovery rates, which can be explained by the roles of Cempre - the Brazilian Recycling Commitment (see Box 3.1) and industry, respectively (Wells, 1994 and Metin et al., 2003). Developed countries' recycling rates fall within the developing countries' range of 0 to $41 \%$ material recovery, with the European Union at $18 \%$ and the United States at approximately $30 \%$. 
Box 3.1 The Brazilian Recycling Commitment Cempre (which in Portuguese stands for Compromiso Empresarial para Reciclagem, and is known in English as the Brazilian Recycling Commitment) was founded in 1992. Two years of experience showed that recycling was taking a very different path in the developing world from that in the developed world. As an economic activity, recycling is easier to develop in poorer countries precisely because it is labor-intensive. Major corporations can and should play a catalytic role in advancing the cause of recycling. Cempre has been consulted on several occasions regarding draft legislation in the waste area. Cempre believes it has become a credible center of hard local data on many aspects of recycling, from costs of curbside collection programs, to a scrap dealer hotline and practical manuals. Cempre also created and distributed a decisionmaker's guide to integrated municipal solid waste management. Source: Wells, 1994.

\subsubsection{Incentives and Barriers to Recycling: Twelve MSWM Factors}

Table 3.5 offers a summary of the factors with specific instances where MSWM acted as a barrier or incentive to recycling identified during a case study review of twenty-two developing countries. Malaysia does not appear in Table 3.5 due to insufficient data from which to confidently identify factors influencing its MSWM. Table 3.5 indicates to what extent each factor acts as a barrier to recycling (second column) in developing countries, as well as which countries face the most barriers to recycling (bottom row), as shown by percentage of total number of cases. Of the twentythree country case studies, fourteen recycle and nine do not recycle. Scavengers, low- to no- income citizens that collect materials of value from streets, dumps, and landfills, are present in sixteen of the twenty-three developing countries in the case study review. Countries with no indication of a scavenger population (' $\mathrm{Y}$ ' or ' $\mathrm{N}$ ') or a factor acting as a barrier or incentive to recycling ('B' or 'I') signify that the literature did not comment on these attributes of MSWM.

The summary of recycling in developing countries shown in Table 3.5 contains two main components to address: 1) the dynamic between classification of recycling and presence of scavengers and 2) the justifications associated with identifying the twelve factors influencing recycling. Some inconsistency is seen among the 'yes' and 'no' indicators for recycling and scavengers shown in the first two rows in Table 3.5. One might expect to see recycling activity in any case study where scavengers are present. However, this is not always the case due to either the resistance against scavengers 
playing an important role within MSWM or the potency of the efforts put forth by the scavengers. Even when a country possesses active scavengers, their efforts may not be great enough or sufficiently organized to constitute $5 \%$ or more waste recovery.

"When scavenging is supported - ending that exploitation and discrimination- it
represents a perfect illustration of sustainable development that can be achieved in the
Third World: jobs are created, poverty is reduced, raw material costs for industry are
lowered (while improving competitiveness), resources are conserved, pollution is
reduced, and the environment is protected."

- Medina (2004)

In analyzing the summarized percentage of case studies where a factor acted as a barrier, it is perhaps not surprising that MSWM Personnel Education, Waste Collection and Segregation, and Government Finances are the three biggest barriers to recycling in developing countries. On the other hand, Household Economics is one of the smallest barriers, which indicates that socio-economic status is not the limiting factor to recycling in developing nations. In other words, a majority of the world's population can participate in this form of sustainable MSWM. Interestingly, Land Availability was evidenced as an incentive in every case that addressed this as a factor influencing recycling. Sixty-percent of the country case studies revealed a relationship between having a majority of factors acting as incentives and having substantial recycling activity.

Table 3.6 provides the title and description of each factor influencing recycling, which were created upon noticing repetition of particular issues acting as incentives for or barriers against recycling in the case studies. 


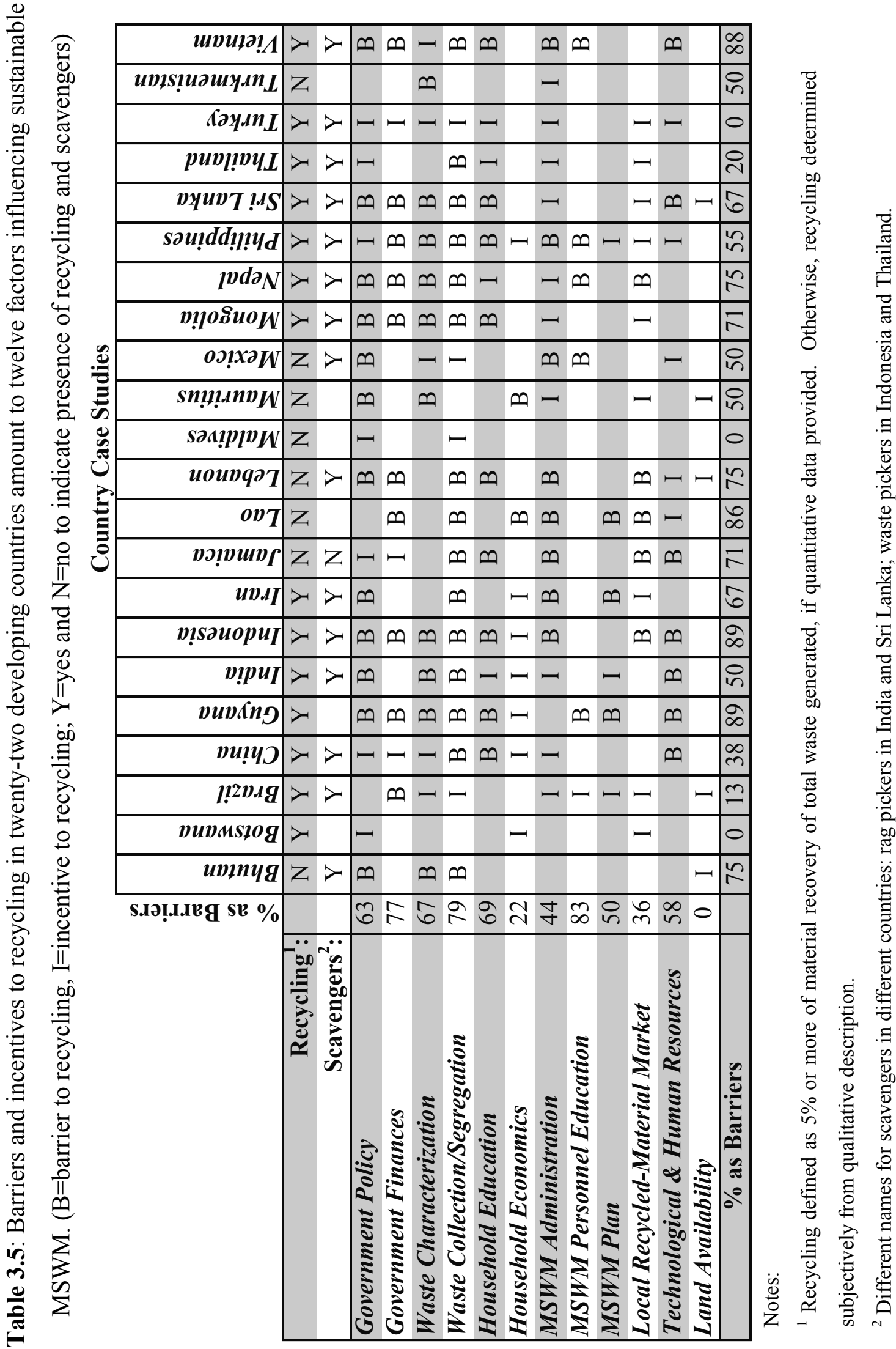


Table 3.6: Summarized descriptions of twelve factors influencing recycling as an element of sustainable municipal solid waste management (MSWM)

in developing countries.

\begin{tabular}{|c|c|}
\hline Title & $\begin{array}{c}\text { Description } \\
\end{array}$ \\
\hline Government Policy & $\begin{array}{l}\text { Presence of regulations, enforcement of laws, } \\
\text { and use of incentive schemes. }\end{array}$ \\
\hline Government Finances & $\begin{array}{l}\text { Cost of operations, budget allocation to } \\
\text { MSWM, stability/reliability of funds. }\end{array}$ \\
\hline Waste Characterization & $\begin{array}{l}\text { Assessment of generation and recovery rates, } \\
\text { and composition of waste stream }\end{array}$ \\
\hline Waste Collection and Segregation & $\begin{array}{l}\text { Presence and efficiency of formal or informal } \\
\text { collection and separation by either scavengers, } \\
\text { municipality, or private contractors. }\end{array}$ \\
\hline Household Education & $\begin{array}{l}\text { Extent of knowledge of waste management } \\
\text { methods and understanding linkages between } \\
\text { human behavior, waste handling, and health/ } \\
\text { sanitation/environment within households. }\end{array}$ \\
\hline Household Economics & $\begin{array}{l}\text { Individuals' income influencing waste } \\
\text { handling behavior (reuse, recycling, illegal } \\
\text { dumping), presence of waste collection/ } \\
\text { disposal fees, and willingness to pay by } \\
\text { residents. }\end{array}$ \\
\hline MSWM Administration & $\begin{array}{l}\text { Presence and effectiveness of private and/or } \\
\text { public management of waste (collection, } \\
\text { recovery, disposal). }\end{array}$ \\
\hline MSWM Personnel Education & $\begin{array}{l}\text { Extent of trained laborers and skilled } \\
\text { professionals in MSWM positions. }\end{array}$ \\
\hline MSWM Plan & $\begin{array}{l}\text { Presence and effectiveness of an integrative, } \\
\text { comprehensive, long-term MSWM strategy. }\end{array}$ \\
\hline Local Recycled-Material Market & $\begin{array}{l}\text { Existence and profitability of market systems } \\
\text { relying on recycled-material throughput, } \\
\text { involvement of small businesses, middlemen, } \\
\text { and large industries/exporters. }\end{array}$ \\
\hline $\begin{array}{l}\text { Technological and Human } \\
\text { Resources }\end{array}$ & $\begin{array}{l}\text { Availability and effective use of technology } \\
\text { and/or human workforce and the safety } \\
\text { considerations of each. }\end{array}$ \\
\hline Land Availability & $\begin{array}{l}\text { Land attributes such as terrain, ownership, and } \\
\text { development dictating MSWM. }\end{array}$ \\
\hline
\end{tabular}

The remainder of this section provides brief discussions on each factor influencing recycling which came to fruition as a result of the barriers and incentives to recycling identified in Table 3.5 and to elaborate on the descriptions of each factor 
provided in Table 3.6. The detailed citations extracted from the relevant literature justifying the incentives and barriers identified for each case study are provided in Appendix C-Justification for Barrier and Incentive Designations. It is important to note here that for any given factor influencing recycling, one country may perceive it as a barrier, whereas another country may view it as an incentive. This irregularity among the case studies is due to the effect of various social, economic, and environmental pressures. A barrier to recycling either denotes the absence of a particular factor, or in cases where the factor is present, the inadequacy of that factor to positively influence recycling. The converse is true for designation of factors as incentives to recycling.

\section{Government Policy}

Incentives for waste reduction and recycling could save money on disposal. The introduction of packaging taxes and other economic incentives for reducing waste and encouraging recycling in many countries have had a larger impact on recycling and waste reduction in these countries than just public awareness and organized recycling programs alone.

- World Bank (2003b)

As noted in Table 3.6, the influence of Government Policy on recycling in developing countries refers to the presence of regulations, enforcement of laws, and use of incentive schemes, all of which vary greatly among the case studies. Of the case studies reviewed, six countries have environmental regulations that do not address MSWM and/or recycling sufficiently or at all (Indonesia, Jamaica, Lebanon, Mauritius, Mongolia, Vietnam), three have effective MSWM regulations (China, Maldives, Thailand), nine have policy that is not practiced or enforced (Bhutan, Guyana, India, Indonesia, Iran, Mexico, Nepal, Philippines, Sri Lanka), and five utilize incentive schemes such as deposits or buy-back policies on recoverable materials (Botswana, Guyana, Mauritius, Thailand, Turkey). An example of an incentive to recycling related to Government Policy is the widespread use of "Garbage Banks" in Thailand (see Box $3.2)$. 
Box 3.2 Garbage Banks In Thailand, garbage banks were conceived as initiatives to encourage recycling activities at the community level, through which participants receive goods or money in exchange for their recyclable waste. Following the success of the first garbage bank in Dan Khun Tod, these types of banks have been replicated around the country. As of 2001 there were 87 of them in the municipal areas of Thailand that process a total of 2,500 tons of recyclables a year. School garbage banks give either cash or a certain number of reward points in exchange for their waste. Community garbage banks direct funds into community improvement projects. "Garbage-for-eggs" projects encourage residents to collect recyclable materials in order to alleviate flood problems of litter-filled canals in order to exchange them for eggs. Within six months of the program's start-date, the amount of waste in the community was reduced by 161 tons. The project is now operating in 23 communities within Bangkok and other provinces. Source: World Bank, $2003 \mathrm{~b}$.

\section{Government Finances}

Cost of MSWM operations, the budget allocated to MSWM by local to national governments, as well as the stability and reliability of funds comprise the Government Finances factor influencing recycling in the third world. Among the case studies, finances were seen as one of the biggest barriers to recycling, mainly due to the lack of funding put toward MSWM by the government (Závodská, 2003; World Bank, 2003a; Nuwayhid et al., 1996; UNEP, 2001e; UNEP, 2001f; Metin et al., 2003; UNEP, 2001g). In Mongolia, "no budget allocation was made for solid waste management for the period 1996-2000 either at the national or the local level. In 2000, the seriousness of the solid waste problem prompted the international donor community to make 1,194 million Mongolian Tugriks (MNT) (approximately 0.9925 million USD) available in loans and grants to address the most pressing challenges related to solid waste collection and management" (World Bank, 2004).

The opposite is true for China, where the government allocated 60 billion yuan (approximately 7.4 billion USD) to environmental infrastructure such as environmentally sound waste treatment facilities in 1998 (Wang and Nie, 2001). Aside from China, another case study demonstrating an incentive to recycling through government finances is Jamaica, where a funds from tax on imported plastics is apportioned to solid waste management as of 2004 (Pendley, 2005). Brazil has found that curbside collection of recyclable materials is more costly than collecting mixed waste, but has recognized that the small additional amount paid to recycle the material is less than the combined 
monetary expense of landfill space and operation and environmental cost of less sustainable MSWM (Wells, 1994).

\section{Waste Characterization}

As many case studies have indicated, understanding the features of a waste stream such as the generation and recovery rates and composition is of utmost importance prior to determining proper management solutions (UNEP, 2001b; UNEP, 2001c; Mohee, 2002; Buenrostro and Bocco, 2003; Bernache-Pérez et al., 2001; UNEP, 2001e; World Bank, 2001; UNEP, 2001g). The assessment of waste streams among the case studies varied greatly from Turkey's highly sophisticated data collection process and opinion surveys (Metin et al., 2003) to the case in Indonesia where "accurate and reliable data available for waste generation, collection, and disposal, as well as for waste characterization, are limited and appear not to be valued" (World Bank, 2003a). Simply the presence of waste characterization does not signify an incentive to recycling; a barrier can occur when there is low confidence in the waste stream data. For example, in Mexico, inconsistencies exist between official and non-official reports of MSW generation rates, and a standardized method for classifying and quantifying municipal solid waste is needed (Buenrostro and Bocco, 2003).

\section{Waste Collection and Segregation}

The presence and efficiency of collection and segregation of waste was most commonly addressed by the case studies, which justified this as a factor influencing material recovery. Waste collection and segregation in developing countries occurs by scavengers, municipalities, or private contractors and can be considered formal or informal, depending on the degree of organization in any of the three sectors. Waste collection and segregation can be viewed as an incentive or barrier depending upon technological and human resources available in a given case study. For countries that employ a more technological approach of material recovery (i.e.; waste segregation with technical machinery), efficient waste collection is seen an incentive because all waste is eventually directed to a processing facility. On the other hand, countries that utilize labor-intensive means of recycling (i.e.; manual separation) may not necessarily require 
gathering waste into one location due to the wide dispersion of scavengers throughout a community (See Box 3.3).

Box 3.3 Scavengers It is common for scavengers, the 'informal sector,' to participate in solid waste management activities in developing countries. This is due primarily to inadequate municipal services, which create a large need for informal waste collection and an opportunity for income among the poor. The size of the informal recycling sector varies significantly from country to country. It has been estimated, for instance, that around 2 percent of Mexico's population live off recycling-related activities, including 30,000 people in the metropolitan area of Mexico City alone. In Colombia, 300,000 people, roughly 1 percent of the country's population, are involved in scavenging activities. The informal waste collection sector in Thailand is considerably smaller, with an estimated 25,000 people involved in informal recycling. The majority of scavengers have no benefits such as medical insurance and pension plans; they have limited job stability and few educational and other job opportunities (World Bank, 2003b). In China, it was estimated that scavengers collected 8$10 \%$ of waste before municipal collection. This is because individual collectors are more aggressive than the municipal collectors, as it is partially through the collection of the recyclables that the scavengers make a living (Wang and Nie, 2001). In Mongolia, 5,000 to 7,000 scavengers, many of whom are young children, are not integrated into the daily waste management operations of the city and are often seen as a nuisance (World Bank, 2004).

Since the accumulation of waste in dumpsites near residential areas poses a major health concern, this research considers higher waste collection efficiencies as an incentive to recycling rather than a barrier. This assumption still affords scavengers the opportunity to collect material of value in the waste stream from a common area, which may promote organization and formalization of this vital player in sustainable MSWM in the third world. Waste collection in most case studies depends upon reliable financial and technological resources, as well as organized administration (World Bank, 2003a; Abduli, 1995; Pendley, 2005; World Bank, 2001; UNEP, 2001f).

In absence of segregation of waste at source, waste treatment alternatives such as recycling, waste-to-energy projects and or composting become uneconomical to operate.

-United Nations Environment Programme (UNEP, 2001c)

"Proper segregation would lead to better options and opportunities for scientific disposal of waste" such as composting and recycling (UNEP, 2001b). Waste segregation taking place at the source (households, neighborhoods) or the processing facility is dependent upon the technological extent of the processing facilities themselves. If a 
facility or series of facilities is capable of separating organic from inorganic materials, recyclable from inert materials, cleansing recyclables, and then processing the recyclables into 'raw' material for sale, then mixed waste collection is sufficient. Since developing countries usually lack such technological advances, segregation of waste at the source by divided or selective collection or segregation of waste at an intermediary step by scavengers is necessary (See Box 3.3).

\section{Household Education}

"Even under difficult living conditions, such as in temporary settlements in the disaster region, regular citizens support and participate in environmental actions, especially when properly informed."

- Metin et al. (2003)

Having knowledge of MSWM and an understanding of the linkages between human behavior, waste handling, and health/sanitation/environment comprise Household Education as a factor influencing recycling. Many of the case studies, including Indonesia, Mexico, Mongolia, Sri Lanka, and Thailand, perceived heightened awareness of sustainable solid waste management as an incentive to inducing more public support of and participation in waste minimization and recovery activities (World Bank, 2003a; Buenrostro and Bocco, 2003; World Bank, 2004; UNEP, 2001f; UNEP, 2001a). In Thailand, government and non-government organizations' projects, like 'Waste Minimization,' 'Thinking Over and Saving Resources,' and 'Community in Your Hands,' aim to increase household education related to reducing, reusing, and recycling MSW. In contrast, administrators in Jamaica overwhelmed by the littering behavior of citizens look to public education campaigns to alleviate their MSW problem (Pendley, 2005).

\section{Household Economics}

Individuals' income influencing waste handling behavior (e.g., reuse, recycling, and illegal dumping), presence of waste collection/disposal fees, and willingness to pay by residents were seen as one of the biggest incentives to recycling, which justified them being combined into the Household Economics factor influencing sustainable MSWM in the third world. In the case study on China, the implementation of a fee system of 3 yuan 
tax/family/month for treatment and disposal of MSW had positive effects on the awareness of waste problems (Wang and Nie, 2001), which in turn encourages participation in other activities to reduce waste such as recycling. In low-income households in Botswana, Guyana, and Iran, the idea of 'waste' is uncommon because every material commonly present in MSW is seen as valuable (Bolaane and Ali, 2004; Závodská, 2003; Abduli, 1995). Also, the role of scavengers as informal recyclers continues to be a result of citizens in need of income. In some cases, as in the study of India, increasing incomes can act as incentives to recycling also due to changing consumption patterns that result in a higher percentage of recyclables in MSW (UNEP, 2001c).

\section{MSWM Administration}

Presence and effectiveness of private and/or public management of waste through collection, recovery, and disposal is one the most heavily cited influences on recycling in the case study review, which substantiates MSWM Administration being one of the twelve factors. A barrier to recycling within MSWM Administration is the lack of collaboration among the various agents collecting, treating, disposing, financing, and regulating wastes, which was evidenced in Indonesia, Iran, Mexico, Nepal, and Vietnam. Due to the unstable/undeveloped political institutions and limited/unreliable financial resources in developing countries' government bodies, most of the case studies identified publicly administered MSWM as being a barrier to recycling, except China. The private administration of MSWM, specifically recycling, has been very successful in many of the case studies, and is therefore viewed as an incentive to recycling in the third world. It has alleviated pressure from the public administrators by making recycling profitable (Pendley, 2005; Mohee, 2002; Metin et al., 2003), modernizing recycling process (i.e.; being able to afford machinery) (Wells, 1994 and World Bank, 2001), and reducing the number of responsibilities (World Bank, 2003a; Buenrostro and Bocco, 2003). 


\section{MSWM Personnel Education}

Although the MSWM Personnel Education factor was only recognized by six of the twenty-two case studies, the lack of trained laborers and skilled professionals in MSWM positions was a barrier to sustainable MSWM in every case but one. Brazil is the one case study with MSWM Personnel Education as an incentive due to Cempre's numerous programs and publications that assist decision-makers in stimulating recycling in a community as part of sustainable MSWM (Wells, 1994).

One of the key factors that boost the diversion rate and thereby lower costs in Sáo José dos Campos, Curitiba, and Santos, Brazil include tireless educational campaigns. In essence, those cities that invested the most in education, attained the best results and lowest costs.

- Wells (1994)

\section{MSWM Plan}

The presence and effectiveness of a comprehensive, integrative, long-term MSWM strategy was highly encouraged by every case study that addressed the MSWM Plan factor in order to positively influence recycling and other forms of sustainable MSWM. The case studies that find this factor to be a barrier to recycling are those countries that do not possess a MSWM Plan or have one that needs improvement. The Philippines is the only case study with an integrated national framework for environmentally-friendly solid waste management (World Bank, 2001).

\section{Local Recycled-Material Market}

Although seemingly a subset of private MSWM administration, the existence and profitability of market systems relying on recycled-material throughput, involvement of small businesses, middlemen, and large industries/exporters is deserving of the Local Recycled-Material Market factor influencing recycling in developing countries. In Jamaica, a small-island developing state, the MSW is comprised of $40 \%$ recyclables, but no viable markets exist due to the overall low quantity of recoverable materials (Pendley, 2005). Conversely, Sri Lanka, also an island nation, experiences high export demand for ferrous metal and substantial export demand for corrugated cardboard and plastic (UNEP, 2001f). 
As MSW has increased in the last 20 years, waste composition has also changed, revealing an increasing amount of organic and recyclable waste. In general, value of the waste in terms of reusability is increasing.

- Wang and Nie (2001)

Several of the case studies recognized that the waste stream contains a significant portion of recyclables and that recovery potential of these materials is foregone. In Thailand, it is estimated that the market value of approximately 4.5 million tons of recyclables would near 16 billion THB (Thai Baht) per year (approximately 390 million USD) (World Bank, 2003b). Likewise is true in Iran, where "if an official system was put into place for paper and cardboard recycling, one could earn 44 million dollars per year" (USD) (Abduli, 1995).

\section{Technological and Human Resources}

Availability and effective use of technology and/or human workforce and the safety considerations of each were recurrent barriers and incentives to recycling to warrant Technological and Human Resources to be a factor influencing sustainable MSWM. In many cases in developing countries, adequate funds are not available to implement technology that is reliable and appropriate. Even when a capital investment can be made for a piece of technical equipment, many times laborers are unskilled or funds are undependable to operate and maintain the equipment properly. Both instances pose health and safety hazards, and both were seen as barriers to recycling in China (Wang and Nie, 2001), Guyana (Závodská, 2003), Jamaica (Pendley, 2005), Sri Lanka (UNEP, 2001f), and Vietnam (UNEP, 2001g).

Many case studies advocate for the use of manual labor in place of technical machinery in developing countries, such as China, Guyana, Jamaica, Lebanon, and Turkey, whereas others simply wanted better technology, namely India, Indonesia, and the Philippines. The Laos and Mexico case studies demonstrated content with the mix of used collection vehicles and manual MSW collection, respectively. In any case, with or without technological inputs, institutions must be in place to safeguard the health of the technicians and manual laborers. 


\section{Land Availability}

Land attributes such as terrain, ownership, and development often times dictate the MSWM options available to developing countries' MSWM administrators. This factor was seen as an incentive to recycling in every case where it acted as an influence to MSWM. Poor terrain, widespread development (population density), and extensive private ownership were cited as hindrances to landfill management of waste. Such constraints force municipalities to consider other MSWM options such as recycling and incineration with or without energy recovery.

In Lebanon, the cost of land if very expensive due to much of it being privately owned, which is prohibitive to the MSWM administrators obtaining it for landfills (Nuwayhid et al., 1996). Rugged terrain causes most Brazilians to live within 100 kilometers of the sea. "This coast-hugging pattern of human settlement has exerted an increasing pressure on available space to bury much of the 90,000 tonnes of MSW that Brazilians generate every day" (Wells, 1994). Sri Lanka and Mauritius are two smallisland developing nations that face issues of high importation of goods and tourism resulting in increasing amounts MSW without a management solution in place.

\subsubsection{Validation of Twelve Factors Influencing Recycling}

The results of this research are supported by other related efforts on understanding the various pressures that influence the effectiveness of MSWM in developing countries. Following an assessment of MSWM projects funded by the World Bank, Bartone (1993) proposes some responsibility should be placed on funding agencies to ensure MSWM projects include aspects of strategic solid waste plans; solid waste collection; transfer, resource recovery, and disposal; hazardous waste management; regulatory framework; institutional arrangements; environmental education and public participation; financing, pricing, and cost recovery; land acquisition; and phasing of MSWM improvements (Buenrostro et al., 2001).

Diaz (1998), focusing on Latin America, encourages the following nontechnological issues to receive more attention with respect to MSWM: national policy, 
institutional capacity, regulatory activity, personnel education, and financial stability (Diaz, 1998). A ten-point checklist was developed by Závodská and Knight (2002) to assist planners and researcher in assessing and improving MSWM in Georgetown, Guyana. Also intending to have broader applicability to most developing countries, it included action items pertaining to the following topics: social factors and education, waste stream information, collection, workforce and productivity, equipment, resource recovery, disposal options, laws and regulations, financial resources, and other issues (Závodská and Knight, 2002).

These previous studies raised attention to key topics within MSWM in developing countries similar to this research, but none considered the pressures specifically on material recovery, understood the relationships among factors influencing recycling, nor identified the drivers behind the MSWM institutions. Nevertheless, the consistency among the results of their research and this research strengthen the significance the twelve factors influencing recycling, a sustainable approach to MSWM, arrived at in this study.

\subsubsection{Relation of Twelve Factors to Big Picture Indicators}

While this research focused on identifying the qualitative factors influencing recycling in developing countries at the local-level, it was attempted to relate recycling activities at a small scale to a larger scale by investigating correlations to national, quantitative indicators representing the social, environmental, and economic dimensions of sustainability. The purpose of finding such correlations could offer insight as to 1) whether or not influences on a large scale affect local activities, and 2) which of those indicators have a significant effect.

Many of the social, environmental, and economic indicators relate to the twelve factors influencing recycling. For instance, the local recycled-material market may be influenced by the imports and exports of goods. There may be a relationship between illiteracy rate and household and MSWM personnel education. Whether or not a nation 
participates in Agenda 21 initiatives or the density of international non-government organizations may have an impact on the degree of recycling.

In a preliminary statistical analysis using XLMiner's classification tree, no correlation was apparent between recycling activity and any of the indicators. Appendix G-Data on Social, Environmental, and Economic Indicators and Appendix HDefinitions of Social, Environmental, and Economic Indicators provides a detailed description on XLMiner's classification tree functions and tabulates all raw data and their definitions utilized in this preliminary statistical analysis.

\subsubsection{Stakeholder Involvement and Sustainability}

While identifying each of the twelve factors that influence recycling in developing countries, the issue of stakeholder involvement and collaboration was mentioned repeatedly as a way to improve the various aspects of MSWM. Thus, it was recognized that stakeholder involvement is an overarching theme essential to each of the twelve factors, and therefore, it is analyzed in-depth separately. The case studies identified collaboration as a catalyst to heighten household awareness about recycling and waste (Wells, 1994 and Buenrostro and Bocco, 2003), improve waste handling and disposal operations including characterization and segregation (UNEP, 2001c; Buenrostro and Bocco, 2003), strengthen law enforcement (World Bank, 2003a), utilize scavengers as a legitimate agent of MSWM (UNEP, 2001d), recommend inclusive policy initiatives (UNEP, 2002; Buenrostro and Bocco, 2003), create integrated, sustainable MSWM plans (UNEP, 2001f), and reduce expenses through cost sharing of facilities and equipment between agencies (World Bank, 2001).

As a result of these reoccurring stakeholder issues addressed in the case studies, the collaboration web shown in Figure 3.5 was created. It can be thought of that accompanying each of the twelve factors are various institutions that represent and govern the issues related to each factor. In Figure 3.5, a solid line represents a relationship between institutions necessary for a given factor to exist, whereas a dashed line implies increased efficiency of a given factor upon interaction of institutions. 
Collaboration, in general, demands active participation by all parties working toward a common goal. In this case, the common goal would be striving for more sustainable MSWM through material recovery. Yet, the collaboration web in Figure 3.5 uses arrows to illustrate the direction of information flow (i.e., the giving and receiving parties of information).

For example, waste collection and segregation (number 4 in Figure 3.5) requires collaborative input from six other factors in order to simply operate, and two additional factors to function efficiently. In order to fulfill the goals of the waste collection and segregation factor, residents need to be educated on how to separate waste properly, laborers and equipment are needed for collection and processing of waste, the government needs to manage the finances associated with such operations, and MSWM administrators need to have a plan in place from which to gain direction of activities. Educating the MSWM personnel (laborers and managers) and understanding the characteristics of the waste stream will promote efficiency in all of the waste collection and segregation activities. Waste segregation and collection is a factor that receives many inputs from other factors.

In contrast, other factors have institutions that act as suppliers of information and direction with respect to MSWM. Government finances (number 2 in Figure 3.5) and government policy (number 1 in Figure 3.5) are two factors that predominantly provide input to other factors, and actually the only input for each of these factors is from one another. Government policy gives regulations from which the MSWM plan is derived. Government finances cover expenditures on technological and human resources, waste collection and segregation, as well as MSWM administration. Another example of two factors that feed off of one another is the relationship between MSWM administration and the MSWM plan. First, the plan itself is created by administrators, and then the administrators are required to continually update it and look to it for direction of their responsibilities. 


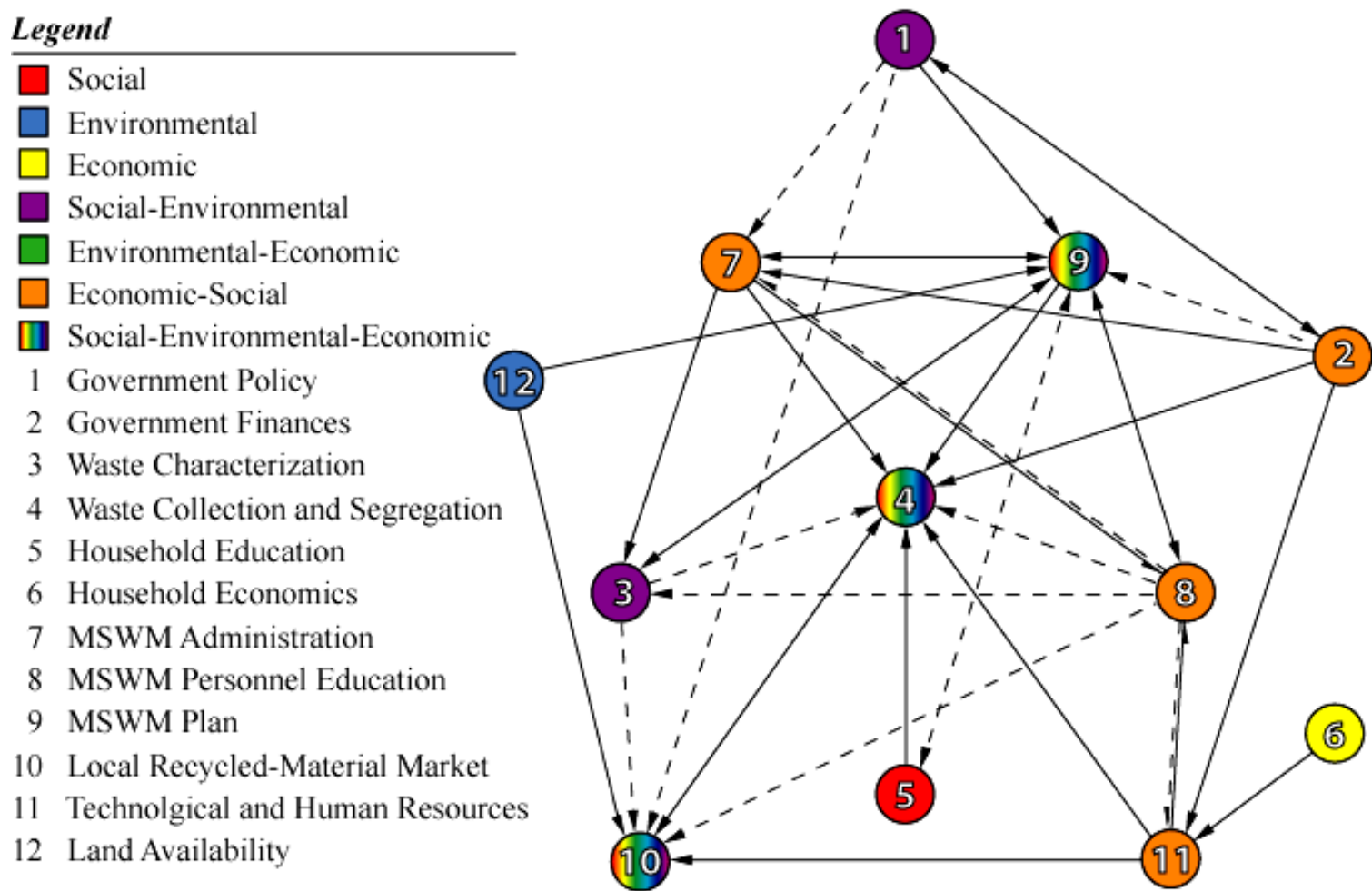

Figure 3.5: Collaboration web illustrating the necessary (solid line) and beneficial (dash line) relationships among the twelve factors influencing recycling in developing countries. Arrows show the direction of information flow between two MSWM institutions to define the stakeholder involvement required of each party. Node color identifies the sustainability dimensions governing q MSWM institutions' responsibilities.

Furthermore, Figure 3.5 not only addresses the collaborative nature required of sustainable MSWM, but also how each of the three sustainability dimensions (social, environmental, economic) govern the responsibilities of the institutions associated with the twelve factors influencing recycling in developing countries. Those factors with inputs from various institutions possess greater multidimensionality. For instance, three factors -waste collection and segregation, MSWM plan, and local recycled-material market- require the most collaboration, as illustrated by the large number of arrows pointing toward these three factor nodes in Figure 3.5, and also are the only three factors inclusive of all three sustainability dimensions. In contrast, factors demanding less stakeholder involvement in regards to MSWM exude only one or two sustainability dimensions, such as household education and waste characterization. Appendix F Detailed Explanation of Factor Relationships elaborates on Figure 3.5's development. 
"Today it is clearly recognized that pollution can seriously impede development processes because they are linked to human health and productivity."

- United Nations Environment Programme (UNEP, 2001b)

Figure 3.5 also offers great utility to any stakeholder involved in MSWM in developing countries. It serves to heighten awareness of the relationships involved in sustainable MSWM, as well as the degree to which these relationships affect the institutional activities associated with each factor. Through its use, the institutions associated with each of the twelve factors can achieve a better understanding of the necessary and beneficial collaborations for more sustainable MSWM. Perhaps, a next step would be to identify the institutions associated with each factor node and to detail the interactions among these institutions within the collaboration web that would support sustainable MSWM. Additionally, this collaboration web should be explored for its applicability to other branches of sustainable MSWM such as waste minimization, incineration with energy recovery, and composting. Translating this collaboration web into a useful tool for developed countries' MSWM should also be investigated. 


\section{CHAPTER FOUR}

\section{Conclusions}

This research studied recycling as one possible solution to the municipal solid waste management (MSWM) problem of the developing world while embracing the idea of sustainability, and successfully met four specific objectives.

While quantifying municipal solid waste (MSW) characteristics globally, it was evident that developed countries have higher generation and recovery rates than developing countries, and the composition of the waste in each socio-economic category vastly differs. MSW generation rates in developed countries typically range from 1.43 to 2.08 kilograms per person per day (kpd), whereas citizens of developing countries generate anywhere from 0.30 to $1.44 \mathrm{kpd}$. On average, a developing country's waste stream comprises twice the organic matter, half the portion of paper and cardboard, and similar fractions of glass and plastic of MSW composition in developed countries. The developed countries of the European Union recover nearly $18 \%$ of their waste, while the United States recovers roughly 30\%, and developing nations report material recovery rates of 0 to $41 \%$, depending on the presence and effectiveness of recycling activities.

A review of research on recycling exemplifies a distinction between recycling initiatives in the first world versus the third world. Recycling and MSWM research in developing countries use practical approaches to define societal, environmental, and economic issues causing MSW problems, assess site specific MSW characteristics, and analyze the operations directly associated to MSWM for efficiency and effectiveness. Conversely, developed countries have sophisticated recycling programs and mature MSW databases, and therefore, research diverges to topics such as psychological motivations to recycling, correlations of generation and recovery rates to socio-economic aspects like income and education, and prediction modeling of recycling behavior. 
During the identification of barriers and incentives to recycling in developing counties, repeating themes were noted which resulted in the creation of twelve key factors influencing sustainable MSWM. The presence of regulations, enforcement of laws, and use of incentive schemes constitutes the first factor, Government Policy. Cost of MSWM operations, the budget allocated to MSWM by local to national governments, as well as the stability and reliability of funds comprise the Government Finances factor influencing recycling in the third world.

Many case studies indicated that understanding features of a waste stream such as the generation and recovery rates and composition is the first measure in determining proper management solutions, which forms the third factor Waste Characterization. The presence and efficiency of waste collection and segregation by scavengers, municipalities, or private contractors was commonly addressed by the case studies, which justified Waste Collection and Segregation as the fourth factor.

Having knowledge of MSWM and an understanding of the linkages between human behavior, waste handling, and health/sanitation/environment comprise the Household Education factor. Individuals' income influencing waste handling behavior (e.g., reuse, recycling, and illegal dumping), presence of waste collection/disposal fees, and willingness to pay by residents were seen as one of the biggest incentives to recycling, which justified them being combined into the Household Economics factor.

The MSWM Administration factor was formed following several references to the presence and effectiveness of private and/or public management of waste through collection, recovery, and disposal influencing recycling activity. Although the MSWM Personnel Education factor was only recognized by six of the twenty-two case studies, the lack of trained laborers and skilled professionals in MSWM positions was a barrier to sustainable MSWM in every case but one. The presence and effectiveness of a comprehensive, integrative, long-term MSWM strategy was highly encouraged by every case study that addressed the tenth factor, MSWM Plan. 
Although seemingly a subset of private MSWM administration, the existence and profitability of market systems relying on recycled-material throughput, involvement of small businesses, middlemen, and large industries/exporters is deserving of the factor Local Recycled-Material Market. Availability and effective use of technology and/or human workforce and the safety considerations of each were recurrent barriers and incentives to recycling to warrant the Technological and Human Resources factor. The Land Availability factor takes into consideration land attributes such as terrain, ownership, and development which can often times dictate MSWM.

In analyzing the summarized percentage of case studies where a factor acted as a barrier, it is perhaps not surprising that MSWM Personnel Education, Waste Collection and Segregation, and Government Finances are the three biggest barriers to recycling in developing countries. On the other hand, Household Economics is one of the smallest barriers, which indicates that socio-economic status is not the limiting factor to recycling in developing nations. In other words, a majority of the world's population can participate in this form of sustainable MSWM. Interestingly, Land Availability was evidenced as an incentive in every case that addressed this as a factor influencing recycling. Sixty-percent of the country case studies revealed a relationship between having a majority of factors acting as incentives and having substantial recycling activity.

Finding relationships among the twelve factors influencing recycling in developing countries, made apparent the collaborative nature required of sustainable MSWM. Two types of relationships were identified, those that are necessary for a given factor to exist and those that upon interaction increase efficiency. Factors requiring the greatest collaborative inputs include waste collection and segregation, MSWM plan, and local recycled-material market. Aligning each factor to the social, environmental, and economic dimensions of sustainability revealed the motives behind the institutions contributing to each factor. A correlation between stakeholder involvement and sustainability existed, as supported by the fact that the only three factors driven by all three dimensions of sustainability were the same three that required the greatest collaboration with other factors. 
"Recycling is not a formula that the developed world has recently discovered and can teach the developing world. It is an economic activity that has existed in many developing countries for decades, but in a form often unrecognizable to those concerned citizens accustomed to separating their bottles and newspapers at home."

-Christopher Wells, Executive Director of CEMPRE

The results of this research are intended to build upon the knowledge of recycling in developing countries and to assist in the transition toward more sustainable MSWM. Specifically, a useful tool, the collaboration web shown in Figure 3.5 of Chapter Three, has been created for MSWM stakeholders in developing countries to gain understanding of the factors influencing recycling. With increasing urbanization, advocating for improved health for all through the Millennium Development Goals, and changing consumption patterns resulting in increasing and more complex waste streams, the utilization of the collaboration web offered by this research is ever needed in the developing world. Through its use, the institutions associated with each of the twelve factors can achieve a better understanding of the collaboration necessary and beneficial for more sustainable MSWM. 


\section{RECOMMENDATIONS FOR FUTURE WORK}

In reaching the above stated conclusions, several research topics were exposed that either elaborate on particular aspects or deviate from the core objectives of this research.

1. Assess six different MSWM guides. Of the eight international non-government organizations and the one international professional association reviewed for MSWM initiatives and positions, six had a MSWM guide of some sort. It is suggested that these guides are first compared for variations and consistencies and analyzed for the integration of sustainability, and then a single comprehensive guide is proposed for use by all of the organizations. Streamlining the available tools will simplify the daunting task of creating a MSWM plan in developing countries.

2. Develop a MSW database. Presently, the United States of America and the European Union each track their own MSW generation and recovery rates, as well as the composition of their waste streams, and the member states of the Organization for Economic Cooperation and Development (OECD) maintain records of MSW generation rates and paper and glass recovery rates. However, similar recordkeeping has not been initiated for developing countries' MSW characterization data. It is suggested that a web database (such as UNEP's GEO Data Portal or World Research Institute's EarthTrends) accepts submissions of MSW characteristics from any nation in order to gain a better understanding of the MSW issues at the global scale. However, this recommendation is contingent upon consistency of characterization methods, which provides for the next suggestion for future work.

\section{Reach consensus on MSWM terminology and MSW characterization} methodology. Several case studies noted the difficulties encountered when attempting to characterize MSW without a well-accepted method (Fehr, 2000; Buenrostro and Bocco, 2003). There is a need for a common definition of MSW, accepted waste categories, distinction between collection rate and generation rate, 
and resolution of various other MSW assessment intricacies. This problem was evidenced by both investigations on developed and developing country waste characterization. A few solutions have been proposed through the ISWA position papers on the definitions of recycling, recovery, and disposal and the prevention and recycling of waste (ISWA 2005), and Buenrostro's detailed classification system for MSW in Mexico (2001).

4. Utilize a more indicative classification of recycling. Specific to this research, a very simple, bimodal classification of a nation's recycling activity was utilized (yes or no). Whether a country, like Brazil, is recycling $41 \%$ of its waste, or a qualitative comment was made about organized recycling, like Mongolia's Women Federation blue bag campaign, both were assigned to the category of yes for a presence of recycling. The $5 \%$ cut-off pertained only to case studies that provided quantitative data; otherwise, presence of recycling was determined subjectively. Greater confidence and possibly more descriptive results would be presented with four categories with one for no recycling, and then three categories for recycling which account for the varying degrees of recycling.

5. Quantitatively analyze factors influencing recycling. With more developed MSW databases, the twelve factors influencing recycling could be analyzed individually to understand their complexities. Also, a site-specific study utilizing the collaboration web is suggested to test the hypothesized relationships and recognize any adjustments to make in order to improve the utility of the web.

6. Quantitatively correlate direct and indirect MSWM attributes to recycling activity. Again, with more developed MSW databases, it would be interesting to find correlations between material recovery rates in developing countries and direct and indirect MSWM variables. Examples of direct variables would include collection efficiency, type of disposal (dumping, non-scientific landfill, burning, sanitary landfill, incineration with and without recovery), and the amount of funding put toward MSWM. Examples of indirect attributes might include import and export activity, Agenda 21 reporting status, and gender empowerment indices. 


\section{REFERENCES}

Abduli, M.A. (1995) "Solid Waste Management in Tehran," Waste Management and Research, Academic Press, London, vol. 13, issue 6, pp. 519-531.

Barlishen, K.D and Baetz, B.W. (1995) "Development of a decision support system for the planning of municipal solid waste composting and recycling programs," Canadian Journal of Civil Engineering, National Research Council Canada, vol. 22, pp. 637-645.

Bernache-Pérez, G., Sánchez-Colón, S., Garmendia, A.M., Dávila-Villarreal, A., Sánchez-Salazar, M.E. (2001) "Solid waste characterization study in the Guadalajara Metropolitan Zone, Mexico," Waste Management and Research, Academic Press, London, vol. 19, pp. 413-424.

Blight, G.E. and Mbande, C.M. (1996) "Some Problems of Waste Management in Developing Countries," Journal of Solid Waste Technology and Management, Widener University School of Engineering and the National Center for Resource Management and Technology at the University of Pennsylvania, vol. 23, no. 1, pp. 19-27.

Bolaane, B. and Ali, M. (2004) "Sampling household waste at source: lessons learnt in Gaborone," Waste Management and Research, Academic Press, London, vol. 22, pp. 142-148.

Buenrostro, O. and Bocco, G. (2003) "Solid waste management in municipalities in Mexico: goals and perspectives," Resources, Conservation and Recycling, Elsevier Science Publishers, vol. 39, issue 3, pp. 251-263.

Buenrostro, O., Bocco, G., Cram, S. (2001) "Classification of sources of municipal solid wastes in developing countries," Resources, Conservation and Recycling, Elsevier Science Publishers, New York, vol. 32, issue 1, pp. 29-41.

Chan, K. (1998) "Mass communication and pro-environmental behaviour: waste recycling in Hong Kong," Journal of Environmental Management, Academic Press, vol. 52, pp. 317-325.

CIA (2004) Appendix B - International Organizations and Groups, The World Factbook, United States Central Intelligence Agency, Retrieved 20 June 2004, http://www.odci.gov/cia/publications/factbook/appendix/appendix-b.html. 
CIA (2005) The World Factbook, United States Central Intelligence Agency, Retrieved 15 May 2005, http://www.cia.gov/cia/publications/factbook/.

Corral-Verdugo, V. (1997) 'Dual 'Realities' of Conservation Behavior: Self-Reports vs Observations of Re-use and Recycling Behavior," Journal of Environmental Psychology, Academic Press, vol. 17, pp. 135-145.

Daskalopoulos, E., Badr, O., Probert, S.D. (1998) "Municipal solid waste: a prediction methodology for the generation rate and composition in the European Union countries and the United States of America," Resources, Conservation and Recycling, Elsevier Science Publishers, London, vol. 24, issue 2, pp. 155-166.

Diaz, L.F. (1998) "Institutional, Economic, and Human Resource Issues Associated with Solid Waste Services in Latin America," Proceedings from ANACON '98: the AsiaNorth American Waste Management Conference, Los Angeles, California, USA, 6 pp.

Domina, T. and Koch, K. (2002) "Convenience and Frequency of Recycling and Waste, Implication for Including Textiles in Curbside Recycling Programs," Environment and Behavior, Sage Publications, vol. 34, no. 2, pp. 216-238.

Ebreo, A. and Vining, J. (2004) "How Similar are Recycling and Waste Reduction? Future Orientation and Reasons for Reducing Waste as Predictors of Self-Reported Behavior," Environment and Behavior, Sage Publications, vol. 33, no. 3, pp. 424-448.

Europa (2005) Waste Management Planning, European Commission, Europa, Retrieved 1 July 2005, http://europa.eu.int/comm/environment/waste/plans/index.htm.

Eurostat (2003) Waste Generated and Treated in Europe: 1998-2001, Theme 8 Environment and Energy, European Commission, ISBN: 92-894-6355-4, Cat. No. KS55-03-471-EN-N, Office for Official Publication of the European Communities, Luxembourg.

Fehr, M., de Castro, M.S.M.V., Calcado, M.d.R. (2000) "A practical solution to the problem of household waste management in Brazil," Resources, Conservation and Recycling, Elsevier Science Publishers, London, vol. 30, issue 3, pp. 245-257.

Guerin, D., Crete, J., Mercier, J. (2001) “A Multilevel Analysis of the Determinants of Recycling Behavior in the European Countries," Social Science Research, Academic Press, London, vol. 30, pp. 195-218.

Hanyu, K., Kishino, H., Yamashita, M., Hayashi, C. (2000) "Linkage between recycling and consumption: a case of toilet paper in Japan," Resources, Conservation and Recycling, Elsevier Science Publishers, London, vol. 30, issue 3, pp. 177-199. 
Hartig, T., Kaiser, F.G., Bowler, P.A. (2001) "Psychological Restoration in Nature as a Positive Motivation for Ecological Behavior," Environment and Behavior, Sage Publications, vol. 33, no. 4, pp. 590-607.

Harvie, M. and Jaques, P. (2003) "Public awareness and the environment: 'How do we encourage environmentally responsible behaviour?'," Water Science and Technology: Water Supply, IWA Publishing, vol. 3, no. 3, pp. 247-254.

Hockett, D., Lober, D.J., Pilgrim, K. (1995) “Determinants of Per Capita Municipal Solid Waste Generation in the Southeastern United States," Journal of Environmental Management, Academic Press, vol. 45, pp. 205-217.

Hornik, J., Cherian, J., Madansky, M., Narayana, C. (1995) "Determinants of Recycling Behavior: A Synthesis of Research Results," The Journal of Socio-Economics, JAI Press Inc., vol. 24, no. 1, pp. 105-127.

ISWA (2005) International Solid Waste Association, Retrieved 1 July 2005, http://www.iswa.org/.

Johnson, C.Y., Bowker, J.M., Cordell, H.K. (2004) "Ethnic Variation in Environmental Belief and Behavior: An Examination of the New Ecological Paradigm in a Social

Psychological Context," Environment and Behavior, Sage Publications, vol. 36, no. 2, pp. 157-186.

Kathirvale, S., Yunus, M.N.M., Sopian, K., Samduddin, A.H., (2003) "Energy potential from municipal solid waste in Malaysia," Renewable Energy, Elsevier Ltd., London, vol. 29, issue 4, pp. 559-567.

Kelly, T.C., Mason, I.G., Leiss, M.W., Ganesh, S. (in press 2005) "University community responses to on-campus resource recycling," Resources, Conservation and Recycling, Elsevier Science Publishers, London.

Kishino, H., Hanyu, K., Yamashita, M., Hayashi, C. (1999) "Recycling and consumption in Germany and Japan: a case of toilet paper," Resources, Conservation and Recycling, Elsevier Science Publishers, London, vol. 26, issue 3, pp. 189-215.

Kobus, D. (2003) Practical Guidebook on Strategic Planning in Municipal Waste Management, A Knowledge Product of Cities of Change, The World Bank Group and Bertelsmann Stiftung. 
Li, S. (2003) "Recycling Behavior under China's Social and Economic Transition, The Case of Metropolitan Wuhan," Environment and Behavior, Sage Publications, vol. 35, no. 6 , pp. $784-801$.

McCarthy, J.E. (1993) "Recycling and reducing packaging waste: How the United States compares to other countries," Resources, Conservation and Recycling, Elsevier Science Publishers, London, vol. 8, issue 3/4, pp. 293-360.

McCarty, J.A. and Shrum, L.J. (1994) "The Recycling of Solid Wastes: Personal Values, Value Orientation, and Attitudes about Recycling as Antecedents of Recycling Behavior," Journal of Business Research, Elsevier Science Ind., New York, vol. 30, pp. 53-62.

Medina, M. (1997) "The Effect of Income on Municipal Solid Waste Generation Rates for Countries of Varying Levels of Economic Development: A Model," Journal of Solid Waste Technology and Management, Widener University School of Engineering and the National Center for Resource Management and Technology at the University of Pennsylvania, vol. 24, no. 3, pp. 149-155.

Medina, M. (2004) "Scavenger Cooperatives in Asia and Latin America," Global Development Network, Retrieved 12 October 2004, http://www.gdnet.org/pdf/medina.pdf.

Metin, E., Eröztürk, A., Neyim, C. (2003) "Solid waste management practices and review of recovery and recycling operations in Turkey," Waste Management, Elsevier Ltd., location, pp. 425-432.

Mihelcic, J.R., Crittenden, J.C., Small, M.J., Shonnard, D.R., Hokanson, D.R., Zhang, Q., Chen, H., Sorby, S.A., James, V.U., Sutherland, J.W., Schnoor, J.L. (2003)

"Sustainability Science and Engineering: The Emergence of a New Metadiscipline," Environmental Science and Technology, American Chemical Society, vol. 37, no. 23, pp. 5314-5324.

Mohee, R. (2002) "Assessing the recovery potential of solid waste in Mauritius," Resources, Conservation and Recycling, Elsevier Science Publishers, vol. 36, issue 1, pp. 33-43.

Mwanthi, M.A., Nyabola, L.O., Tenambergen, E.D. (1997) "The present and future status of municipal solid management in Nairobi," International Journal of Environmental Health Research, Taylor \& Francis, vol. 7, no. 4, pp. 345-354. 
Noehammer, H.C. and Byer, P.H. (1997) "Effect of Design Variables on Participation in Residential Curbside Recycling Programs," Waste Management and Research, Academic Press, London, vol. 15, pp. 407-427.

Nuwayhid, R.Y., Ayoub, G.M., Saba, E.F., Abi-Said, S. (1996) "The Solid Waste Management Scene in Greater Beirut," Waste Management and Research, Academic Press, London, vol. 14, issue 2, pp. 171-187.

Oliveira, L.B. and Rosa, L.P. (2003) "Brazilian waste potential: energy, environmental, social and economic benefits," Energy Policy, Elsevier Science Publishers, vol. 31, pp. 1481-1491.

Owens, J., Dickerson, S., MacIntosh, D.L. (2000) "Demographic Covariates of Residential Recycling Efficiency,” Environment and Behavior, Sage Publications, vol. 32 , no. 5, pp. 637-650.

Pendley, P.S. (2005) "Feasibility and Action Plan for Composting Operation Incorporating Appropriate Technology at Riverton Disposal Site, Kingston, Jamaica," Masters of Science in Environmental Engineering Report, Michigan Technological University.

Prüss, A., E. Giroult, and P. Rushbrook. (1999) Safe Management of Waste from Health Care Activities, ISBN: 924154525 9, Order no. 1150453, World Health Organization.

Schübeler (1996) Conceptual Framework for Municipal Solid Waste Management In Low-Income Countries, Urban Management and Infrastructure, UNDP/UNCHS (Habitat)/World Bank/SDC Collaborative Programme On Municipal Solid Waste Management in Low-Income Countries, Working Paper No. 9, St. Gallen, Switzerland.

Shinkuma, T. (2003) "On the Second-Best Policy of Household's Waste Recycling," Environmental and Resource Economics, Kluwer Academic Publishers, Netherlands, vol. 24, issue 1, pp. 77-95.

Steel, B.S. (1996) "Thinking Globally and Acting Locally?: Environmental Attitudes, Behavior and Activism," Journal of Environmental Management, Academic Press, vol. 47, pp. 27-36.

Taylor, D.C. (2000) "Policy incentives to minimize generation of municipal solid waste," Waste Management and Research, Academic Press, London, vol. 18, issue 5, pp. 406419. 
Thapa, B. (1999) "Environmentalism: The Relation of Environmental Attitudes and Environmentally Responsible Behaviors Among Undergraduate Students," Bulletin of Science, Technology \& Society, Sage Publications, vol. 19, no. 5, pp. 426-438.

UNDESA (2005) Agenda 21 - Chapter 21 Environmentally Sound Management of Solid Wastes and Sewage-related Issues, Division for Sustainable Development, United Nations Department of Economic and Social Affairs, Retrieved 1 July 2005, http://www.un.org/esa/sustdev/documents/agenda21/index.htm.

UNEP (2001a) "Solid and Hazardous Waste," Bangkok: State of the Environment 2001, United Nations Environment Programme, Chapter 4 pp. 35-44.

UNEP (2001b) Bhutan: State of the Environment 2001, United Nations Environment Programme, Chapter 12 pp. 91-97.

UNEP (2001c) India: State of the Environment 2001, United Nations Environment Programme, Chapter 12 pp.133-149.

UNEP (2001d) Lao PDR: State of the Environment 2001, United Nations Environment Programme, Chapter 5 pp. 60-66.

UNEP (2001e) "Solid Waste Management," Nepal: State of the Environment 2001, United Nations Environment Programme, Chapter 3.3 pp. 97-118, 2001.

UNEP (2001f) "Waste Disposal," Sri Lanka: State of the Environment 2001, United Nations Environment Programme, Chapter 3.2 pp. 42-52.

UNEP (2001g) “Solid Waste State and Impact," State of the Environment Vietnam, United Nations Environment Programme, Retrieved 10 January 2005, http://www.rrcap.unep.org/reports/soe/vietnam/issues/state_and_impact/solid_waste_stat e_and_impact.htm.

UNEP (2002) "Key environmental issues: management of solid waste and sewage," Maldives: State of the Environment 2002, United Nations Environment Programme, Chapter 3.3 pp. 41-44.

UNEP (2005a) Global Environment Outlook (GEO) 3 Data Portal, United Nations Environment Programme, Retrieved 1 July 2005, http://geodata.grid.unep.ch/.

UNEP (2005b) "Wastes," State of the Environment Turkmenistan, United Nations Environment Programme, Retrieved 04 February 2005, http:/enrin.grida.no/htmls/turkmen/soe/htmeng/waste.htm. 
UNEP and ISWA (2004) Waste Management Planning, An Environmentally Sound Approach for Sustainable Urban Waste Management: An Introductory Guide for Decision-makers, Integrative Management Series No. 6, International Environmental Technology Center, United Nations Environment Programme's Division of Technology, Industry, and Economics.

UNEP-IETC (2005) Sustainable Production and Consumption, International Environmental Technology Centre, United Nations Environment Programme, Retrieved 1 July 2005, http://www.unep.or.jp/ietc/spc/index.asp.

UNDESA (2004) World Urbanization Prospects: The 2003 Revision, Sales No. E.04.XIII.6, UNDESA Population Division, New York.

UN-HABITAT (2005a) Sustainable Urbanization through Community Involvement - 3 Case Studies From the Colombo Core-Area, Sri Lanka, Fukuoka Office (Regional Office for Asia and the Pacific), United Nations Human Settlements Programme, Retrieved 1 July 2005, http://www.fukuoka.unhabitat.org/out/siryo/project_b/12/srl.casestudies2002e.html.

UN-HABITAT (2005b) Waste, Priorities, UN-HABITAT in Afghanistan, United Nations Human Settlements Programme, Retrieved 1 July 2005, http://www.unhabitat.org/afghanistan/priorities.asp\#waste.

UNMDG (2005) United Nations Millennium Development Goals, Retrieved 15 March 2005, http://www.un.org/millenniumgoals/.

USEPA (2003) Municipal Solid Waste Generation, Recycling, and Disposal in the United States: Facts and Figures for 2003, United States Environmental Protection Agency, Washington, D.C.

Wang, H. and Nie, Y. (2001) "Municipal Solid Waste Characteristics and Management in China," Journal of Air and Waste Management Association, Air and Waste Management Association, vol. 51, pp. 250-263.

Wells, C. (1994) “The Brazilian Recycling Commitment: helping stimulate recycling in a developing country," Industry and Environment, United Nations Environment Program, Paris, France, vol. 17, issue 2, pp. 14-17.

Werner, C.M. and Makela, E. (1998) "Motivations and Behaviors that Support Recycling," Journal of Environmental Psychology, Academic Press, vol. 18, pp. 373-386. 
WHO (2005a) Pamphlets - Waste, Regional Office of Europe, World Health Organization, Retrieved 1 July 2005, http://www.euro.who.int/eprise/main/who/progs/hoh/publications/20020430_1.

WHO (2005b) Needle-removing and recycling of the plastic from auto-disable (AD) syringes, Waste Management - WHO Policy and Activities, Immunization Safety, World Health Organization, Retrieved 1 July 2005, http://www.who.int/immunization_safety/waste_management/update/en/index3.html.

WHO (2005c) Information Management for Municipal Solid Waste Management Services, Environmental Health Centre (EHC), Western Pacific Regional Office, World Health Organization, January 1993.

World Bank (2001) Philippines Environment Monitor 2001, World Bank - Country Office Manila, Pasig City, Philippines, 29 pp.

World Bank (2003a) Indonesia Environment Monitor 2003, World Bank Indonesia Office, Jakarta, Indonesia, pp. 33-41.

World Bank (2003b) "Waste Reduction, Reuse, and Recycling," Thailand Environment Monitor 2003, The World Bank Group, Washington, D.C., pp. 13-18.

World Bank (2004) Mongolia Environment Monitor 2004, World Bank Mongolia Office, Ulaanbaatar, Mongolia, 41 pp.

World Bank (2005) Urban Development, Urban Solid Waste Management, The World Bank Group, Retrieved 1 July 2005, http://web.worldbank.org/WBSITE/EXTERNAL/ TOPICS/EXTURBANDEVELOPMENT/EXTUSWM/0,,menuPK:463847 pagePK:1490 18 piPK:149093 theSitePK:463841,00.html.

WRI (2005) "EarthTrends: The Environmental Information Portal," World Resources Institute, Retrieved 15 May 2005, http://earthtrends.wri.org/.

Závodská, A. (2003) "A Study on Residential Solid Waste Composition and Management in a Selected Developing Country - Guyana," Journal of Solid Waste Technology and Management, vol. 29, no. 1, pp. 1-7.

Závodská, A. and Knight, J. (2002) "A Practical Approach to Future Municipal Solid Waste Management in Developing Countries - A Closer Look at Georgetown, Guyana," AIAEE Proceedings of the $18^{\text {th }}$ Annual Conference, Durban, South Africa, pp. 485-492. 


\section{APPENDIX A}

\section{Country Classification}

All of the definitions below are provided, courtesy of:

CIA (2004) Appendix B - International Organizations and Groups, The World Factbook, United States Central Intelligence Agency, Retrieved 20 June 2004, http://www.odci.gov/cia/publications/factbook/appendix/appendix-b.html.

\section{Advanced Economies}

A term used by the International Monetary FUND (IMF) for the top group in its hierarchy of advanced economies, countries in transition, and developing countries; it includes the following 28 advanced economies: Australia, Austria, Belgium, Canada, Denmark, Finland, France, Germany, Greece, Hong Kong, Iceland, Ireland, Israel, Italy, Japan, South Korea, Luxembourg, Netherlands, NZ, Norway, Portugal, Singapore, Spain, Sweden, Switzerland, Taiwan, UK, US; note - this group would presumably also cover the following seven smaller countries of Andorra, Bermuda, Faroe Islands, Holy See, Liechtenstein, Monaco, and San Marino which are included in the more comprehensive group of "developed countries"

\section{Countries in Transition}

A term used by the International Monetary Fund (IMF) for the middle group in its hierarchy of advanced economies, countries in transition, and developing countries; recently published IMF statistics include the following 28 countries in transition: Albania, Armenia, Azerbaijan, Belarus, Bosnia and Herzegovina, Bulgaria, Croatia, Czech Republic, Estonia, Georgia, Hungary, Kazakhstan, Kyrgyzstan, Latvia, Lithuania, The Former Yugoslav Republic of Macedonia, Moldova, Mongolia, Poland, Romania, Russia, Serbia and Montenegro, Slovakia, Slovenia, Tajikistan, Turkmenistan, Ukraine, Uzbekistan; note - this group is identical to the group traditionally referred to as the "former USSR/Eastern Europe" except for the addition of Mongolia. 


\section{Developing Countries}

A term used by the International Monetary Fund (IMF) for the bottom group in its hierarchy of advanced economies, countries in transition, and developing countries; recently published IMF statistics include the following 126 developing countries: Afghanistan, Algeria, Angola, Antigua and Barbuda, Argentina, Aruba, The Bahamas, Bahrain, Bangladesh, Barbados, Belize, Benin, Bhutan, Bolivia, Botswana, Brazil, Burkina Faso, Burma, Burundi, Cambodia, Cameroon, Cape Verde, Central African Republic, Chad, Chile, China, Colombia, Comoros, Democratic Republic of the Congo, Republic of the Congo, Costa Rica, Cote d'Ivoire, Cyprus, Djibouti, Dominica, Dominican Republic, Ecuador, Egypt, El Salvador, Equatorial Guinea, Ethiopia, Fiji, Gabon, The Gambia, Ghana, Grenada, Guatemala, Guinea, Guinea-Bissau, Guyana, Haiti, Honduras, India, Indonesia, Iran, Iraq, Jamaica, Jordan, Kenya, Kiribati, Kuwait, Laos, Lebanon, Lesotho, Liberia, Libya, Madagascar, Malawi, Malaysia, Maldives, Mali, Malta, Marshall Islands, Mauritania, Mauritius, Mexico, Federated States of Micronesia, Morocco, Mozambique, Namibia, Nepal, Netherlands Antilles, Nicaragua, Niger, Nigeria, Oman, Pakistan, Panama, Papua New Guinea, Paraguay, Peru, Philippines, Qatar, Rwanda, Saint Kitts and Nevis, Saint Lucia, Saint Vincent and the Grenadines, Samoa, Sao Tome and Principe, Saudi Arabia, Senegal, Seychelles, Sierra Leone, Solomon Islands, Somalia, South Africa, Sri Lanka, Sudan, Suriname, Swaziland, Syria, Tanzania, Thailand, Togo, Trinidad and Tobago, Tunisia, Turkey, UAE, Uganda, Uruguay, Vanuatu, Venezuela, Vietnam, Yemen, Zambia, Zimbabwe; note - this category would presumably also cover the following 46 other countries that are traditionally included in the more comprehensive group of "less developed countries": American Samoa, Anguilla, British Virgin Islands, Brunei, Cayman Islands, Christmas Island, Cocos Islands, Cook Islands, Cuba, Eritrea, Falkland Islands, French Guiana, French Polynesia, Gaza Strip, Gibraltar, Greenland, Grenada, Guadeloupe, Guam, Guernsey, Jersey, North Korea, Macau, Isle of Man, Martinique, Mayotte, Montserrat, Nauru, New Caledonia, Niue, Norfolk Island, Northern Mariana Islands, Palau, Pitcairn Islands, Puerto Rico, Reunion, Saint Helena, Saint Pierre and Miquelon, Tokelau, Tonga, Turks and Caicos Islands, Tuvalu, Virgin Islands, Wallis and Futuna, West Bank, Western Sahara least developed countries (LLDCs) that subgroup of the less developed countries 
(LDCs) initially identified by the UN General Assembly in 1971 as having no significant economic growth, per capita GDPs normally less than $\$ 1,000$, and low literacy rates; also known as the undeveloped countries; the 42 LLDCs are: Afghanistan, Bangladesh, Benin, Bhutan, Botswana, Burkina Faso, Burma, Burundi, Cape Verde, Central African Republic, Chad, Comoros, Djibouti, Equatorial Guinea, Eritrea, Ethiopia, The Gambia, Guinea, Guinea-Bissau, Haiti, Kiribati, Laos, Lesotho, Malawi, Maldives, Mali, Mauritania, Mozambique, Nepal, Niger, Rwanda, Samoa, Sao Tome and Principe, Sierra Leone, Somalia, Sudan, Tanzania, Togo, Tuvalu, Uganda, Vanuatu, Yemen

\section{Developed Countries (DCs)}

The top group in the hierarchy of developed countries (DCs), former USSR/Eastern Europe (former USSR/EE), and less developed countries (LDCs); includes the marketoriented economies of the mainly democratic nations in the Organization for Economic Cooperation and Development (OECD), Bermuda, Israel, South Africa, and the European ministates; also known as the First World, high-income countries, the North, industrial countries; generally have a per capita GDP in excess of $\$ 10,000$ although four OECD countries and South Africa have figures well under $\$ 10,000$ and two of the excluded OPEC countries have figures of more than $\$ 10,000$; the 34 DCs are: Andorra, Australia, Austria, Belgium, Bermuda, Canada, Denmark, Faroe Islands, Finland, France, Germany, Greece, Holy See, Iceland, Ireland, Israel, Italy, Japan, Liechtenstein, Luxembourg, Malta, Monaco, Netherlands, NZ, Norway, Portugal, San Marino, South Africa, Spain, Sweden, Switzerland, Turkey, UK, US; note - similar to the new International Monetary Fund (IMF) term "advanced economies" which adds Hong Kong, South Korea, Singapore, and Taiwan but drops Malta, Mexico, South Africa, and Turkey.

\section{Less Developed Countries (LDCs)}

The bottom group in the hierarchy of developed countries (DCs), former USSR/Eastern Europe (former USSR/EE), and less developed countries (LDCs); mainly countries and dependent areas with low levels of output, living standards, and technology; per capita GDPs are generally below $\$ 5,000$ and often less than $\$ 1,500$; however, the group also includes a number of countries with high per capita incomes, areas of advanced technology, and rapid rates of growth; includes the advanced developing countries, 
developing countries, Four Dragons (Four Tigers), least developed countries (LLDCs), low-income countries, middle-income countries, newly industrializing economies (NIEs), the South, Third World, underdeveloped countries, undeveloped countries; the 172 LDCs are: Afghanistan, Algeria, American Samoa, Angola, Anguilla, Antigua and Barbuda, Argentina, Aruba, The Bahamas, Bahrain, Bangladesh, Barbados, Belize, Benin, Bhutan, Bolivia, Botswana, Brazil, British Virgin Islands, Brunei, Burkina Faso, Burma, Burundi, Cambodia, Cameroon, Cape Verde, Cayman Islands, Central African Republic, Chad, Chile, China, Christmas Island, Cocos Islands, Colombia, Comoros, Democratic Republic of the Congo, Republic of the Congo, Cook Islands, Costa Rica, Cote d'Ivoire, Cuba, Cyprus, Djibouti, Dominica, Dominican Republic, Ecuador, Egypt, El Salvador, Equatorial Guinea, Eritrea, Ethiopia, Falkland Islands, Fiji, French Guiana, French Polynesia, Gabon, The Gambia, Gaza Strip, Ghana, Gibraltar, Greenland, Grenada, Guadeloupe, Guam, Guatemala, Guernsey, Guinea, Guinea-Bissau, Guyana, Haiti, Honduras, Hong Kong, India, Indonesia, Iran, Iraq, Jamaica, Jersey, Jordan, Kenya, Kiribati, North Korea, South Korea, Kuwait, Laos, Lebanon, Lesotho, Liberia, Libya, Macau, Madagascar, Malawi, Malaysia, Maldives, Mali, Isle of Man, Marshall Islands, Martinique, Mauritania, Mauritius, Mayotte, Federated States of Micronesia, Mongolia, Montserrat, Morocco, Mozambique, Namibia, Nauru, Nepal, Netherlands Antilles, New Caledonia, Nicaragua, Niger, Nigeria, Niue, Norfolk Island, Northern Mariana Islands, Oman, Palau, Pakistan, Panama, Papua New Guinea, Paraguay, Peru, Philippines, Pitcairn Islands, Puerto Rico, Qatar, Reunion, Rwanda, Saint Helena, Saint Kitts and Nevis, Saint Lucia, Saint Pierre and Miquelon, Saint Vincent and the Grenadines, Samoa, Sao Tome and Principe, Saudi Arabia, Senegal, Seychelles, Sierra Leone, Singapore, Solomon Islands, Somalia, Sri Lanka, Sudan, Suriname, Swaziland, Syria, Taiwan, Tanzania, Thailand, Togo, Tokelau, Tonga, Trinidad and Tobago, Tunisia, Turks and Caicos Islands, Tuvalu, UAE, Uganda, Uruguay, Vanuatu, Venezuela, Vietnam, Virgin Islands, Wallis and Futuna, West Bank, Western Sahara, Yemen, Zambia, Zimbabwe; note - similar to the new International Monetary Fund (IMF) term "developing countries" which adds Malta, Mexico, South Africa, and Turkey but omits in its recently published statistics American Samoa, Anguilla, British Virgin Islands, Brunei, Cayman Islands, Christmas Island, Cocos Islands, Cook Islands, Cuba, Eritrea, Falkland Islands, French 
Guiana, French Polynesia, Gaza Strip, Gibraltar, Greenland, Grenada, Guadeloupe, Guam, Guernsey, Jersey, North Korea, Macau, Isle of Man, Martinique, Mayotte, Montserrat, Nauru, New Caledonia, Niue, Norfolk Island, Northern Mariana Islands, Palau, Pitcairn Islands, Puerto Rico, Reunion, Saint Helena, Saint Pierre and Miquelon, Tokelau, Tonga, Turks and Caicos Islands, Tuvalu, Virgin Islands, Wallis and Futuna, West Bank, Western Sahara

\section{Least Developed Countries (LLDCs)}

That subgroup of the less developed countries (LDCs) initially identified by the UN General Assembly in 1971 as having no significant economic growth, per capita GDPs normally less than $\$ 1,000$, and low literacy rates; also known as the undeveloped countries; the 42 LLDCs are: Afghanistan, Bangladesh, Benin, Bhutan, Botswana, Burkina Faso, Burma, Burundi, Cape Verde, Central African Republic, Chad, Comoros, Djibouti, Equatorial Guinea, Eritrea, Ethiopia, The Gambia, Guinea, Guinea-Bissau, Haiti, Kiribati, Laos, Lesotho, Malawi, Maldives, Mali, Mauritania, Mozambique, Nepal, Niger, Rwanda, Samoa, Sao Tome and Principe, Sierra Leone, Somalia, Sudan, Tanzania, Togo, Tuvalu, Uganda, Vanuatu, Yemen 


\section{APPENDIX B}

\section{SUPPLEMENTAL DEVELOPED COUNTRY RESEARCH}

\section{Additional Literature Review (not addressed in thesis body)}

Ebreo, et al. (1999) surveyed several communities to understand the public's opinions on solid waste issues. It is noted that respondents were more concerned with product toxicity than product packaging, age and gender were two predictors of respondents' survey answers, and self-reported recycling behavior was consistent with source reduction and recycling activities.

Otten and Salguero (1996) showcase the "environmental complex" which is one solution to minimizing municipal solid waste generation in Andalucía, Spain that consists of a degasification facility, a recycling and composting plant, and the landfill and educational center.

Chueng, et al. (1999) examined the constructs of the theory of planned behavior in the context of waste paper recycling behavior among college students in Hong Kong.

Guagnano (2001) places willingness-to-pay for recycled products in a market-like context where he concludes that behavior is altruistically-motivated despite common belief that self-interested behavior dominates.

Bratt (1999) utilizes Norwegian survey data to analyze whether recycling behavior causes unintended affects in other or related fields. It is evident from the survey results that recycling does not cause compensatory behavior, consumers do not possess "general" environmental behavior (as opposed to specific behavior), and higher correlations between behavior increases with similarity.

Bratt (1999) utilizes Norwegian survey data and structural equation models to better understand influences of environmental behavior and identify predictive factors of such behavior.

Oom do Valle (2004) proposes guidelines to promote recycling which are based upon motivating factors of recycling that several multivariate data analyses concluded. 


\section{Correlation between Generation and Recovery Rates for OECD?}

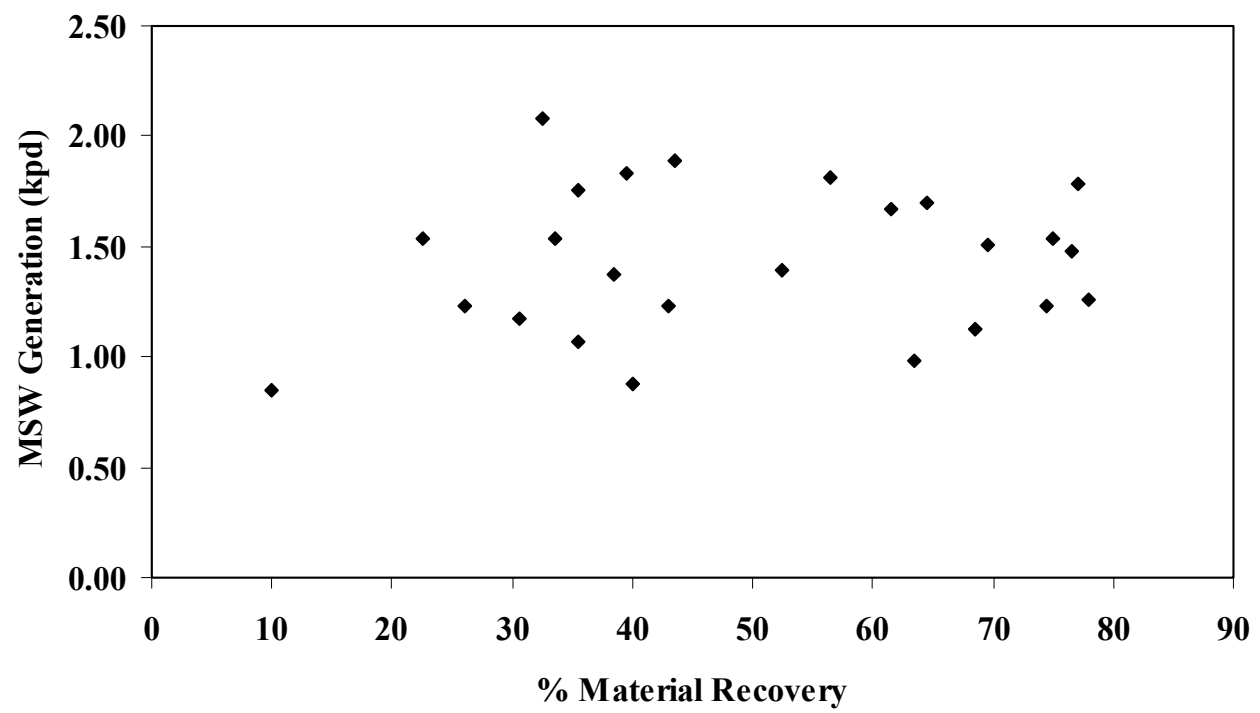

Figure B.1: Lack of correlation shown for MSW generation rate and recovery rate of combined paper and glass material recycling for 25 OECD member states.

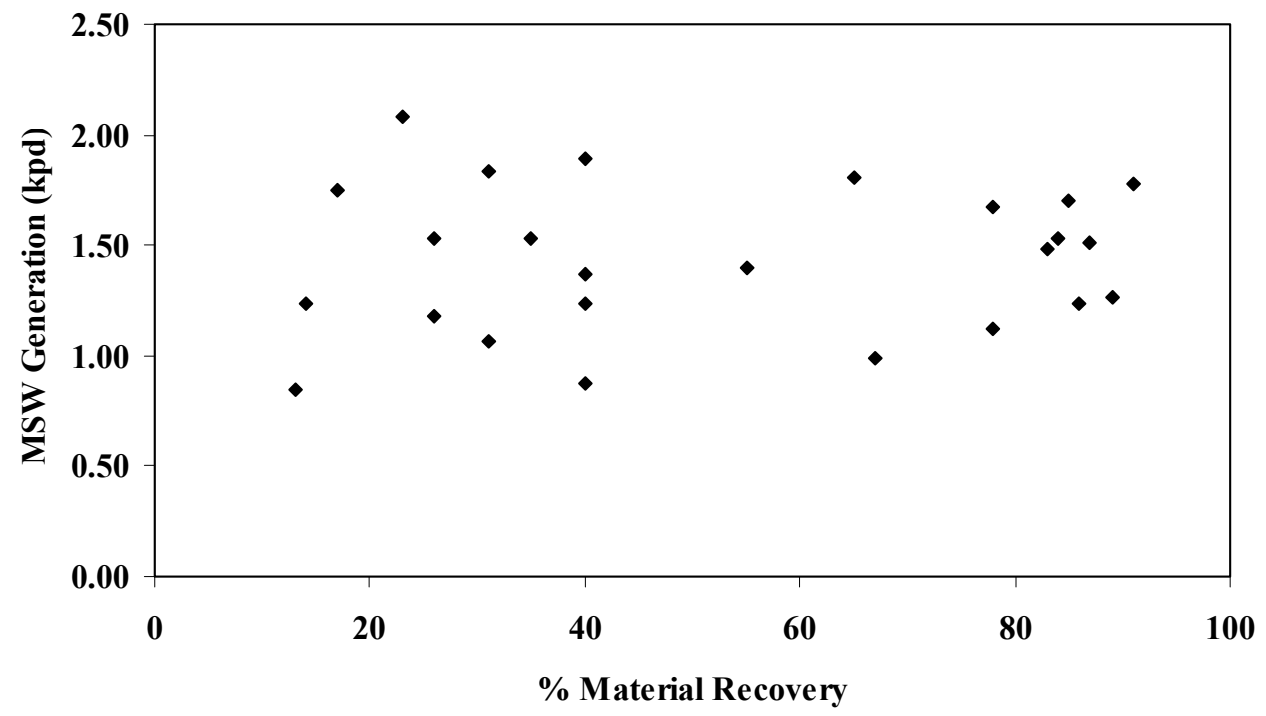

Figure B.2: Lack of correlation shown for MSW generation rate and recovery rate of glass material recycling for 25 OECD member states. 


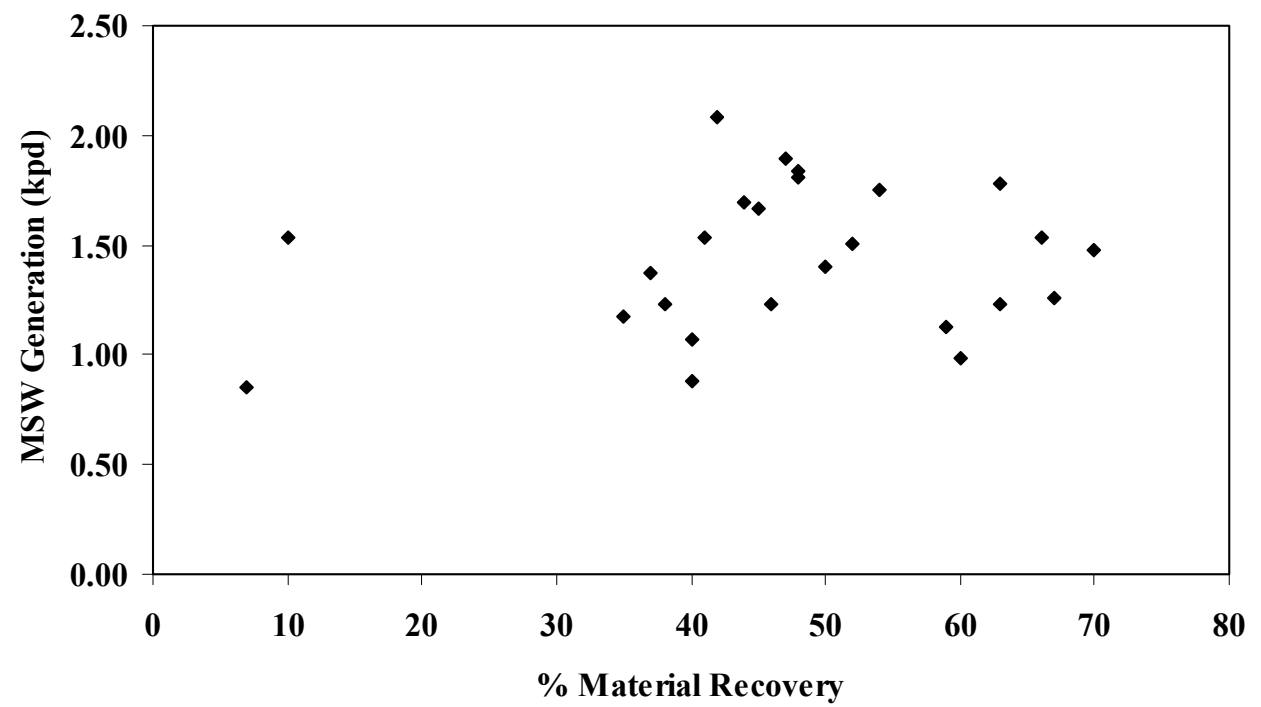

Figure B.3: Lack of correlation shown for MSW generation rate and recovery rate of paper material recycling for $25 \mathrm{OECD}$ member states.

Figures B.1, B.2, and B.3 clearly illustrate that no correlation of any kind in any combination exists between MSW generation rate and recovery rate for the OECD member states. 


\section{APPENDIX C}

\section{JUSTIFICATION FOR BARRIER AND INCENTIVE DESIGNATIONS}

Table C.1: Listing of sources that correspond to each country case study discussed in Appendix C. Detailed citations are located in the References section of thesis' main body.

\begin{tabular}{lc}
\hline \multicolumn{1}{c}{ Country } & Source \\
\hline Bhutan & UNEP, 2001b \\
Botswana & Bolaane and Ali, 2001 \\
Brazil & Wells, 1994 and Fehr, 2000 \\
China & Wang and Nie, 2001 \\
Guyana & Závodská, 2003 \\
India & UNEP, 2001c \\
Indonesia & World Bank, 2003a \\
Iran & Abduli, 1995 \\
Jamaica & Pendley, 2005 \\
Lao & UNEP, 2001d \\
Lebanon & Nuwayhid et al., 1996 \\
Malaysia & Kathirvale et al., 2003 \\
Maldives & UNEP, 2002 \\
Mauritius & Mohee, 2002 \\
Mexico & Buenrostro and Bocco, 2003 \\
Mongolia & World Bank, 2004 \\
Nepal & UNEP, 2001e \\
Philippines & World Bank, 2001 \\
Sri Lanka & UNEP, 2001f \\
Thailand & UNEP, 2001a and \\
Turkey & World Bank, 2003b \\
Turkmenistan & Metin et al., 2003 \\
Vietnam & UNEP, 2005b \\
\hline
\end{tabular}

\section{Government Policy:}

Bhutan: "Extensive review of the existing policies as the EA Act 2000, Water and Sanitation Rules 1995 is not in practice and there exists a lack of strict enforcement of these" 
Botswana: "Apart from that, there is a deposit refund scheme for refillable beverage bottles that is reported to be recovering $90 \%$ of the distributed bottles, and a"

Brazil: "Cempre has been consulted on several occasions regarding draft legislation in the waste area.

China: very established and enforced "The Act of Prevention and Control of Solid Waste Pollution to the Environment, P.R. China (1995), abbreviated as the Solid Waste Act, is the basic law on MSW management in China. In addition, the State Council, SEPA, and the Ministry of Construction have promulgated many ordinances, regulations, standards, and roles, such as the Municipal and Environmental Sanitary Regulation (1992), the Municipal Solid Waste Management Ordinance (1993), the Technical Standard for Municipal Solid Waste Sanitary Landfills (CJJ17-88), the Sanitary Standard for Manure Treatment, etc. etc. etc." “ Different provincial and municipal environmental protection bureaus have also issued many related regulation and guidelines based on the local conditions. These laws, regulation, standards, and guidelines are the legal basis for the management of MSW in China. At the national level, it is the People's Congress and the State Council that legislate concerning municipal waste management. Also, ministries and state agencies have their right to promulgate ordinances, regulations, guidelines, and standards."

Guyana: "Mismanagement, personal gain, and general disinterest by politicians, planners, and administrators alike, have been the reason for many problems." "Even though there are specific requirements that waste receptacles should follow, due to the lack of enforcement, these laws are not complied with." "Dumping waste in the street or any other public area is also against the law. Other laws regarding solid waste in the city that are also not being enforced include the fact that homeowners are supposed to keep their drains clean ad that contravention of these laws could lead to fines and even symbolic incarceration. These laws have not been revised since they were approved in November 1981, so that in itself speaks about their perceived importance." "If people begin to realize that simply throwing garbage on the streets as they walk or dumping their household waste in any open area is not allowed mainly for health and aesthetic reasons ad can result in fines, in time, attitudes will change and littering and dumping will be normal occurrences." "There are laws in Georgetown regarding SWM but most of those are not being followed as there is virtually no enforcement." "Glass bottles that are used for sodas and beer are returned to the manufacturer via retail merchants as there is a deposit paid on each bottle purchased."

India: very young policy directly related to MSWM that is not effectual yet "The MoEF, Government of India has now issued the Municipal Solid Wastes (Managmenet and Handling) Rules in the year 2000." "Based on the recommendation of the task force, the MoEF in 1998, came out with draft Recycled Plastic Usage Rules, which bans storing, 
carrying, and packing of food items in recycled plastic bags. It also specifies the quality standards for manufacturing recycled plastic bags." "The $12^{\text {th }}$ schedule in the $74^{\text {th }}$ Amendment Act $1992 \ldots$ empowers the local bodies by giving them independence, authority, and power to impose taxes, duties, tolls, and fees for services including public health, sanitation, conservancy, and solid waste management."

Indonesia: "Waste collection has decreased significantly... this could be attributed to the ... lack of enforcement of and compliance with rules and regulations." "Although street waste constitutes a very small faction of the overall waste stream, a significant portion of the work force and waste management is allocated to maintaining street cleanliness. The importance placed upon street sweeping might be a result of the competition for the ADIPURA (Clean City) award, which is given every year by the President to the cleanest small, medium, and large cities." Most of the environmental policy is for hazardous wastes. See E088.

Iran: Author notes the following problems with the plan for MSW collection and disposal:

- does not consider all aspects of MSWM, socio-economic factors, and urban structures

- lack of organization with the three organizations, public relations, rules/regs/guidelines of MSWM, sanitary landfill ops.

Jamaica: "Significant challenges exist in all aspects of Jamaica's solid waste sector, nationalized by legislature in 2002." "National Solid Waste Management Act" This act has done a lot for waste management, but not recycling specifically.

Lebanon: "...suggestion of incorporating the disposal cost into the purchase cost of an item has been considered, but again the applicability to Lebanon is currently doubtful especially since there is no proper disposal as yet."

Maldives: "In the past, waste and garbage which could not be burned was dumped into the sea. This practice is now prohibited by law and waste incinerators and crushers have to be used in all resorts." "The present form of tourism development has not generated any serious environmental impacts. This has been accomplished through appropriate policies, legislation and plans and instituted mechanisms to apply strict standards and regulations." "The Ministry of Home Affairs, Housing and Environment is currently in the process of developing a national waste management strategy for the country." however, none of this policy speaks of material recovery.

Mauritius: “...there are presently no incentive schemes designed to promote recycling or reuse." "Economic instruments to facilitate small enterprises and public/private partnership to implement waste minimization and product responsibility schemes must be made available." "There is presently a deposit/refund scheme on glass bottles. These bottles are recollected and reused by their manufacturers." "There is presently a plan to 
initiate deposit/refund schemes on plastic bottles of type polyethylene terephthalate (PETE) in view of recycling." "In parallel, effective legal and economic instruments to promote waste reduction and resource recovery should be developed. At present, there is no legislation pertaining solely to solid waste. Solid waste rules and regulations are dispersed in various places of legislation."

Mexico: "In Mexico, it is the responsibility of each municipality to provide free public sanitation service via the collection and transportation of SW. Nevertheless, this service is limited to those wastes that are catalogued as municipal SW... Unfortunately, there exists an enormous conceptual confusion in Mexican legislation due to the indistinct definition of what are MSW, urban solid wastes (USW), domiciliary SWs, and domestic solid wastes (DSW)." "On one hand, it encourages confusion with respect to the planning and design of waste generation analysis and inconsistency in the interpretation of the results since the types of sources that have been analyzed have been confused. This has occurred, because it is unclear if SW is considered municipal because of the source that produces it or because the municipality takes on the responsibility of collecting SW. At the same time, it favors irresponsibility on the part of the source that generates the SW and allows for gaps in legislation with regard to the supervision of adequate SW disposal. Both of these facts permit the dumping of $\mathrm{SW}$ in inadequate areas, thereby causing a marked environmental impact." "... the fact still remains that the majority of sanitary landfills in Mexico do not comply with environmental legislation." "there is... a great gulf between policy and practice"

Mongolia: in it's infancy... "The Ministry of Nature and Environment (MNE) has nationwide responsibility for environmental protection." "In case of prosecution for environmental offences, no protocols have been established as to the roles and responsibility of the prosecutor, police, inspectors, ranger, and government witnesses. This drawback significantly reduces the seriousness with which inspection is carried out." "Local governments are responsible for all environmental management..."

Nepal: "The country has formulated some policies on waste management, but implementation of these policies is clearly lacking." "Although the National Policy was a good start on the part of the government to addressing the issue of waste management, it has not been followed up by plans and programmes. As a result, the policy has not yet been implemented."

"The current legislation for waste management, the Solid Waste Management and Resource Mobilisation Act (1987), is obsolete and needs to be changed. A new legislation on waste management, which clearly defines the responsibilities of various organisations, such as municipalities, SWMRMC, MoPE, Ministry of Health, and so on, and states the applicable standards and guidelines for effective waste management practices, should be enacted." "The Local Self-Governance Act has increased the responsibilities of municipalities but abolished the octroi tax (levied on goods and vehicles entering into or passing through municipal areas) which was the main source for 
income of the municipalities." "The scrap tax, which is charged by the District Development Committees (DDC) and the SWMRMC, on materials collected for recycling, is a perfect example. While the policy says recycling should be promoted, the scrap tax is hurting the recycling industry. Instead of abolishing this regressive tax, the government has recently increased the rates on the request of the DDC. The scrap tax needs to be abolished."

Philippines: "In recent times, many civil society and community organizations have opposed improper management of open dumps and landfills, the siting of future facilities, and incineration of waste. Their sustained efforts led to the drafting of RA 9003 also known as the Ecological Solid Waste Management Act of 2000 (ESWMA), which was signed into law early this year. This law replaces the piecemeal provisions previously covered in several laws, and for the first time, provides an integrated national framework for environmentally-friendly solid waste management." "Strengthening enforcement... The current lax enforcement situation needs to be improved to make the ESWMA an effective piece of legislation." "This can be attributed to LGUs' weak capacity, ... and weak enforcement of regulations." "providing better incentives... In addition, providing incentives would reduce waste generation at source and improve management of waste disposal facilities." "The incomplete collection could be attributed to ... lack of enforcement of and compliance with, rules and regulations."

Sri Lanka: "As in many other developing countries, waste disposal has been given relatively low priority. As a result, the enforcement of laws is weak. For example, although all LAs that operate sites receiving more than 100 tonnes of waste per day should obtain environmental clearance, none of them have done so. The CEA does not and is unable to enforce the regulation and prohibit the use of such sites, as there are no alternative systems in place. Without proper waste disposal facilities, regulations pertaining to waste cannot be enforced and the objectives of legislation cannot be accomplished. Furthermore, some of the clauses related to SWM in the Municipal Councils, Urban Councils and Pradeshiya Sabha Ordinances are outdated and need to be revised. Current laws and regulations need to be amended to introduce an integrated approach to solid waste management." "Provide incentives for enhancing materials recovery, recycling and re-use."

Thailand: Public Cleanliness and Orderliness Act and Enhancement and Conservation of National Environmental Quality Act legislate on the management of solid wastes. "Garbage banks were conceived as initiatives to encourage recycling activities at the community level, through which participants receive goods or money in exchange for their recyclable waste. Following the success of the first garbage bank in Dan Khun Tod, these types of banks have been replicated around the country. As of 2001 there were 87 of them in the municipal areas of Thailand that process a total of 2,500 tons of recyclables a year. School garbage banks are typically set up in local schools, where students can bring recyclable waste for collection. Students receive either cash or a 
certain number of reward points in exchange for their waste, depending on the volume and the type of material presented. Reward points can be redeemed to procure sports equipment, stationary, and other goods, the purchase of which is funded with profits from the sale of the recyclable materials. Garbage banks are typically managed by students, with support from teachers and parents. Community garbage banks are variations of the school banks, run by communities and municipalities. In Phitsanulok, a community garbage bank is profitably managed by local youth, with the support of the municipality and of a private waste trading firm. In Phicit, profits generated from a garbage bank were used to set up a communal convenience store, where goods are sold to members at a lower price. In Udon Thani province, members of the garbage bank receive shares of proceeds from the sale of all the collected recyclable waste. The "garbage-f for-or-eggs" project was instituted in one of Bangkok's poorest residential areas by Klong Toey Environmental Protection Group. The primary objective of the project was to solve yearly flooding problems faced by the community, due to the blocking of canals and sewerage systems by improperly discarded waste. Residents were encouraged to collect recyclable materials and to exchange them for eggs. Within six months of the program's start-date, the amount of waste in the community was reduced by 161 tons. The project is now operating in 23 communities within Bangkok and other provinces." "Incentives for waste reduction and recycling could save money on disposal. The introduction of packaging taxes and other economic incentives for reducing waste and encouraging recycling in many countries have had a larger impact on recycling and waste reduction in these countries than just public awareness and organized recycling programs alone."

Turkey: "There exist five major buy back centers and glass cullet preparation units nationwide. Significant efforts have been made, in recent years, to increase the number of glass bottle banks and separate collection systems. The plastics and metal packaging collection system is essentially the same."

Vietnam: "Operation and management of current waste disposal sites are inadequate to ensure that on going environmental and public health protection measures..." "Completed waste disposal sites lack agreement on, and implementation of, closure plans. This would be required to ensure effective environmental and public health protection measures are in place."

\section{Government Finances:}

Brazil: Although recycling can be a profitable endeavor, Brazil is seeing that it is more costly for recyclable collection than garbage collection. "The average cost per tonne of recyclables collected was $\$ 262$, about ten times the cost of regular garbage collection. This figure already reflected the revenue gained from the sale of the recyclables, which averaged around only $\$ 30$ a tonne. These figures... have helped city governments get an idea of how to measure the success of their programmes. In those communities that still send their garbage to open dumps, the high costs contrasted with the need to improve the conditions of final disposal." Turned it into a positive: basically going to pay for just 
disposing to landfill or dumps later through other sanitation/health/pollution causes. This is a very progressive attitude about MSWM and recovery costs.

China: China has been able to pour financial resources into environmental infrastructure such as environmentally sound treatment facilities. "The Chinese government invested 60 billion yuan RMB (US $\$ 7.2$ billion, US $\$ 1=8.3 \mathrm{RMB}$ ) in environmental infrastructure construction in 1998, which is the greatest investment China has ever made in environmental projects. More investment is planned for the next few years." “... in 1995 , the cost to the government of MSW handling from collection to final disposal was 5.75 billion yuan (693 million USD)."

Guyana: "Guyana, a low-income country like many developing ones, is facing tremendous economic problems..." "Guyana, which has been cited as one of the poorest countries in the Western Hemisphere, has been suffering from serious economic problems for almost 30 years." "The present SWM system in Georgetown has suffered from years of under-funding..." "Due to insufficient funds, the Cleansing Department (which is the body that is in charge of SWM) is unable to perform the function of providing adequate numbers of litter receptacles throughout the city." "Repeated interviews with officials in the Cleansing Department indicated that the most basic problem associated with the SWM program is the lack of funding."

Indonesia: "Approximately half of these fees are used to cover the waste collection services, and the rest is used for neighborhood security and special events." "Enforcement of existing laws is generally weak due to ... lack of adequate funding."

Jamaica: "After a tax was levied on plastics importing in 2004, and earmarked for solid waste management..."

Lao: "In its present form, the solid waste collection system will not remain financially sustainable." "All central solid waste management systems shall be based on the following criteria: i) full coverage of the urban area, and therefore, ii) full fee paying, iii) payment by households dependent on level of service, iv) a minimum investment in mechanical equipment, and an emphasis on organization and community mobilization, there by reducing capital and running costs of the systems."

Lebanon: many funds are being put toward rebuilding the city after the war.

Mongolia: “...no budget allocation was made for solid waste management for the period 1996-2000 either at the national or the local level. In 2000, the seriousness of the solid waste problem prompted the international donor community to make 1,194 million MNT available in loans and grants to address the most pressing challenges related to solid waste collection and management." "budget transfers from the Central government, which apparently cover approximately a third of their estimated funding requirements." 
Nepal: "As a result, most municipalities are now struggling to mobilise resources just to meet their regular expenses. The municipalities of Nepal are therefore unable to spend enough on waste management, especially on capital investment for the purchase of equipment and the construction of infrastructure. Most municipalities are only involved in sweeping streets and dumping the waste along a nearby river or in a public place." "...many municipalities lack the ... financial resources for effective waste management."

Philippines: "Further, the lack of a cost-sharing formula between the national government and LGUs for financing capital costs is also hampering the establishment of proper disposal facilities." "Increasing expenditures on SWM. A back-of-the envelope analysis indicates that the Philippines will need to spend an additional PhP150 billion (US\$3 billion) over the next 10 years for SWM." "Mainstreaming the utilization of new funding sources and employing cost-effective approaches. New funding sources such as national government cost sharing; private sector participation; and user fees should be explored along with cost saving measures, such as shared facilities and producing power using landfill gas."

Sri Lanka: "LAs with regulatory responsibility exercise little control over these practices mainly owing to a lack of resources." "Financial constraints being the primary cause for lack of proper solid waste management, donor agencies have initiated a number of projects." "The main source of revenue for the LAs is through the collection of property rates and taxes. Local Government ordinances do not permit the levying of fees for services rendered in connection with solid waste collection." "The fundamental problem faced by the LAs in providing adequate service coverage is the lack of ...adequacy of finances."

Turkey: "This [recycling] obviously is driven by ... the limited economic conditions in the country that provide an employment opportunity for this sector."

Vietnam: "Current investment in waste management services and facilities is constrained through lack of available finance." "The operational budget for waste management services is presently insufficient to ensure a fully effective and sustainable service." "...mobilisation of increased operational budget is necessary." "Cost recovery and fee collection is presently low. Improved cost recovery would assist the development of waste management services."

\section{Waste Characterization:}

Bhutan: UNEP comments about the insufficient amount of data on the amount of MSW generated, its composition, and its disposal. Such data could give could give an indication of the potential for composting and recycling. 
Brazil: “...Cempre believes it has become a credible centre of hard local data (as opposed to frequently-cited figures from developed countries) on many aspects of recycling, from costs of curbside collection programmes, to a scrap dealer hotline and practical manuals." "Scrap broker hotline - Cempre offers an information hotline service on scrap brokers around the country. The data bank currently covers more than 700 firms that buy up to 14 types of materials, from paper to lubricants. This service proved useful for city governments embarking on collection programmes, and for factories separating their recyclable waste. Cempre also offers a similar service for equipment needed to collect, separate, reprocess, and compost material.

\section{China: sufficiently understands the waste stream attributes}

Guyana: "It is therefore not surprising that even the Cleansing Department does not have reliable data about the most basic aspects of Georgetown's solid waste, such as daily generation and makeup of the waste."

India: "Although attempts have been made at the city level in some selected pockets of the country to identify and quantify municipal waste and biomedical waste, there are no state/nation-wide waste inventories available in both the cases. It becomes very difficult in the absence of such an inventory to prepare waste management plans."

Indonesia: "Accurate and reliable data available for waste generation, collection, and disposal, as well as for waste characterization, are limited and appear not to be valued."

Mauritius: "More so, is the fact that in Mauritius, there is very little information about the quantity of solid waste generated as well as its composition. Data is a fundamental parameter to decide upon any solid waste management strategy and the nature of wastes, dictate up to a certain level, the strategy to be adopted."

Mexico: "Generally speaking, official statistics report a higher rate of SW generation than those reported by non-official sources, whose results, for the most part, tend to agree with each other. These differences indicate an excessive generalization in regional data, all of which have been extrapolated from larger areas for the country. There is the need to substantiate different methods for classifying and quantifying SW." "A detailed characterization of HSW and MSW is a mandatory first step to develop sound strategies of integrated solid waste management. (E034 Bernache Pérez, 2001)"

Mongolia: "There is limited reliable and accurate data for waste generation, collection and disposal, for Ulaanbaatar and other main urban areas."

Nepal: "Effective management of waste requires information on the amount of waste generated, characteristics of various types of waste, resources allocated for waste management, effectiveness of waste management systems, and impact of waste on human 
health, the environment, and the economy. This information is lacking. There should be a system for regularly collecting such information and storing it so that it is easily accessible, can be used for analysis for planning and management purposes, and can be disseminated to all stakeholders. At the municipal level, municipalities should be responsible for collecting and managing this information; and at the national level, SWMRMC should be responsible for collecting the information from all the municipalities and regularly monitoring their activities."

Philippines: "Obtaining reliable information for national, regional, and local planning. Without proper data, long-term planning decisions cannot be made."

Sri Lanka: "The data available that would help estimate the total quantity of municipal waste collected or generated in the country is not entirely accurate." "Discrepancies arise on account of lack of measurement of waste collected."

Turkey: "The State Institute of Statistics (SIS) has published one of the major sources of information in solid waste in Turkey. This extensive research published in 1993, provides valuable data on compositional variations in the household solid waste in Turkey (SIS, 1993)." "A continuous data collection process is typical for all material recovery facilities and for weekly collection programmes. Data is being collected in the form of the amount of recyclable solid waste collected, sorted, and recycled. Opinion surveys and analysis are conducted to measure participation rate and attract public interest."

Turkmenistan: “ $\ldots$ in 1991 the form of statistical report for wastes was abolished. According to the plan of measures on realization the State program "Health" of the President of Turkmenistan, the Ministry of the Use of Natural Resources and Environmental Protection has developed the form of statistical reports for industrial and domestic wastes and ... The form is approved by the State Statistical Committee of Turkmenistan and is in force starting from 1998."

Vietnam: "Solid waste analysis in composition plays an important role in selecting treatment technology." Vietnam has done a sufficient job at characterizing their waste in several large cities.

\section{Waste Collection and Segregation::}

Bhutan: Bhutan's collection efficiency is quite high compared to most developing countries. "...collection efficiency of about $72 \%$ by the city corporation. However it is very important for the authorities to further improve their collection efficiency in order to prevent the waste reaching water bodies and the drainage system due to informal disposal." currently is not widely practiced. "Proper segregation would lead to better options and opportunities for scientific disposal of waste." 
Brazil: "These curbside collection programmes educate their communities about the link between an individual's waste generation and the environment, and are very popular." "Other major cities, notably Saó Paulo, Porto Alegre, Santos, São José dos Campos and São Sebastião, have sizeable curbside recycling programmes. While it is hard to calculate the exact number of these programmes, Cempre estimates that there are a dozen major initiatives in cities plus perhaps two or three times that number in smaller towns." "the largest number of such collection programmes outside of Western Europe, the US and Canada." "The result of this reflection is the model of divided collection. What does this term express? It distinguishes between humid and dry waste, of in biological terms, between biodegradable and inert waste. The biodegradable waste, in the case of the city under study, has been shown to represent 72 weight percent of the regular official street collection. Logically, any model aspiring to divert waste from landfill, has to address this part with top priority. As technologies for transforming this humid waste into compost already exist, the management effort to separate it is well justified and can produce visible results in the short term. At this point of the model development, it is irrelevant whether the compost can or should be sold or not. The target of the model is landfill diversion, and compost is recycled inert matter which does not need to be tipped at a landfill. It may be tipped anywhere without causing pollution." "Selective collection is not economically self-sustaining and, therefore, competes with mixed collection for the same public funds." "Divided collection excludes mixed collection, but opens up and encourages activities of selective collection as an integral part of its philosophy, executed by private initiative. Divided collection can be performed by the householder with little effort. Its basic premise is to place the subsequent sorting operation into the hands of professionals, with results demand superior to those of mandatory selective street collection performed by amateurs." Selective: sort all materials, one truck comes by for organics, another for recyclables, another for all other waste - this is expensive - [may not be all that bad in low-income areas because it could utilize the large number of unskilled laborers. E081]

Divided: sort by organic and non-organic, then professionally sort at a waste processing center. More efficient! Jobs! Less contamination!

Mixed: all waste in one; makes for a challenge of professional sorting when organic matter has contaminated inorganic matter (adds another process of cleaning).

China: fairly high waste collection, but it is mixed collection which makes recovery difficult. "Though collection, transfer, and transport of municipal solid waste have greatly improved in the past 20 years in China, waste collection and transport systems cannot adapt quickly enough to the rapid demands of city development. Only in large cities is the waste transported in sealed vehicles. Data from 1998 shows that the streets and parks actually cleaned occupy only $90 \%$ of the area that needs to be cleaned. Even in the large cities such as Beijing, one can find places where no one is responsible for waste collection." "Except for some communities within some cities, municipal waste is collected without any separation. This results in low-fertility compost... [which] cannot be used by farmers because of its low quality and must be given away to the forestry 
sectors." "In the area of household waste recycling, support for source separation of household waste and waste recover practice in Guangzhou were found to be greater than those in Hong Kong. Since a new door to door bagged waste collection system is being phased into replace the older waste collection method in Guangzhou, it is expected that the traditional waste scavenging system will be adversely affected and the waste recovery rate may decrease as a result. For the purpose of resource conservation, it is suggested that a systematic and comprehensive household waste source separation program should be tried out in Guangzhou. Deploying an unskilled labour force and existing scavengers in organized source separation programmes is also a recommended solution. [E038 Chung and Poon (1999)]"

Guyana: "It has experienced and continues to have problems with inadequate collection and disposal of ...MSW." "The results have been delayed payment to workers, contractors, and all alike, infrequent waste pickup, obsolete and malfunctioning equipment and a litter-filled city, which is ironically named "The Garden City."

India: needs to be improved "One immediate measure to revamp the existing collection service structure is to provide community waste bins conveniently placed for the people to deposit domestic waste. As a first step, this will ensure that people do not throw their garbage on the roads and hence do not create open dumpsites." "In absence of segregation of waste at source, waste treatment alternatives such as recycling, waste-toenergy projects and or composting become uneconomical to operate." "Proper segregation would lead to better option and opportunities for scientific disposal of waste. Recyclables could be straightaway transported to recycling units, which in turn, would pay the corporations for it, thereby adding to their income. The organic matter could be disposed of either by aerobic composting, anaerobic digestion or sanitary landfilling."

Indonesia: "Solid waste collection is very decentralized and varies across regions, depending on economic prosperity, degree of urbanization, and cultural practices. Local governments have the primary responsibility for garbage collection, which is generally done by them, through contractors, or by residents themselves." "Over the past ten years, waste collection has decreased significantly in proportion to the amount of wastes produced, and this could be attributed to the limited number of appropriate collection vehicles, absence of transfer points, the lack of enforcement of and compliance with rules and regulations."

Iran: systems to handle waste at the source have not been devised and therefore trash ends up all over the streets (unsanitary/poor aesthetics) which makes it more difficult for the waste collectors to collect all the trash intended for pick-up. Collection occurs everyday though. 
Jamaica: "Collection services are not optimal due to high downtime for maintenance and repair of the public compactor fleet." "Jamaica has a number of private companies offering solid waste collection."

Lao: "The Municipality Government dictates collection frequency and payments by households." "Only five major towns have some form of solid waste collection systems. In all other urban centers, waste is disposed off on randomly selected plots, or simply anywhere. Occasionally, campaigns may be organized at village level to clean the immediate environment of waste, in particular at the beginning of the rains."

Lebanon: "frequently incomplete and sometimes sporadic" "waste was being dumped on street corners for many days before collection" "...the problem of civil compliance is still open in Lebanon. Sorting at the source is presently difficult to introduce..."

Maldives: "Presently, solid waste generated in Malé is collected and taken to a transfer station. From the transfer station, the waste is transported to a municipal landfill, located $5 \mathrm{~km}$ away from Malé."

Mexico: "For the most part, the majority of rural towns lack the necessary SW collection services; these are usually limited to the head municipality." However, on the whole, they have a fairly high colln' rate.

Mongolia: "Waste is collected with varying frequency and efficiency..." "Solid waste ... is supposed to be collected twice a week. In reality, collection occurs closer to once a week, leading to severe odor and cleanliness problems." "waste collection is irregular, sometimes just once a month [referring to ger areas]" "The Blue Bag campaign run by the Mongolian Women's Federation supports the sorting of wastes into blue bags and sending them for commercial recycling." However, the size of this effort is unknown.

Nepal: "In the absence of adequate waste management services, people have begun to take action in a few communities where the problem is the most severe and where people are aware of the implications of improper waste management. In most places, this is in the form of door-to-door waste collection. KMC's Solid Waste Management Section has a record of 51 groups involved in waste management. Most of these groups serve a few hundred households. According to the survey by Thapa and Devkota (1999), 15.4\% of the people in Kathmandu have made their own arrangements for waste removal." not currently occurring according to this... "The amount of recyclable materials that remain in Kathmandu's waste indicates that recycling by the private sector can be increased. This would require separation of waste at source..."

Philippines: "The incomplete collection could be attributed to the limited number and inappropriate collection vehicles, absence of transfer points, traffic congestion, and lack of enforcement of and compliance with, rules and regulations." "Though waste in the 
country has high composition of organic matter and recyclables, household segregation is not widely practiced. The ESWMA now mandates household segregation." The affects of this mandate were not reported on...

Sri Lanka: "Overall, there is significantly low-level collection service coverage in Urban Councils and Pradeshiya Sabhas. The fundamental problem faced by the LAs in providing adequate service coverage is the lack of resources, primarily in respect of suitable collection vehicles, adequacy of finances and shortage of manpower."

Thailand: "In order to improve the waste collection, the new waste collection systems are introduced for the waste, which are as follows: BMA's Database of Waste Collection, Vehicles Project, Setting Containers for Pedestrians Project, Vehicle Supply for Retaining Waste Collection Efficiency Project, Waste Collection Truck Care Project, Improvement of Collection Routes Project, and Waterway Waste Collection Project." "inadequate municipal services, which create a large need for informal waste collection" "Households do little separation of waste. Separation of recyclables by households is currently limited to that which is encouraged through Garbage Banks and the relatively small quantities of paper and glass that households store for sale or donation to sa leng or recycling shops."

Turkey: "Separate/curbside collection of the recyclable materials has started within the last ten years in Turkey. Currently more than 60 municipal recovery programmes are operational nationwide."

Vietnam: "They [waste] are collected together and transported to the treatment sites." "There appears to be opportunities for increased socialisation of some services such as waste collection to help improve cost efficiencies." There is a $36 \%$ collection efficiency, which is pretty low, and they would just like to see it be more cost-effective. "In general, solid wastes are not segregated at source."

\section{Household Education:}

China: Since most people consider municipal waste handling a public service, they do not care about where their waste goes. In many cities, particularly in smaller cities, low public awareness creates problems. From time to time, public waste collection equipment is destroyed.

Guyana: "Another serious consequence of the lack of funding is the absence of public relation programs without which it is very difficult to educate the public about SWM.

Indonesia: "The high percentage of organic waste indicates that it could be used usefully as compost, although this would require significantly more awareness-building, demonstrations, and training before it could be adopted on a large scale." 
Jamaica: "Public perception of solid waste is such that littering is extensive (including human waste), illegal dumpsites still exist, waterways contaminated and/or flood, and the impacts of this poor solid waste management are not recognized." "Many Jamaicans suffer from a lower overall awareness of the impact of poor solid waste management." "Administrators with the NSWMA and with the National Environmental Protection Agency (NEPA) are faced with the daunting task of changing this behavior. A combination of public education and legal enforcement is being used to begin the task..."

\section{Lebanon: noted the need to start a campaign of public environmental awareness.}

Mexico: "Decisions concerning SW management, should be presented to the general population in a simplified manner, by professions. This will be a good starting point for improved environmental education. Campaigns must focus on the adolescent population since they appear to be environmentally unaware. It is in this population, where there has been noted a large increase in consumption patterns in addition to a greater level of apathy and ignorance toward environmental and social implications with regard to inadequate management of SW."

Mongolia: "Mongolians are becoming increasingly aware of the deteriorating environmental conditions in their country. However, understanding the root causes of the current environmental degradation is still limited, thus preventing the public from playing a more active role in managing and protecting natural resources."

Nepal: "Some NGOs are also involved in raising public awareness... In the past few years, many children's groups have also been involved in waste management in Kathmandu and Lalitpur. KMC's Children and Environment Programme is working with 12 schools."

Philippines: "Many non-governmental organizations (NGOs) have been active since the early 1990s through recycling programs such as Zero Waste Recycling Movement and Linis Ganda." However, some citizens still haven't been reached... "Since the publiclydemanded closure of the Carmona and San Mateo landfills, the metropolis has been buried in its own waste with few alternatives aside from open dumping." "Addressing the NIMBY syndrome... This has prevented the siting of solid waste management (SWM) facilities and could be addressed through better awareness and consultation, and the demonstration of safe landfill practices." "Raising public awareness on the benefits of proper solid waste management."

Sri Lanka: "It is necessary to carry out awareness programmes to encourage minimisation of waste generation at source. These programmes should include waste minimization and recycling possibilities as well as emphasise health impacts of haphazard waste disposal." 
Thailand: Projects like: “Good Looking Home Front Project : To foster people's sense of responsibility on their own homes, society and environment, BMA supports public participation in cleaning their communities, by encouraging row houses, schools, shops and others situated along main streets to join in keeping their compound, public sidewalks clear and clean. Waste Minimization Project: To decrease the amount of solid waste by urging people to reduce and separate wastes before disposal, encouragement on "Waste Minimization" is carried out by involving public participation by "Thinking Over and Saving Resources". For this, people are given suggestions on how to reuse, repair, recycle and reduce excessive use in order to reduce the waste generation. Community in Your Hands Project: To draw public attention on waste minimization. District Offices and Build up of Public Awareness Project: To conduct pilot project to generate public awareness on waste, BMA targeted on six groups of educational institutes, medical centers, enterprises, department stores, organizations and communities in four districts of Bang Sue, Khlong Toei, Rat Burana and Laksi."

Thailand: "Municipalities are encouraging participation in recycling. Bangkok, as well as most small to medium-sized regional cities, is undertaking some public awareness campaigns for recycling and waste separation. While participation in recycling is crucial, only modest success has been reported in most of these programs."

Turkey: "Public participation and awareness in municipal recovery programmes has been an important issue in all curbside/separate collection programmes. Several types of tests and opinion polls have been conducted in order to gain an insight to the role of public awareness in these types of environmental programmes." "Even under difficult living conditions, such as in temporary settlements in the disaster region, regular citizens support and participate in environmental actions, especially when properly informed." “... Bursa Municipal Recovery Program... which covered 10,869 residents, has shown that $66.4 \%$ are aware of the separate collection and recovery program and $51.8 \%$ are claiming regular and active participation. Similar participation measurement polls have shown that the overall participation rate varies between 30 and $35 \%$ in other programs in Turkey."

Vietnam: "There is presently insufficient socialisation (involvement of the community and increased public private partnerships) in waste management services." "The level of public awareness of environmental, health and safety issues of waste management issues appears to be relatively low."

\section{Household Economics:}

Botswana: "This could be attributed to the relatively higher income and absence of reuse culture in the other countries. For example, old clothes are often given to relatives, and food leftovers are stored and consumed at later times." "Despite an explanation that the survey was for academic purposes, most participants especially in the low-income households were suspicious that the results of the survey would lead to them being 
required to pay for their waste management services." This comment made me think about how people may want to reduce their waste generation if they must pay proportionally to the amount they generate...

China: “...the Beijing municipality levies a 3 yuan tax per family per month for the treatment and disposal of MSW. This is $0.12 \%$ of the total average income of a 3-person family (the average income of a 3-person family was 2525 yuan/month in 1998). Though this amount of money is not enough, it provides a new source of financing." "Implementation of the municipal waste management fee system and waste separation in some communities of cities has had positive effects on awareness of the waste problems."

Guyana: "Recyclable materials were also found, but not in large quantities. This can also be explained by the waste ethic in Guyana: containers that can be reused for storing things are saved. The thought of buying new containers, especially for storage, is unheard of. Food containers are reused to store food and other containers are used similarly. This includes glass bottles, ferrous and nonferrous cans, plastic bottles and containers, paperboard and cardboard boxes." "Due to economic conditions of the country, waste is not a common phenomenon. When such "expensive" products are bought, they are either consumed, shared, or stored with future use." (products: paint, oil, pesticides, cleaning products)

India: “...percentage of recyclable waste is increasing in the municipal waste streams. This can be largely attributed to changing lifestyles and increasing consumerism."

Indonesia: "All residential areas in Jakarta are expected to pay for initial waste collection. Depending on the level of income of the community and/or the level of service desired, households pay anything from a few rupiah up to a maximum of 3 US dollars a month."

Iran: recovery of bread for sale for traditional/religious beliefs; bottles reused in the home;

Lao: "The Municipality Government dictates collection frequency and payments by households." "The common risk in all towns with collection system is the gradual reduction in the number of households willing to pay to collection charges. In part, this reluctance may be due to the lack of satisfaction with the service provided."

Mauritius: "Citizens in rural areas do not pay for solid waste management services at all, while urban citizens pay indirectly through municipal taxes, which to not reflect the price they actually pay for the service." a barrier b/c some aren't paying at all and others cannot clearly see how much of their municipal taxes goes to MSWM.

Philippines: "Mainstreaming the utilization of new funding sources... New funding sources such as ... and user fees should be explored..." 


\section{Administration:}

Brazil: "Major corporations can and should play a catalytic role in advancing the cause of recycling." Private sector could be backbone to modernizing recycling in developing countries. Materials are becoming more sophisticated and require processing that requires expensive machinery. "It was clear that the diversion goal could only be reached through the supply of adequate raw material to recycling operations. The quality of this material would naturally attract private initiatives and thus alleviate the burden on public administration."

China: "In accordance with the growth of the governmental investment, industrial sectors are becoming more interested in MSW management project. This provides a great opportunity for the improvement of China's current MSW management system." "Recycling is a significant industry in China. According to 1996 data, this industry accounted for 5000 recycling firms and 120,000 collection stations in China with 8 million employees. In the 44 years from 1950 to 1994, 238 million tons of recyclable materials, valued at $\sim 134$ billion yuan (US $\$ 16.3$ billion), was recovered from the MSW stream." very strong and organized "There are three governmental organizations that are responsible for the management of MSW in China: the Ministry of Constitution, SEPA, and the Ministry of Domestic Trade... The national authority for MSW administration in China is the Ministry of Construction. Municipal Sanitary Bureaus operating in individual cities in combination with their enterprises take the responsibilities of collection, transfer, transport, treatment, and disposal of MSW generated in their own municipalities. They are also responsible for the monitoring, supervision, and enforcement of the legislation. Despite municipal sanitary organizations, the Ministry of Domestic Trade and its local supply and marketing systems are responsible for the material recovery from MSW. When environmental pollution caused by solid waste occurs, environmental protection organizations become involved as the responsible government authority for pollution."

India: "Institutional and regulatory reforms. The municipalities are the primary institutions responsible for solid waste management in India, but most of the urban local bodies, barring a few progressive ones, are unable to provide the desirable level of conservancy services."

Indonesia: "With decentralization, local governments have acquired more responsibilities in planning and implementing solid waste management programs within their locality." "Enforcement of existing laws is generally weak due to the lack of political will, inadequate coordination among various agencies, low technical capability for proving violations, limited access to information, and lack of adequate funding." 
Iran: 3 organizations work actively to manage MSW - Regional Municipalities (collection), Machinery Organization (transport), and OWRC (processing, recovery, and disposal). Author comments later that these three do not function collaboratively.

Iran: Author notes the following problems with the plan for MSW collection and disposal:

- does not consider all aspects of MSWM, socio-economic factors, and urban structures

- lack of organization with the three organizations, public relations, rules/regs/guidelines of MSWM, sanitary landfill ops.

Jamaica: "The National Solid Waste Management Authority (NSWMA) is a Government of Jamaica (GOJ) agency responsible for collection and disposal of solid waste to protect public health and the environment." "A private collection company, GDSS, has begun recycling glass and cardboard on a commercial scale across Jamaica. "GDSS is aiming to recycle 6,096 tons of glass and 3,657 tons of cardboard annually" (STATIN, 2005). In 2004, GDSS agreed to partner with newly formed company, Caribbean Paper Recycling, in efforts to create an economy of scale for exporting recyclable material to reach economic solvency." "A distributor of lead-acid batteries, Tropical Batteries, receives batteries and ships them away for recycling, but the scale of their operation is limited." "The Recycle for Life organization (RFL) was a subcompany of Jamaican soft drink producers focused on grass roots collection programs through, for example, encouraging schools and churches. The plastic was purchased from collectors for a bounty; this opportunity also encouraged sorting and scavenging for plastic at disposal sites. After a tax was levied on plastics... the soft drink producers felt that the government accepted the impetus for recycling and closed the doors of RFL."

Lao: "In Vientiane, a combination of state and private companies, assigned different sections of the four urban districts, take up the task of waste collection." "...private companies operating the systems cannot remain financially viable for long. Moreover, local municipal efforts to achieve a sustainable urban environment will continue to encounter more difficulties without a viable waste collection system."

Coll'n is currently handled by both (operation private, funds public) and they are clearly not coordinating well to get the job done. "The Ministry of Communications, Transport, Post and Construction (MCTPC) is the ministry with direct responsibility for solid waste management at the national level. The provincial office of Department of Communication Transport, Post, and Construction (DCTPC) takes charge at the provincial level. The administrative arrangements in each province may differ, where individual districts may have authority for solid waste management. Although municipalities do not exist officially, urban areas create de facto municipalities that are recognized as having special needs and are managed through a municipal committee chaired by the provincial governor. This committee designates an implementing agency for solid waste issues. In Louangphabang, Savvannakhet, Thakhek and Pakse, the UDAA represents the implementing agency." 
Lebanon: "given weak administrative structure for solid waste disposal at present"

Mauritius: "The two existing recycling industries are within the private sector and operate entirely as profit making organizations...."

Mexico: "Another serious limitation that the Mexican municipalities face, is the lack of administrative organization between departments. On the whole, the responsibility for sanitation services in the small municipalities is left to the Deputy Mayor at City Hall, who also has other responsibilities such as the upkeep of public parks, green areas, public cemeteries, etc. This excessive responsibility has negative repercussions on the quality of services and causes a conflict of interest in the application of the available funds. This results in the lack of any integrated coordination with respect to adequate handling and final disposal." "In addition, private investment is minimal, if not nonexistent, since there is a lack of state and municipal legislation that provides legal protection for those in the private sector who wish to invest in and create effective systems for the public."

Mongolia: "The Blue Bag campaign run by the Mongolian Women's Federation supports the sorting of wastes into blue bags and sending them for commercial recycling."

Nepal: "the Solid Waste Management and Resource Mobilisation Centre (SWMRMC) to manage Kathmandu's waste and introduced a modern waste management system." "The government was unable to provide the SWMRMC with the necessary support and there was little coordination between SWMRMC and the municipalities. The latter were also involved in waste management. Currently the SWMRMC is only a small unit under the Ministry of Local development (MLD) and its role is not yet clear." "The private sector is mostly involved in recycling waste. Scavengers and scrap dealers buy or collect scrap materials and sell them to factories in Nepal and India."

Philippines: "Except for a handful of Local Government Units (LGUs), the performance of cities and municipalities in the provision of services to collect and dispose solid waste has been poor. This can be attributed to LGUs' weak capacity, inadequate budget, limited understanding of appropriate and cost-effective practices, and weak enforcement of regulations." "Building the capacity of national and local institutions... Capacity building for LGUs and barangays and improving strategic planning at all levels of government will be necessary."

Sri Lanka: "Local Authorities are responsible for the collection and disposal of solid waste..." "LAs with regulatory responsibility exercise little control over these practices mainly owing to a lack of resources." "Some LAs have initiated various treatment technologies for part of the waste stream with a view to resource recovery and reduction of waste quantity requiring final disposal." "The Ceylon Glass Company recycles the white and amber cullet whereas green cullet is recycled on small scale by private glass 
manufacturers." "The Vallachchanai paper factory of the National Paper Corporation runs wholly on recycled paper." "Over the past 2 years a few LAs have privatized waste collection services. A marked improvement in the street cleansing and door-to-door waste collection is evident. The smaller LAs view privatisation as a means to increase the coverage area and collection efficiency."

Thailand: "Improvement of Waste Disposal: Private Contractors for Transferring Waste from BMA's Waste Transfer Stations to Landfill Site Project, Private Contractors for Old Waste at On-Nuch Solid Waste Treatment Plant Project, Private Contractors for Old Waste at Nong Khaem Solid Waste Treatment Plant Project, Private Contractors for Infectious Waste Collection Project, and Private Contractors for Compost Plant Improvement at On-Nuch Project." "The Public Health Act ... is relevant to the solid waste disposal which indicates that the local government should be responsible for disposal of solid waste in the respective area. For maintaining cleanliness and establishment of orderliness in collecting, transporting, and disposing of solid waste the local governments have powers to establish local provisions (forbidding littering, management operations, fees/taxes, etc.)"

Turkey: "Solid waste recovery and recycling has been a longstanding commercial activity in Turkey. Glass and paper recycling have been conducted at industrial scales since the 1950 s. With the recent investments in the recycling industry, almost all types of plastic materials, glass, paper, and metals can be recycled at industrial levels in Turkey. Recycling of scrap metal should be considered at a scale beyond the municipal solid waste management system; however, due to similarities of the collection process of recyclable waste, it will only be mentioned briefly here. Turkey, as one of the biggest steel scrap importers of the world, recycles more than 2 million tons of steel scrap annually. Recycling of nonferrous metals is also widespread and conducted at industrial scale, including aluminum, copper, lead, and silver. This type of operation is valid for most of the collection and recovery of recyclable MSW." "...packaging waste recycling in Turkey is well above 30\%. However, most of these activities operate within the hands of private entrepreneurs and waste collectors working on streets and in waste yards." "Glass recycling also works on the free market principles, which is mostly operated by the Glassworks Co. of Turkey, consuming more than $90 \%$ of the collected used glass bottles."

Turkmenistan: "The export of wastes is carried out according to the contracts with municipal services of cities, etraps, and etc. The Ministry of the Use of Natural Resources and Environmental Protection issues out the sanctions to warehousing of wastes."

Vietnam: "Specific responsibilities within waste management sector have not been clearly defined and, as such, development of improvements to the service is being hindered." "waste picking activities are completely spontaneous without any form of organisation and management." "There is presently insufficient socialisation 
(involvement of the community and increased public private partnerships) in waste management services."

\section{MSWM Personnel Education:}

Brazil: "Cempre's programmes and publications focus on the operational and educational aspects of recycling, generally aimed at assisting the decision-maker in taking the correct path towards stimulating recycling in his or her community, company, school, or other organization." "In essence, those cities that invested the most in education attained the best results and lowest costs." "Decision-maker's guide to integrated waste management - In conjunction with the Technological Research Institute (IPT) in São Paulo, Brazil's foremost research center, Cempre is preparing a 200-page manual to introduce municipal cleaning authorities to the concept of integrated waste management, which encompasses proper use of sanitary landfills, recycling, composting, and incineration of toxic wastes. The manual is written in a decision-tree format, starting from the assumption that each city government possess little more than an uncontrolled open dump."

Guyana: "All of the problems that the SWM system is faced with in Georgetown are only exacerbated by the lack of trained personnel. This includes workers in all ranks, from the administrators to the garbage men. There are no formal training programs..."

Mexico: "Another consequence of poor administrative planning of public sanitation systems is that the majority of these services are directed by personnel with a low educational level and no SW management and /or technical training. This last point results from the low salaries paid in this sector and consequently, the person in charge does not have the proper qualifications." "The lack of technical training is reflected in the production of overly ambitious public bylaws, which lack surveillance and control mechanisms."

Nepal: "Some NGOs are also involved in ... providing training on waste management." "...many municipalities lack the technical knowledge ... for effective waste management."

Philippines: "This can be attributed to LGUs' ... limited understanding of appropriate and cost-effective practices..."

Vietnam: "There remains a need for increased training and capacity building programs within the waste management sector." "Lack of proper ... management skills at the landfill sites."

\section{MSWM Plan:}

Brazil: "Origins and, as much as possible, destinations of waste items or fractions may be easily identified. Knowledge of the origins provides clues for appropriate actions that could reduce waste generation. Knowledge of destination allows for improved planning 
of transportation logistics, of final disposal siting, and of recycling operations. ... it is easy to predict the need for adequate disposal of $16 \%$ of the waste officially collected in the city, namely $10 \%$ to common landfill and $6 \%$ to special landfill or treatment." $B y$ understanding the origin of waste types in the city, it is easier to plan for new recycling, composting, and landfill locations.

Guyana: "The present SWM system in Georgetown has suffered from years of underfunding, improper planning and mismanagement. It has experienced and continues to have problems..." "... do not extend into the rural areas along the inhabited coastal plain or into the interior of the country because there is no comprehensive national plan."

Iran: Author notes the following problems with the plan for MSW collection and disposal:

- does not consider all aspects of MSWM, socio-economic factors, and urban structures

- lack of organization with the three organizations, public relations, rules/regs/guidelines of MSWM, sanitary landfill ops.

Lao: "Most drains are clogged with garbage, reflecting the absence of an organized system for solid waste disposal in Vientiane and other towns."

Philippines: "This law replaces the piecemeal provisions... and... provides an integrated national framework for environmentally-friendly solid waste management." "A growing number of LGUs in the country are now implementing integrated waste management, which includes waste reduction, composting, recycling, and re-use."

\section{Local Recycled Material Market:}

Botswana: "buy-back scheme for steel metals cans that is reported to be recovering $65 \%$ of the distributed cans (NCSA 1998)."

Brazil: "Small business development - Another partnership has been with the Small Business Development Service (Sebrae), a privately-funded association that helps develop small business opportunities in each state. With the Rio chapter of Sebrae, Cempre is producing a series of manuals for potential investors in the recycling industry. The first manual, for example, outlines the investments and structure necessary to make polyethylene pellets from plastic bottles. The partnership also offers courses to small businesses on waste minimization."

Indonesia: "Only a small portion of solid waste is recycled, in spite of the existence of a relatively large market for used products made from recycled plastics, glass bottles, scrap paper, and scrap metals."

Iran: “...if an official system was put into place for paper and cardboard recycling, one could earn 44 million dollars per year; plastic collected from waterway channels by 
scavengers and purchased from households by hawkers, then sold to 2000 small workshops to be ground and used for raw material."

Jamaica: "Recycling programs and opportunities are few. These are limited in part because small island developing states (SIDS) do not produce recyclables on a scale to justify high capital processing facilities." However, a look at the composition of Jamaican waste shows nearly 40\% recyclable materials (paper, glass, metal, plastics). Also, the following statement made by UNEP in Pendley's report indicates that there is no other place for the inorganic wastes to go from Jamaica: "The region is at the end of the line for many waste streams generated by manufacturing countries" "In 2004, GDSS agreed to partner with newly formed company, Caribbean Paper Recycling, in efforts to create an economy of scale for exporting recyclable material to reach economic solvency." "The company has stated that the operation breaks even, and the operation is more a service for greater good than a legitimate part of the business plan."

Lao: have not recognized the economic benefits "Vientiane represents the only urban area where the commercial venture of recycling has taken root."

Lebanon: "the markets for recovered products have not been defined"

Mauritius: "The two existing recycling industries are within the private sector and operate entirely as profit making organizations...."

Mongolia: "Only a small portion of waste is recycled despite the existence of a potential market for used products from recycled plastics, glass bottles, and scrap metals."

Nepal: "Bhaktapur has operated a small compost plant, which has a capacity to process four tonnes waste per day. The plant, however, is currently processing less than one tonne per day because of poor management and marketing of compost. Analysis of the plant, however, indicates that, with some simple improvements in composting techniques and management, the plant can sustain itself and can be a model for other municipalities in Nepal."

Philippines: "the existence of a relatively large market for compost and used products made from recycled plastics, glass bottles, scrap paper, and scrap metals."

Sri Lanka: "Recycling of materials is carried out through an informal market driven system. Items are recovered at various points of the waste stream: at household level, collection and transport by LA workers or at the final disposal site by rag pickers and municipal workers." "Ferrous metal: recycled locally and exported in bales, after sorting and cleaning. The price of scrap metals is high due to the export demand." "A small quantity of corrugated cardboard is exported after shredding and baling." "HDPE (high density polyethylene), LDPE (Low density polyethylene), PET (polyethylene 
terephthalate) and PP (polypropylene) are recycled locally. However, the demand for plastic waste is seasonal as it dependent on the international price of the virgin material. The high cost of collection of clean plastic reduces demand." "The retrieved materials are sold to collection shops where they are cleaned and sold for recycling by local industrialists or exported overseas." "Some Local Authorities, through the intervention of NGOs, have established collection points where residents are requested to bring recyclable materials for purchase. However, this method has not proved to be effective owing to a lack of public response." "Newspapers are re-used mainly as a packaging material." "Research is being carried out by various individuals and organizations on fuel recovery from plastics and production of items such as fence posts using unclean plastics.”

Thailand: "Roughly 42 percent of Thailand's municipal solid waste is comprised of glass, plastic, paper, and metal, which has the potential to be recycled commercially and then reused in various manufacturing and industrial activities. As a result, almost 4.5 million tons of commercially recyclable materials 12 are discarded each year. The potential market value of these materials is THB 16 billion per year. Metal and paper, in particular, have tremendous recycling potential and approximately two thirds of these recyclables are currently discarded."

Turkey: "This obviously is driven by the fact that a strong used material market operates in Turkey ..." "The scrap metal recycling industry essentially is built on small medium scrap dealers spread around the country." "Several small-scale plastics recyclers (like PVC recycling operation) exist, since these facilities can be established with fairly low initial investments. In summary, a strong market demand exists..." Several small-scale aluminum recyclers are spread around the country..."

\section{Stakeholder Involvement:}

Brazil: "In its first two years of existence, Cempre has contributed greatly to the dissemination of information about recycling as well as to the development of information about recycling as well as to the development of a mature debate about this form of waste management."

India: "The National Waste Management Council (NWMC) was constituted in 1990 and one of its objectives was municipal solid waste management. The council is at present engaged in a survey of 22 municipalities to estimate the quantity of recyclable waste and its fate during waste collection, transportation, and disposal. NWMC in 1993 constituted a national plastic waste management task force to suggest measures to minimize the adverse environmental and health impacts arising out of plastic recycling."

Indonesia: "Enforcement of existing laws is generally weak due to ... inadequate coordination among various agencies..." 
Lao: "The Government aims to minimize the volume of waste by encouraging ... formal recycling ... [and] community participation through structured utilization of the informal sector communities that presently render a useful service through scavenging.

Maldives: "An interagency technical committee was formed in April 2000 to advise the Ministry on the national waste management strategy."

Mexico: "This in turn, results in a lack of coordination between the departments (such as the Public Health Department and the Environmental Protection Agency) involved with SW management." "This results in the lack of any integrated coordination with respect to adequate handling and final disposal." "It is important to develop mechanisms to improve the cooperation between the Ministry of Education and the Ministry of Environmental Protection, with the object of developing and implementing environmental education programs. This is important in order to make the general society more conscious about the implication and causes of SW production and to put pressure on the different levels of government to deliver coherent policies."

Nepal: "The MLD also has a National Council for Solid Waste Management, which is headed by the Minister for Local Development and includes representatives of all related ministries, municipalities, the private sector, and experts. The Council, however, is not active and has not met for several years." "The government was unable to provide the SWMRMC with the necessary support and there was little coordination between SWMRMC and the municipalities."

Philippines: "Support and participation of the people in SWM programs will be key to the successful implementation of the ESWMA."

Sri Lanka: "In order to address the need for a sustainable integrated solid waste management system/s in the Island, the MoFE has developed a National Strategy for Solid Waste Management in collaboration with relevant stakeholders."

\section{Technological \& Human Resources:}

China: "Landfills in many cities are not engineered or cannot meet required national standards with liners, drainage systems, landfill gas control, systems, leachate treatment systems, and environmental monitoring systems. China has many composting plants. Municipal waste is usually composted with manure and agricultural waste, such as crop stalks. Technology used in most of the composting plants is rather traditional or out of date and can only produce low-quality compost that is not suitable for farmland application. Hence, most of the plants have difficulty selling their products." poor technology makes material separation difficult "For the purpose of resource conservation, it is suggested that a systematic and comprehensive household waste source separation program should be tried out in Guangzhou. Deploying an unskilled labour 
force and existing scavengers in organized source separation programmes is also a recommended solution. [E038 Chung and Poon (1999)]"

Guyana: "The country's infrastructure is very run down." "The results have been delayed payment to workers, contractors and all alike, infrequent waste pick-up, obsolete and malfunctioning equipment and a litter-filled city, which is ironically named "The Garden City."' "Interviews were conducted with workers at Mandela Avenue landfill, as well as with the garbage truck drivers and while some workers complained about the inadequate attire they were provided for their jobs, no one expressed any concern about health. Some individuals mentioned that due to the lack of protective gear, they had to exercise caution when dealing with waste, but apart from that, they were not overly concerned. Gloves and boots are worn when available." "Manually-labor intensive solutions should be used to solve the current problems of littering and general city cleanliness. Instead of attempting to acquire and utilize technological solutions for the problems that exist, decision-makers should use the ample labor force that is available to them." a lot of unemployed individuals that would be more than willing to take a job sorting waste...

India: "Plastics are recycled mostly in factories, which do not have adequate technologies to process them in a safe manner." "India has lagged behind in adopting technologies for solid waste management. In particular, three technical components, collection, transportation, and treatment and disposal of waste need urgent attention." "Waste should be carried in covered vehicles."

Indonesia: "This threat is compounded by the lack of environmentally sound waste disposal and treatment facilities." "Waste collection has decreased significantly... this could be attributed to the limited number of appropriate collection vehicles..."

Jamaica: "The resources for developing countries many times are sources from the more wealthy states in the world. Solutions then may be developed that, although appropriate for developed nations, are not appropriate for the countries requesting assistance. Examples are many in which high mechanization and technical processes are favored even though labor costs are lower in developing countries, unskilled laborers are more available than skilled professionals, and resources for maintenance or repair are not available." "The plastic was purchased from collectors for a bounty; this opportunity also encouraged sorting and scavenging for plastic at disposal sites."

Lao: "Vehicles in use are a mix of new Japanese trucks, reconditioned French waste collection vehicles and locally purchased vehicles." "The Government aims to minimize the volume of waste by encouraging at source waste reduction technologies..."

Lebanon: “...a certain amount of manual sorting at the site would have the added benefit of creating employment opportunities.” 
Mexico: "There is incentive use of manual labor for street cleaning and SW collection in the majority of the 2400 municipalities, which make up the country."

Philippines: "With the operation of two new recycling and composting facilities handling 200 tons/day each, recycling is expected to further increase." "The incomplete collection could be attributed to the limited number and inappropriate collection vehicles, absence of transfer points, traffic congestion..."

Sri Lanka: "Some LAs have initiated various treatment technologies for part of the waste stream with a view to resource recovery and reduction of waste quantity requiring final disposal." "The fundamental problem faced by the LAs in providing adequate service coverage is the lack of resources, primarily in respect of suitable collection vehicles, adequacy of finances and shortage of manpower." "Newspapers cannot be recycled in the absence of de-inking facilities in the country..." "One of the fundamental problems in SWM is the lack of proper waste disposal facilities."

Turkey: from the amount of scavengers, Turkey is making adequate use of manual labor; also, the above 'private administration' section recognizes the technological development with respect to recycling facilities.

Vietnam: "There is still inconsistency in technology for collection and transportation, with a mix of different forms" "Lack of proper waste treatment facilities ... at the landfill sites." "The informal waste recycling sector is active both at source and at final disposal points but health and safety provisions were low in this sector. It caused high risks for public health to the people."

\section{Land Availability:}

Bhutan: The terrain of Bhutan does not afford much space for landfills, and therefore the little land available in Bhutan is actually an incentive for implementing recycling efforts.

Brazil: "The country is bigger in territory than the United States without Alaska and has slightly over 155 million people. Virtually all Brazilians, though, live within 100 kilometers of the sea, three quarters of them clustered in the South and Northeast regions. Within this densely populated coastal band are two of the world's biggest megacities: Saó Paulo (population 16 million) and Rio de Janeiro (population 10 million). In addition, there are at least another seven cities with population exceeding one million, including the capital, Brasilia. This coast-hugging pattern of human settlement has exerted an increasing pressure on available space to bury much of the 90,000 tonnes of municipal solid waste (MSW) that Brazilians generate every day. Many cities, in fact, have dumps or landfills that are running out of space." 
Lebanon: "landfill sites are becoming scarce" which acts as an incentive to recycling. Rugged terrain and pop density. Cost of land is very expensive due to private ownership.

Mauritius: "This will prove to be very difficult in the local context as land is limited and there is already severe competition between land uses especially for residential and commercial purposes such as development of hotels."

Sri Lanka: "Due to various factors such as urban sprawl and severe public opposition to the siting of such facilities (Not In My Back Yard - NIMBY syndrome), finding disposal sites in urban areas is increasingly difficult."

\section{Miscellaneous:}

India: Incentives for MSWM Plan, Administration, Household Education, Government Policy, Technological \& Human Resources, and Stakeholder Involvement below (UNEP, 2001c):

Box 5 Surat: a success story

The plague outbreak in Surat in 1994 was a stern reminder of what negligence in the area of solid waste management can lead to. After that disaster the city diligently tried to improve its living conditions. Institutional changes were the first thing to happen when the city began its journey from a city ridden with plague to the second cleanest city in the country, a status it achieved in a short span of 18 months. The city was divided into six zones to decentralise the responsibilities for all civic functions. A commissioner was appointed for each zone with additional powers; the officials responsible for solid waste management were made accountable for their work; and field visits were made mandatory for them each day. The solid waste management department and other related departments were made to work in concert and cooperate with one another. Indeed, these are some of the very basic changes that need to be introduced in the functioning of all urban local bodies. Community participation played a key role in the rapid implementation of decisions taken by the corporation. People were issued grievance redressal cards, which they could fill in and drop at the zonal office to register their complaints. The complaint was attended within 24 hours and the card returned to the citizen. In addition to the administrative changes, the changed laws had an important role to play in improving the conditions by also making the citizens aware of and responsible for certain preventive actions. Initially, the Gujarat Municipal Act did not have the provision of imposing a penalty for littering, which was introduced later as a fine of Rs 50 for every offence of littering and the fine was doubled for every subsequent offence. The corporation, in an appreciable attempt, has now engaged private sweepers to cover different inner areas of the town. Private contractors are also actively involved in the transport, collection, and disposal of solid waste.

"From a survey of various income groups, it may be concluded that 10-20 percent of the generated household waste ends up as litter." - Norconsult, 1996 (Jamaica)

40\% have access to solid waste disposal services; although Mongolia is struggling with a new "population" - folks in the peri-urban environment (called ger); people in ger generally do not have any municipal services (heat, water, waste, etc).

"Compared to other countries, Nepal still generates very little waste and most of what is generated is not hazardous and easily recyclable. Therefore, the increasing volumes of waste being generated would not be a problem if waste was viewed as a resource and managed properly." -UNEP, 2001e 


\section{APPENDIX D}

\section{THE ROLE OF SCAVENGERS IN DEVELOPING WORLD MSWM}

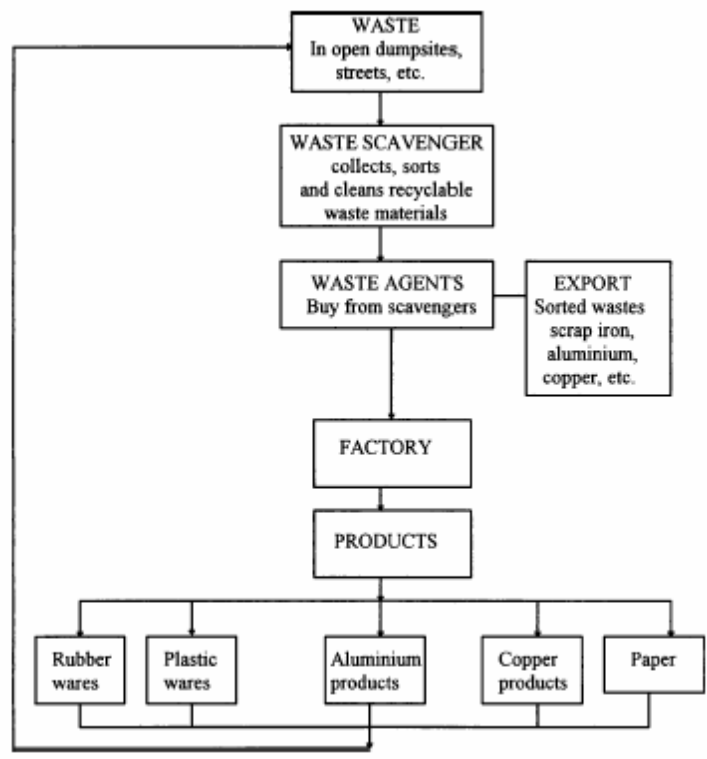

Figure 3. The role of scavenger in waste recycling, Nigeria.

Source of "Figure 3" in the upper left: Adeyemi, A.S., Olorunfemi, J.F., Adewoye, T.O. (2001) "Waste scavenging in Third World countries: A case study in Ilorin, Nigeria," The Environmentalist, Kluwer Academic Publishers, Netherlands, vol. 21, pp. 93-96.

Brazil: "Recycling in middle and lower-income countries depends primarily on hundreds of thousands of scavengers who pick at garbage bags, on the curb or in the dumps. This situation is no model for managing waste and is itself a by-product of the lack of proper treatment and disposal facilities in these countries." "The informal channel swelled by the growing ranks of unemployed, has become so pervasive that in Rio de Janeiro it has affected the composition of the officially-collected waste by trucks." "...less than $1 \%$ of officially-collected MSW is recycled." "Educational kit for scavengers: One of the survey's most intriguing findings was the effectiveness of scavengers when organized into cooperatives. Several successful co-ops have been formed in Sao Paulo, Santos, PortoAlegre and other southern Brazilian cities. Some of them have been integrated with the work scavengers. In Curitiba, the local government collects about 800 tonnes a month of recyclables and catadores pick up about four times that much even though there is no form of organization for scavengers. For city governments, recycling co-ops are a way to reduce the costs of officially-run curbside programmes." "In addition to cutting costs for city governments, co-ops provide a source of revenue for their members that is, surprisingly, higher than the average Brazilian salary. In a country where half the population earns less than the minimum wage of $\$ 80$ a month, co-op members earn two to three times that much. This is possible largely because of the high quality of Brazilian packaging (compared with other developing countries) and to the growing amount of disposable packages reaching the consumer. This trend in packaging growth and increasingly prevalent scavenging is not unique to Brazil - indeed, it is worldwide." 
China: "Note that MSW generation ... excludes the amount of materials recovered from MSW by individual collectors before collection, which is estimated to account for $8-10 \%$ of the total MSW. This is because individual collectors are more aggressive than the collection stations, as it is partially through collecting the recyclables that the individuals make a living."

India: "Moreover, since the ragpicking sector is not formalized, not all the recyclables, particularly plastic bags, get picked up and are found littered everywhere, reaching the drains and water bodies ultimately and choking them."

Indonesia: "Data in 1996 from the Indonesian Scavengers Association revealed that in Jakarta there are more than 150 facilities that process recyclable material for different industries."

Iran: plastic collected from waterway channels by scavengers and purchased from households by hawkers, then sold to 2000 small workshops to be ground and used for raw material.

Lebanon: "Like many other developing countries, scavenging plays a role in reducing the volume of waste disposed. It is common to see underprivileged persons scavenging through the waste mostly in search for cardboard, tins, and plastic bottles." Middlemen pass recyclables onto factories or even for export.

Mexico: "the increase in the number of people who live at or in the landfills (dumpsites) is a result of the economic deprivation of a wide range of social classes within the country, as well as the inefficient ways with which public and private funds in public sanitation systems are used." "...the unhealthy conditions in which these people work put these groups at great risk." "The internal organization of these groups is based on family relationships and friendships that each person establishes, which are motivated by two common reasons: 1) safety and 2) the necessity to survive." "On the one hand, the composition of these groups is extremely variable, which is the reason why it is difficult to establish permanent work programs and to monitor their activities. They are increasingly at risk of being exploited and manipulated by government leaders. However, the labor organizations (unions) for the scavengers and garbage collectors are currently the ones who have increased the SW collection and transportation problems that exist in Mexico. Although their work is cataloged as 'disorganized' and 'informal,' the reality is that they possess very complex forms of organization. They are able to recover and recycle a large quantity of materials; so large are these quantities that they surpass those obtained in developed countries. This fact demonstrates the necessity to include these groups in the decision-making process with respect to the handling of SW." "The activity, of these groups, is of great environmental importance since they succeed in recovering natural resources and reintegrating them into the industrial and economic 
process. Nevertheless, the SW handling conditions under which these groups operate gives rise to their economic level. The fact is, these people are forced to sell the recovered materials to others for very little profit and it is those who ultimately resell these materials that benefit financially the most. The existing practices (legal and practical frameworks) fail to regulate access to these resources and to effectively regulate the distribution of benefits. For this reason, it will be necessary to legislate in order to improve the conditions in which these groups are forced to work." "The State must develop mechanisms to include these groups of people in decision making with respect to SW management."

Mongolia: In Ulaanbaatar, Mongolia, "there are 5,000 to 7,000 scavengers, many of whom are young children. These scavengers are not integrated into the daily waste management operations of the city and are often seen as a nuisance."

\section{Thailand, Philippines, Colombia}

It is common for the informal sector to participate in solid waste management activities in developing countries. This is due primarily to inadequate municipal services, which create a large need for informal waste collection, and the consequent opportunity it provides for income among the poor. The size of the informal recycling sector varies significantly from country to country. It has been estimated, for instance, that around 2 percent of Mexico's population live off recycling-related activities, including 30,000 people in the metropolitan area of Mexico City alone. In Colombia, 300,000 people, roughly 1 percent of the country's population, are involved in scavenging activities.

The informal waste collection sector in Thailand is considerably smaller, with an estimated 25,000 people involved in informal recycling. This includes more than 15,000 sa leng waste collectors, 2,000 waste agents, and just under 4,000 scavengers who collect waste from disposal sites and transfer stations. In addition, over 3,000 municipal collectors in the country supplement their income by selling recyclables on an informal basis. Moreover, in Thailand, the income gap between formal and informal sectors is not as significant as in other countries. For example, at the On-nuch transfer station in Bangkok, scavengers earn between 150 and 400 baht per day while municipal collection workers earn an average of 700 baht per day. At the same time, informal recyclers, especially scavengers, are truly marginalized groups in Thailand that are subject to dangerous and unsanitary working conditions. The majority have no benefits such as medical insurance and pension plans; they have limited job stability and few educational and other job opportunities. The following initiatives, implemented in Colombia and the Philippines, may provide some innovative ideas to help these people:

Colombia, various cities - The support of government agencies and local NGOs has greatly contributed to the improvement of working conditions for waste pickers throughout Colombia. Recycling organizations started to emerge during the early 1990s, and progressively became small-scale enterprises and regional cooperatives. These cooperatives have gradually given their members employment benefits that are typical in the formal sector, such as subsidized health care, paid vacations, and pensions. 
Membership improves overall behavioral traits because recyclers have access to training, and they participate in meetings, social activities, and community life. Working conditions of recyclers typically improve after joining cooperatives because they are provided stable access to sources of recyclable materials (away from the landfills), as well as equipment and uniforms.

The Philippines, Quezon City - In 1993, the community of scavengers that lives in Metro Manila's Payatas dumpsite established the Payatas Scavengers Association. This initiative has considerably improved the living standards of its members by filling some of the typical voids found in the informal sector. The Association has promoted programs, among others, that aim at stabilizing the monthly incomes of scavengers through: 1) the establishment of home-based solid waste microenterprises, where recyclable materials are processed and subsequently resold at a profit, on a steady basis; and 2) the creation of a communal savings fund that provides access to loans for members of limited and uncertain monthly incomes.

Turkey: "Recyclable household waste (i.e., mostly the packaging waste) is a major focus of this publication. Recovery of plastics, paper, glass, and metal from municipal solid waste is mostly conducted, as indicated above, by the scrap dealers and individual collectors (scavengers, etc). These individual collectors and scrap dealers purchase the used packaging (mostly paper and cardboard) from commercial units, markets and business centers and reprocess (sort and bale) these materials to sell directly to the industrial recycling facilities. In addition, scavenging and collection from the waste bins is a widespread activity. Since this type of collection and recovery is part of the "unregistered" economic activity, it is difficult to specify figures reflecting actual collection and recovery. This is essentially a widespread collection and recovery method utilized in Turkey." 


\section{APPENDIX E}

\section{DETAILED DEVELOPING COUNTRY QUANTITaTive DATA}

Table E.1: Detailed background data on MSW generation rate.

\begin{tabular}{|c|c|c|c|c|}
\hline Country & $\begin{array}{c}\text { MSW } \\
\text { Generation Rate } \\
\text { (kg/person/day) }\end{array}$ & $\begin{array}{c}\text { Date of Data } \\
\text { Collection }\end{array}$ & $\begin{array}{c}\text { Type of } \\
\text { National Data }\end{array}$ & $\begin{array}{c}\% \\
\text { National } \\
\text { Population } \\
\end{array}$ \\
\hline Bhutan & 0.300 & 2001 & Actual & $\mathrm{n} / \mathrm{a}$ \\
\hline Botswana & 0.330 & 2001 & Representative & 10.6 \\
\hline Brazil & 0.854 & $1991 \& 1992$ & Representative & 13.5 \\
\hline China & 1.081 & 1998 & Actual & $\mathrm{n} / \mathrm{a}$ \\
\hline Guyana & 0.545 & 1997 & Representative & 36.0 \\
\hline India & 0.456 & 1995 & Actual & $\mathrm{n} / \mathrm{a}$ \\
\hline Indonesia & 0.697 & 1998 & Representative & 19.2 \\
\hline Iran & 0.888 & 1992 & Representative & 12.7 \\
\hline Jamaica & 1.000 & 2000 & Actual & $\mathrm{n} / \mathrm{a}$ \\
\hline Lao & 0.750 & 2000 & Actual & $\mathrm{n} / \mathrm{a}$ \\
\hline Lebanon & 0.500 & 1991 & Representative & 27.7 \\
\hline Malaysia & 0.650 & 2001 & Actual & $\mathrm{n} / \mathrm{a}$ \\
\hline Maldives & 2.480 & 2002 & Representative & 25.6 \\
\hline Mauritius & 1.300 & 2000 & Actual & $\mathrm{n} / \mathrm{a}$ \\
\hline Mexico & 0.318 & 1998 & Actual & $\mathrm{n} / \mathrm{a}$ \\
\hline Mongolia & 0.716 & 2002 & Representative & 30 \\
\hline Nepal & 0.480 & 1999 & Actual & $\mathrm{n} / \mathrm{a}$ \\
\hline Philippines & 0.431 & 2000 & Actual & $\mathrm{n} / \mathrm{a}$ \\
\hline Sri Lanka & 0.542 & 1997 & Actual & $\mathrm{n} / \mathrm{a}$ \\
\hline Thailand & 1.443 & $2000 \& 2001$ & Representative & 10.4 \\
\hline Turkey & 0.970 & 1994 & Actual & $\mathrm{n} / \mathrm{a}$ \\
\hline Turkmenistan & 0.399 & 1994 & Actual & $\mathrm{n} / \mathrm{a}$ \\
\hline Vietnam & 0.575 & 1998 & Representative & 10.3 \\
\hline
\end{tabular}




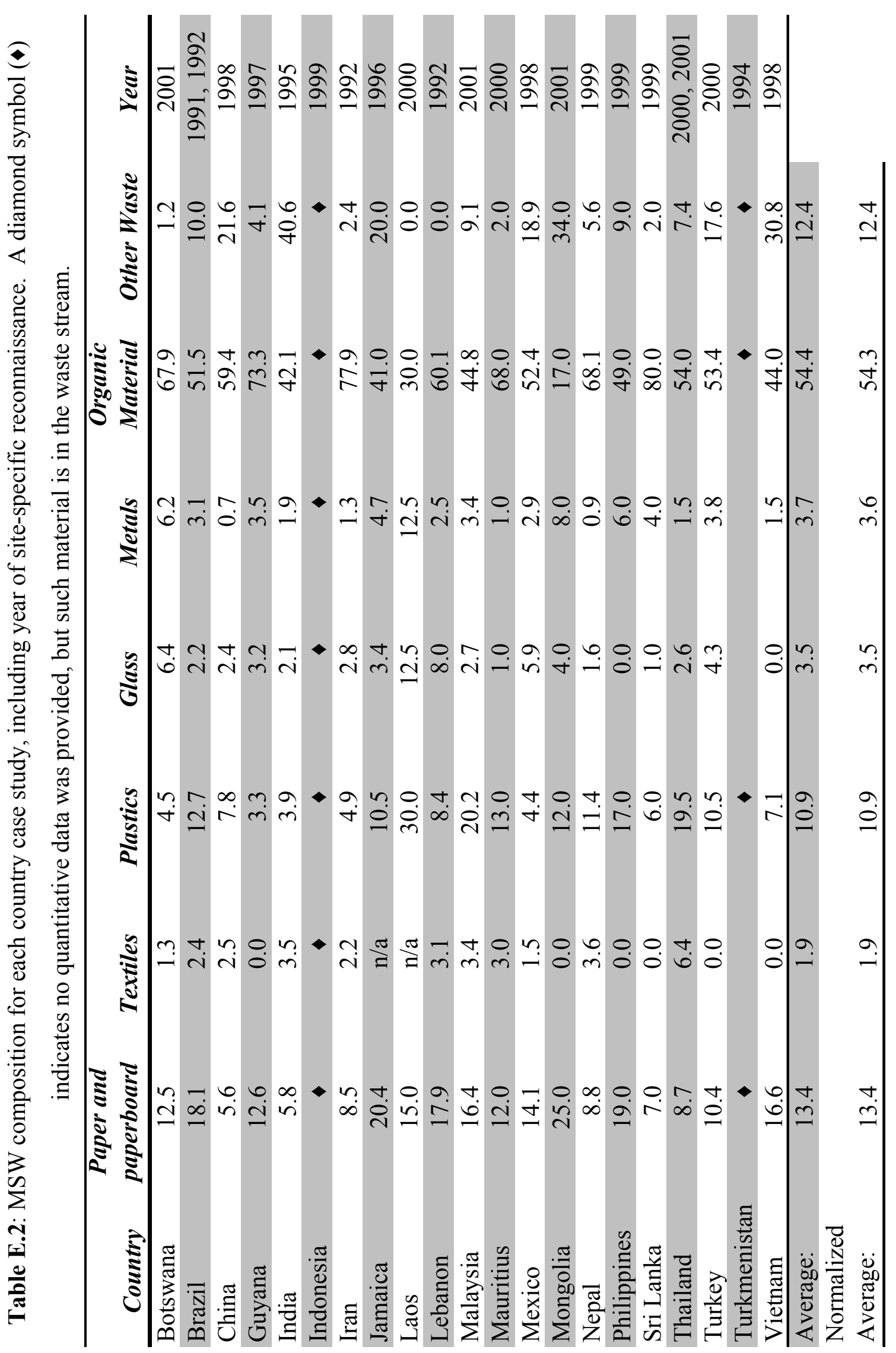




\section{APPENDIX F}

\section{DETAILED EXPLANATION OF FACTOR RELATIONSHIPS}

This appendix aims to provide further explanation to the creation of the collaboration web shown in Figure 3.3 in Chapter 3. Each relationship will be discussed with respect to the inflows of information of each factor. For instance, the Government Policy will be discussed with regard to the relationships the institutions associated with this factor need to function and those that benefit the institution by increasing efficiency.

\section{1) Government Policy}

Government Finances: Government policy requires funding to back the initiatives set out as well as to support the individuals managing the programs. Many times in the case studies a correlation was drawn between weak law enforcement and available funds.

\section{2) Government Finances}

Government Policy: The allocation of finances for MSWM is often times governed by regulatory requirements. If a topic is a priority to a nation or urban center, then laws will be made accordingly, and finances will go toward achieving the goals set out by the laws. In this study, six of the nineteen countries addressing government policy as a barrier to recycling did so due to no or few laws on MSWM.

3) WASTE CHARACTERIZATION

MSWM Administration: A MSWM plan alone can not make waste assessment occur; the MSWM administrators need to be active at addressing the goals and activities laid out in the plan. 
MSWM Plan: Characterizing the waste stream needs to be a goal set out by a comprehensive MSWM plan. In the plan, the motivation behind characterizing waste would need to be explained, as well as a standard method for conducting the assessment, how to report the results, and what to do with the results.

MSWM Personnel Education: If those conducting the waste assessment are skilled at the process, the waste characterization would be much more accurate and reliable, thereby providing more utility of and confidence in the results.

\section{4) Waste Collection / Segregation}

Government Finances: Both collection and segregation can be quite costly ventures due to the equipment and workforce needed.

Waste Characterization: Waste collection and segregation requires waste characterization to understand what equipment, workforce, and level of service will be needed.

Household Education: Public awareness of waste issues and management techniques employed by the municipality will positively impact the source operations. If the public understands the implications of litter around the city to health, safety, and the environment, then they will more easily adapt to a requirement placed upon them. Also, at-source segregation can be successful with educational campaigns about recycling, and a burden to the whole system without informing the public on what to do.

MSWM Administration: All the operations behind collection and segregation of waste require reliable leadership from whom to receive direction and coordinate individual efforts.

MSWM Plan: The plan offers guidance and direction to the many operations involved with waste collection and segregation.

Local Recycled-Material Market: In order for material to be recovered, it must be collected and separated by material type. Without the materials to recover, one end of the market system would be missing.

Technological and Human Resources: A substantial amount of equipment can be necessary to collect and separate waste, at minimum a municipality needs trucks to gather trash and transport it to one location for processing. With respect to collection and 
separation, some equipment can be replaced by labor-intensive activities, and vice versa. In developing countries, high unemployment rates justify utilizing manual labor to meet some of the goals that could require equipment.

MSWM Personnel Education: Waste collection and separation can occur much more efficiently and effectively if all personnel involved, from the garbage collector to the head MSW manager, are educated on their own duties in detail and have an understanding of the other operations conducted by others.

\section{5) Household EduCATion}

No MSWM factors were identified as inputs to public education/awareness.

6) HouseHold ECONOMICS

No MSWM factors were identified as inputs to individuals' incomes.

7) MSWM ADMINISTRATION

Government Finances: To ensure MSWM that is consistent and continuing, a secure source of funding must be allocated to MSWM administration.

MSWM Plan: An integrated, comprehensive, long-term MSWM plan needs to be in place in every municipality to guide those providing collection / segregation services and conducting collection and treatment operations.

Government Policy: Enforceable laws in place can greatly assist the administrators of MSWM in achieving their goals. Also, government policy formed on MSWM feeds into the direction that MSWM administrators can follow in their operations.

MSWM Personnel Education: Administrators will be much better at what they do if they fully understand all of the operations and implications of conducting or avoiding operations.

\section{8) MSWM PERSONNEL EDUCATION}

MSWM Administration: The head managers of MSWM administration would be responsible for maintaining the skills of their technicians and laborers, and may need to coordinate trainings/workshops to convey new information. 
MSWM Plan: The plan will identify the skills that administrators, laborers, and technicians to adequately meet the plan's goals.

Technological and Human Resources: Educating the personnel may require outside (non-MSWM) resources to conduct workshops if the expertise does not readily exist within the organization.

9) MSWM PLAN

Waste Characterization: The characteristics of the waste need to be fully understood to make appropriate plans for collection, segregation, treatment, and disposal, as well as to prepare for the health and safety provisions of the employees doing all of the operations.

Government Policy: While the plan is intended to direct the actions of the municipality and MSWM administration, government policy are necessary to guide the plan directives. Also, if policies and regulations are aligned with the plan, then the plan may hold more weight with all parties involved.

MSWM Administration: For the plan to be effective, the administrators need to take responsibility of carrying out all the objectives of the plan.

MSWM Personnel Education: Personnel education is needed to disseminate all information contained within the plan.

Land Availability: The amount of land available for waste treatment facilities governs the types of management options the administration should pursue and organize.

Government Finances: Without finances, most objectives of the MSWM plan may not be achievable, and the plan would simply be a lofty set of goals never to be acted upon.

Household Education: Public awareness of an established MSWM plan and its objectives may offer greater compliance of collection and segregation requirement when the citizens understand the contribution to the 'bigger picture.'

\section{0) LOCAL RECYCLED MATERIAL MARKET}

Waste Collection / Segregation: For a market to exist, a material input to that market must exist. Therefore, waste collection and segregation is fundamental to a localrecycled material market. 
Technological and Human Resources: Equipment for processing material into new products (or even just to the point of creating a valuable raw material) and the workforce to support these operations are an important part of the market as a whole.

Land Availability: Reduced land availability due to terrain or development may cause landfill to be less attractive on a MSWM option and may drive municipalities to offset landfill space with treatments like material recovery and incineration.

Government Policy: Policy can direct regulation that ensures safety to laborers involved in the operations of the market and provide structure and motivation to equipment upkeep which can directly prevent injury to workers and indirectly make for a more efficient material recovery process.

Waste Characterization: Understanding the quantity and types of waste can greatly assist those involved in the recycling of waste to adequately prepare for labor, equipment, and processes.

MSWM Personnel Education: A better understanding of how equipment and processes function may positively influence the safety of workers as well as increase efficiency.

\section{1) TeChNological and Human Resources}

Government Finances: Laborers, technicians, and administrators need to be paid, and equipment can be costly. MSWM is commonly viewed as a public service, and therefore, much pressure is on the municipalities to fund the operations.

Household Economics: A workforce is readily available in poor developing countries. MSWM Personnel Education: Equipment can last longer if the users (laborers, technicians, administrators) are skilled at operating them and therefore less turnover of technological resources would be necessary. In order to maintain a reliable workforce (retention and safety), they need to be skilled at their operations.

12) LAND AVAILABILITY

No MSWM factors were identified as inputs to land attributes. 


\section{APPENDIX G}

\section{DATA ON SOCIAL, ENVIRONMENTAL, AND ECONOMIC INDICATORS}

This appendix provides all data utilized to run preliminary statistical analysis to determine if correlations exist between these indicators and whether or not recycling occurs in a given country. No correlations were evidenced when utilizing XLMiner v.2.4.1 to create a classification tree.

Classification tree (also known as decision tree) methods are useful when trying to categorize or predict outcomes and to generate rules that can be easily understood. In XLMiner, classification tree labels, records, and assigns data to discrete classes. In this study, it was presence or absence of recycling activity. A classification tree in XLMiner can also provide the measure of confidence that the classification is correct. The classification tree is built through a process called binary recursive partitioning. This is an iterative process of splitting the data into partitions, and then splitting it up further on each of the branches.

The following four web databases were mainly utilized to populate the tables in this appendix:

Earthtrends, The Environmental Information Portal, World Resources Institute, $<$ http://earthtrends.wri.org/>.

UNEP GEO Data Portal, The United Nations Environment Programme Global Environment Outlook Data Portal, <http://geodata.grid.unep.ch/>.

World Bank, The World Bank Group, Millennium Development Goals Data, $<$ http://ddp-ext.worldbank.org/ext/MDG/homePages.do $>$.

CIA, The United States Central Intelligence Agency World Factbook, $<$ http://www.cia.gov/cia/publications/factbook/>.

If data sources other than those listed above, they are noted in the footnotes of each table. Definitions of each indicator are provided in Appendix H. 
Table G.1a: Social Indicators

\begin{tabular}{|c|c|c|c|c|}
\hline & $\begin{array}{c}\text { Human } \\
\text { Development } \\
\text { Index }\end{array}$ & $\begin{array}{c}\text { Population } \\
\text { Density }\end{array}$ & $\begin{array}{c}\text { Life } \\
\text { Expectancy }\end{array}$ & $\begin{array}{l}\text { Population } \\
\text { Growth Rate }\end{array}$ \\
\hline Data Date: & 2001 & 2002 & $95-00$ & $95-00$ \\
\hline Units: & ratio & people $/ \mathrm{km}^{2}$ & years & $\%$ \\
\hline \multirow{2}{*}{ Source: } & UNEP GEO & UNEP GEO & UNEP GEO & UNEP GEO \\
\hline & Data Portal & Data Portal & Data Portal & Data Portal \\
\hline Bhutan & 0.51 & 46.6 & 60.7 & 2.57 \\
\hline Botswana & 0.61 & 3.1 & 56.3 & 2.14 \\
\hline Brazil & 0.78 & 20.8 & 67.1 & 1.36 \\
\hline China & 0.72 & 139.6 & 69.7 & 0.90 \\
\hline Guyana & 0.74 & 3.9 & 63.6 & 0.47 \\
\hline India & 0.59 & 353.0 & 62.1 & 1.76 \\
\hline Indonesia & 0.68 & 120.3 & 64.9 & 1.40 \\
\hline Iran & 0.72 & 42.0 & 68.6 & 1.26 \\
\hline Jamaica & 0.76 & 242.5 & 74.8 & 0.86 \\
\hline Lao & 0.53 & 24.0 & 52.5 & 2.38 \\
\hline Lebanon & 0.75 & 351.5 & 72.6 & 1.98 \\
\hline Malaysia & 0.79 & 72.9 & 71.9 & 2.44 \\
\hline Maldives & 0.75 & 1029.7 & 65.4 & 3.02 \\
\hline Mauritius & 0.45 & 595.8 & 70.7 & 1.06 \\
\hline Mexico & 0.80 & 53.4 & 72.5 & 1.64 \\
\hline Mongolia & 0.66 & 1.6 & 61.9 & 0.88 \\
\hline Nepal & 0.50 & 172.1 & 57.4 & 2.32 \\
\hline Philippines & 0.75 & 263.5 & 68.6 & 2.03 \\
\hline Sri Lanka & 0.73 & 292.6 & 71.6 & 0.90 \\
\hline Thailand & 0.77 & 121.7 & 68.1 & 1.04 \\
\hline Turkey & 0.73 & 91.4 & 69.0 & 1.59 \\
\hline Turkmenistan & 0.75 & 10.2 & 65.4 & 1.96 \\
\hline Vietnam & 0.69 & 246.6 & 67.2 & 1.40 \\
\hline
\end{tabular}


Table G.1b: Social Indicators

\begin{tabular}{|c|c|c|c|c|}
\hline & $\begin{array}{l}\text { Sex Ratio of } \\
\text { the Total } \\
\text { Population }\end{array}$ & $\begin{array}{l}\text { Telephone } \\
\text { Main Lines } \\
\text { in Use per } \\
1000 \text { People }\end{array}$ & $\begin{array}{c}\text { Television } \\
\text { Sets per } \\
1000 \text { people }\end{array}$ & $\begin{array}{l}\text { Political } \\
\text { Stability }\end{array}$ \\
\hline Data Date: & 2000 & 2001 & 1999 & 2004 \\
\hline Units: & $\begin{array}{l}\text { males per } \\
100 \text { females }\end{array}$ & $\begin{array}{c}\text { lines per } \\
\text { thousand } \\
\text { people }\end{array}$ & $\begin{array}{c}\text { televisions } \\
\text { per thousand } \\
\text { people }\end{array}$ & $\begin{array}{l}\text { percentile } \\
\quad \text { rank }\end{array}$ \\
\hline Source: & $\begin{array}{l}\text { UNEP GEO } \\
\text { Data Portal }\end{array}$ & $\begin{array}{l}\text { UNEP GEO } \\
\text { Data Portal }\end{array}$ & $\begin{array}{l}\text { UNEP GEO } \\
\text { Data Portal }\end{array}$ & World Bank \\
\hline Bhutan & 102 & 8 & 6 & 73.8 \\
\hline Botswana & 96 & 81 & 19 & 69.4 \\
\hline Brazil & 97 & 215 & 330 & 43.7 \\
\hline China & 106 & 140 & 291 & 46.6 \\
\hline Guyana & 94 & 105 & 79 & 33.0 \\
\hline India & 106 & 37 & 75 & 24.3 \\
\hline Indonesia & 100 & 34 & 143 & 9.2 \\
\hline Iran & 103 & 162 & 157 & 19.9 \\
\hline Jamaica & 97 & 204 & 192 & 37.4 \\
\hline Lao & 100 & 10 & 10 & 24.8 \\
\hline Lebanon & 96 & 209 & 336 & 23.3 \\
\hline Malaysia & 103 & 200 & 169 & 58.7 \\
\hline Maldives & 105 & 91 & 39 & 72.3 \\
\hline Mauritius & 99 & 256 & 243 & 78.2 \\
\hline Mexico & 97 & 137 & 272 & 43.7 \\
\hline Mongolia & 100 & 49 & 62 & 61.2 \\
\hline Nepal & 104 & 12 & 7 & 5.3 \\
\hline Philippines & 101 & 43 & 110 & 15.0 \\
\hline Sri Lanka & 108 & 44 & 103 & 14.1 \\
\hline Thailand & 97 & 98 & 277 & 41.7 \\
\hline Turkey & 102 & 273 & 320 & 30.6 \\
\hline Turkmenistan & 102 & 82 & 191 & 18.9 \\
\hline Vietnam & 99 & 39 & 188 & 51.9 \\
\hline
\end{tabular}


Table G.1c: Social Indicators

\begin{tabular}{|c|c|c|c|c|}
\hline & $\begin{array}{l}\text { Government } \\
\text { Effectiveness }\end{array}$ & $\begin{array}{c}\text { Regulatory } \\
\text { Quality }\end{array}$ & Rule of Law & $\begin{array}{c}\text { INGOs } \\
\text { membership } \\
\text { density }\end{array}$ \\
\hline Data Date: & 2004 & 2004 & 2004 & 2002 \\
\hline Units: & $\begin{array}{l}\text { percentile } \\
\text { rank }\end{array}$ & $\begin{array}{l}\text { percentile } \\
\text { rank }\end{array}$ & $\begin{array}{l}\text { percentile } \\
\text { rank }\end{array}$ & $\begin{array}{l}\text { no. of INGOs } \\
\text { with } \\
\text { memberships } \\
\text { per million } \\
\text { population }\end{array}$ \\
\hline Source: & World Bank & World Bank & World Bank & EarthTrends \\
\hline Bhutan & 53.4 & 51.7 & 59.9 & 64.5 \\
\hline Botswana & 76.9 & 79.8 & 70.5 & 419.8 \\
\hline Brazil & 58.2 & 58.1 & 46.9 & 18.0 \\
\hline China & 60.1 & 35.0 & 40.6 & 3.4 \\
\hline Guyana & 49.0 & 47.3 & 40.1 & 701.9 \\
\hline India & 55.8 & 26.6 & 50.7 & 3.0 \\
\hline Indonesia & 40.9 & 36.9 & 20.8 & 8.2 \\
\hline Iran & 28.8 & 7.9 & 23.2 & 14.3 \\
\hline Jamaica & 60.6 & 56.7 & 43.5 & 331.7 \\
\hline Lao & 14.4 & 9.9 & 8.2 & 43.4 \\
\hline Lebanon & 42.3 & 31.0 & 43.5 & 280.1 \\
\hline Malaysia & 81.3 & 64.5 & 64.7 & 86.7 \\
\hline Maldives & 66.8 & 51.7 & 36.7 & 493.5 \\
\hline Mauritius & 70.7 & 62.6 & 78.3 & 660.7 \\
\hline Mexico & 56.7 & 68.0 & 45.9 & 27.1 \\
\hline Mongolia & 36.5 & 57.6 & 56.5 & 160.4 \\
\hline Nepal & 17.8 & 25.1 & 24.2 & 32.2 \\
\hline Philippines & 46.2 & 49.8 & 32.4 & 24.5 \\
\hline Sri Lanka & 45.7 & 59.6 & 53.1 & 68.0 \\
\hline Thailand & 65.4 & 51.2 & 51.7 & 30.1 \\
\hline Turkey & 57.2 & 48.8 & 54.6 & 35.6 \\
\hline Turkmenistan & 5.3 & 1.0 & 5.8 & 33.9 \\
\hline Vietnam & 44.2 & 27.6 & 35.7 & 10.9 \\
\hline
\end{tabular}


Table G.1d: Social Indicators

\begin{tabular}{|c|c|c|c|}
\hline & $\begin{array}{l}\text { Illiteracy rate } \\
\text { (age } 15 \text { \& over) }\end{array}$ & $\begin{array}{c}\text { Gender } \\
\text { Empowerment: } \\
\text { Proportion of seats } \\
\text { held by women in } \\
\text { national parliament }\end{array}$ & Population \\
\hline Data Date: & 1999 & various & 2000 \\
\hline Units: & $\%$ & $\%$ & thousand people \\
\hline Source: & $\begin{array}{l}\text { UNEP GEO } \\
\text { Data Portal }\end{array}$ & World Bank & $\begin{array}{l}\text { UNEP GEO } \\
\text { Data Portal }\end{array}$ \\
\hline Bhutan & $57.8^{1}$ & 9 & 2063 \\
\hline Botswana & 23.6 & 17 & 1725 \\
\hline Brazil & 15.1 & 9 & 171796 \\
\hline China & 16.5 & 22 & 1282022 \\
\hline Guyana & 1.6 & 20 & 759 \\
\hline India & 43.5 & 9 & 1016938 \\
\hline Indonesia & 13.7 & 8 & 212261 \\
\hline Iran & 24.3 & 4 & 66443 \\
\hline Jamaica & 13.6 & 12 & 2580 \\
\hline Lao & 52.7 & 23 & 5279 \\
\hline Lebanon & 14.4 & 2 & 3478 \\
\hline Malaysia & 13 & 10 & 23001 \\
\hline Maldives & 3.8 & 6 & 291 \\
\hline Mauritius & 15.8 & 6 & 1186 \\
\hline Mexico & 8.9 & 16 & 98933 \\
\hline Mongolia & 37.7 & 11 & 2500 \\
\hline Nepal & 59.6 & 6 & 23518 \\
\hline Philippines & 4.9 & 18 & 75711 \\
\hline Sri Lanka & 8.6 & 4 & 18595 \\
\hline Thailand & 4.7 & 9 & 60925 \\
\hline Turkey & 15.4 & 4 & 68281 \\
\hline Turkmenistan & $1.2^{2}$ & 26 & 4643 \\
\hline Vietnam & 6.9 & 27 & 78137 \\
\hline Notes: & & & \\
\hline
\end{tabular}


Table G.2a: Environmental Indicators

\begin{tabular}{|c|c|c|c|}
\hline & $\begin{array}{c}\text { MSW } \\
\text { Generation } \\
\text { rate }\end{array}$ & $\begin{array}{l}\text { Paper and } \\
\text { paperboard } \\
\text { consumption } \\
\text { per capita }\end{array}$ & $\begin{array}{c}\text { Agenda 21: } \\
\text { national } \\
\text { reporting status }\end{array}$ \\
\hline Data Date: & varies $^{1}$ & 2002 & 2002 \\
\hline Units: & $\mathrm{kg} /$ person/day & $\mathrm{kg} /$ person/yr & status $^{2}$ \\
\hline Source: & various $^{3}$ & EarthTrends & EarthTrends \\
\hline Bhutan & 0.300 & 0.04 & 1 \\
\hline Botswana & 0.330 & 5.65 & 2 \\
\hline Brazil & 0.854 & 42.04 & 3 \\
\hline China & 1.081 & 34.24 & 2 \\
\hline Guyana & 0.545 & 8.64 & 2 \\
\hline India & 0.456 & 4.28 & 2 \\
\hline Indonesia & 0.697 & 22.61 & 3 \\
\hline Iran & 0.888 & 8.02 & 2 \\
\hline Jamaica & 1.000 & 15.65 & 2 \\
\hline Lao & 0.750 & 0.60 & 1 \\
\hline Lebanon & 0.500 & 45.02 & 2 \\
\hline Malaysia & 0.650 & 75.46 & 2 \\
\hline Maldives & 2.480 & 3.60 & 1 \\
\hline Mauritius & 1.300 & 30.7 & 3 \\
\hline Mexico & 0.318 & 54.65 & 3 \\
\hline Mongolia & 0.716 & 1.76 & 2 \\
\hline Nepal & 0.480 & 0.60 & 3 \\
\hline Philippines & 0.431 & 18.53 & 3 \\
\hline Sri Lanka & 0.542 & 3.72 & 3 \\
\hline Thailand & 1.443 & 30.80 & 3 \\
\hline Turkey & 0.970 & 35.39 & 3 \\
\hline Turkmenistan & 0.399 & 0.20 & 1 \\
\hline Vietnam & 0.575 & 6.51 & 2 \\
\hline
\end{tabular}

Notes:

${ }^{1}$ For the date of each country's MSW generation rate, refer to Table E. 1 in Appendix E.

${ }^{2}$ Status: $1=$ non-reporting, $2=$ pending, $3=$ submitted. See detailed definition in Appendix H.

${ }^{3}$ For each country's source, refer to Table 3.1 in Chapter Three of the thesis main body. 
Table G.2b: Environmental Indicators

\begin{tabular}{|c|c|c|c|}
\hline & $\begin{array}{c}\text { Protected } \\
\text { Area Ration to } \\
\text { Surface Area }\end{array}$ & $\begin{array}{c}\text { Access to } \\
\text { improved } \\
\text { water source } \\
\end{array}$ & $\begin{array}{l}\text { Access to } \\
\text { improved } \\
\text { sanitation } \\
\end{array}$ \\
\hline Data Date: & 1997 & 2000 & 2000 \\
\hline Units: & Ratio & $\%$ & $\%$ \\
\hline Source: & $\begin{array}{l}\text { UNEP GEO } \\
\text { Data Portal }\end{array}$ & EarthTrends & EarthTrends \\
\hline Bhutan & 0.21 & 62 & 70 \\
\hline Botswana & 0.18 & 95 & 66 \\
\hline Brazil & 0.06 & 87 & 76 \\
\hline China & $0.12^{1}$ & 75 & 40 \\
\hline Guyana & 0.00 & 94 & 87 \\
\hline India & 0.04 & 84 & 28 \\
\hline Indonesia & 0.18 & 78 & 55 \\
\hline Iran & 0.05 & 92 & 83 \\
\hline Jamaica & 0.09 & 92 & 99 \\
\hline Lao & 0.12 & 37 & 30 \\
\hline Lebanon & 0.00 & 100 & 99 \\
\hline Malaysia & 0.05 & $95^{2}$ & $96^{3}$ \\
\hline Maldives & $0.00^{1}$ & 100 & 56 \\
\hline Mauritius & 0.08 & 100 & 99 \\
\hline Mexico & 0.08 & 88 & 74 \\
\hline Mongolia & 0.10 & 60 & 30 \\
\hline Nepal & 0.09 & 88 & 28 \\
\hline Philippines & 0.05 & 86 & 83 \\
\hline Sri Lanka & 0.13 & 77 & 94 \\
\hline Thailand & 0.14 & 84 & 96 \\
\hline Turkey & 0.02 & 82 & 90 \\
\hline Turkmenistan & 0.04 & $71^{2}$ & $62^{4}$ \\
\hline Vietnam & 0.03 & 77 & 47 \\
\hline
\end{tabular}

Notes:

${ }^{1}$ EarthTrends.

${ }^{2}$ UNEP GEO Data Portal, 2002 Improved Drinking Water Coverage - Total Population [Percent of Total Population].

${ }^{3}$ UNEP GEO Data Portal, 1996 Improved Sanitation Coverage - Total Population [Percent of Total Population].

${ }^{4}$ UNEP GEO Data Portal, 2002 Improved Sanitation Coverage - Total Population [Percent of Total Population]. 
Table G.2c: Environmental Indicators

\begin{tabular}{|c|c|c|c|}
\hline & $\begin{array}{l}\text { Water Use } \\
\text { per capita }\end{array}$ & $\begin{array}{c}\text { Water Use as } \\
\text { Percentage of } \\
\text { Renewable } \\
\text { Resources } \\
\end{array}$ & $\begin{array}{c}\text { Recycling } \\
\text { Activity }\end{array}$ \\
\hline Data Date: & 2000 & 2000 & varies $^{1}$ \\
\hline Units: & $\mathrm{m}^{3} /$ person & $\%$ & $\begin{array}{l}\mathrm{Yes}=1 \\
\mathrm{No}=0\end{array}$ \\
\hline Source: & $\begin{array}{l}\text { UNEP GEO } \\
\text { Data Portal }\end{array}$ & $\begin{array}{l}\text { UNEP GEO } \\
\text { Data Portal }\end{array}$ & various $^{2}$ \\
\hline Bhutan & 204 & 0.4 & 0 \\
\hline Botswana & 81 & 1.0 & 1 \\
\hline Brazil & 345 & 0.7 & 1 \\
\hline China & 492 & 21.8 & 1 \\
\hline Guyana & 2164 & 0.7 & 1 \\
\hline India & 635 & 33.9 & 1 \\
\hline Indonesia & 390 & 2.9 & 1 \\
\hline Iran & 1097 & 53.0 & 1 \\
\hline Jamaica & 159 & 4.4 & 0 \\
\hline Lao & 567 & 0.9 & 0 \\
\hline Lebanon & 394 & 28.4 & 0 \\
\hline Malaysia & 392 & 1.6 & 0 \\
\hline Maldives & $17^{3}$ & $17.7^{4}$ & 0 \\
\hline Mauritius & 516 & 27.7 & 0 \\
\hline Mexico & 791 & 17.1 & 0 \\
\hline Mongolia & 178 & 1.3 & 1 \\
\hline Nepal & 433 & 4.8 & 1 \\
\hline Philippines & 377 & 6.0 & 1 \\
\hline Sri Lanka & 678 & 25.2 & 1 \\
\hline Thailand & 1429 & 21.2 & 1 \\
\hline Turkey & 549 & 16.2 & 1 \\
\hline Turkmenistan & 5307 & 40.5 & 0 \\
\hline Vietnam & 914 & 8.0 & 1 \\
\hline
\end{tabular}

Notes:

${ }^{1}$ For the date of each country's recycling activity, refer to Table E. 2 in Appendix E.

${ }^{2}$ For each country's source, refer to Table 3.1 in Chapter Three of the thesis main body.

${ }^{3}$ EarthTrends, 1987.

${ }^{4}$ EarthTrends, 1987 Withdrawals as a percentage of actual renewable water resources. 
Table G.3a: Economic Indicators

\begin{tabular}{|c|c|c|c|c|}
\hline & $\begin{array}{l}\text { Household Final } \\
\text { Consumption } \\
\text { Expenditure - } \\
\text { per capita } \\
\end{array}$ & $\begin{array}{c}\text { Economically } \\
\text { Active } \\
\text { Population }\end{array}$ & $\begin{array}{l}\text { GDP, PPP } \\
\text { per capita }\end{array}$ & $\begin{array}{l}\text { Industrialized? } \\
\text { Percent of labor } \\
\text { force in industry }\end{array}$ \\
\hline Data Date: & 1999 & 2000 & 2003 & various \\
\hline Units: & $\begin{array}{l}\text { Constant } 1995 \\
\text { US\$ per Person }\end{array}$ & $\%$ & $\begin{array}{c}\text { current } \\
\text { international } \\
\text { dollars }\end{array}$ & $\%$ \\
\hline Source: & $\begin{array}{l}\text { UNEP GEO } \\
\text { Data Portal }\end{array}$ & $\begin{array}{c}\text { adapted }^{1} \text { from } \\
\text { UNEP GEO } \\
\text { Data Portal }\end{array}$ & EarthTrends & CIA \\
\hline Bhutan & 0 & 48.7 & $1400^{2}$ & 2.0 \\
\hline Botswana & 1761 & 39.0 & 8359 & $10.7^{4}$ \\
\hline Brazil & 2676 & 46.1 & 7767 & 14.0 \\
\hline China & 333 & 59.8 & 4995 & 22.0 \\
\hline Guyana & 613 & 42.2 & 4194 & $44.5^{5}$ \\
\hline India & 278 & 43.5 & 2909 & 17.0 \\
\hline Indonesia & 698 & 48.5 & 3364 & 16.0 \\
\hline Iran & 816 & 36.4 & 7145 & 25.0 \\
\hline Jamaica & 903 & 49.8 & 4184 & 16.6 \\
\hline Lao & 0 & 49.7 & 1896 & 0.0 \\
\hline Lebanon & 0 & 36.1 & 5073 & $31.0^{6}$ \\
\hline Malaysia & 2003 & 41.0 & 9696 & 36.0 \\
\hline Maldives & 0 & 42.3 & $3900^{3}$ & 18.0 \\
\hline Mauritius & 2595 & 42.7 & 11258 & 36.0 \\
\hline Mexico & 2359 & 41.2 & 9136 & 24.0 \\
\hline Mongolia & 0 & 51.8 & 1802 & 10.0 \\
\hline Nepal & 178 & 46.2 & 1418 & 3.0 \\
\hline Philippines & 863 & 41.4 & 4321 & 16.0 \\
\hline Sri Lanka & 645 & 45.9 & 3776 & 17.0 \\
\hline Thailand & 1384 & 61.4 & 7580 & 14.0 \\
\hline Turkey & 2106 & 45.7 & 6749 & 22.8 \\
\hline Turkmenistan & 0 & 44.1 & 5884 & 13.8 \\
\hline Vietnam & 256 & 52.3 & 2490 & 37.0 \\
\hline
\end{tabular}

Notes:

${ }^{1}$ The original data was in absolute economically active population. In order to make easier comparisons between countries, the absolute economically active population in 2000 was divided by the national population in 2000 and multiplied by 100 to offer a percentage of economically active population.

${ }^{2}$ CIA World Factbook, 2003 estimate.

${ }^{3}$ CIA World Factbook, 2002 estimate.

${ }^{4}$ Bollinger, L. and Stover, J. "The Economic Impacts of AIDS in Botswana," The Policy Project, The

Futures Group International, September 1999, http://www.policyproject.com/pubs/SEImpact/botswana.pdf.

${ }^{5}$ CIA World Factbook 1996, http://www.umsl.edu/services/govdocs/wofact96/112.htm.

${ }^{6}$ Mapquest World Atlas, Lebanon, http://www.mapquest.com/atlas/?region=lebanon. 
Table G.3b: Economic Indicators

\begin{tabular}{|c|c|c|c|c|}
\hline & $\begin{array}{c}\text { GNI per } \\
\text { capita, Atlas } \\
\text { method }\end{array}$ & $\begin{array}{l}\text { Exports of } \\
\text { Goods \& } \\
\text { Services } \\
\end{array}$ & $\begin{array}{l}\text { Imports of } \\
\text { Goods \& } \\
\text { Services } \\
\end{array}$ & $\begin{array}{c}\text { Total Unemployment } \\
\text { - Percent of Total } \\
\text { Labor Force } \\
\end{array}$ \\
\hline Data Date: & 2003 & 2002 & 2002 & 2001 \\
\hline Units: & current USD & $\begin{array}{l}\text { million } \\
\text { constant } \\
1995 \text { USD }\end{array}$ & $\begin{array}{l}\text { million } \\
\text { constant } \\
1995 \text { USD }\end{array}$ & $\%$ \\
\hline Source: & World Bank & $\begin{array}{l}\text { UNEP GEO } \\
\text { Data Portal }\end{array}$ & $\begin{array}{l}\text { UNEP GEO } \\
\text { Data Portal }\end{array}$ & $\begin{array}{l}\text { UNEP GEO } \\
\text { Data Portal }\end{array}$ \\
\hline Bhutan & 630 & $163.0^{1,4}$ & $331.0^{1,4}$ & $1.2^{5}$ \\
\hline Botswana & 3530 & 3181.0 & 2630.7 & $23.8^{6 \mathrm{a}}$ \\
\hline Brazil & 2720 & 91394.0 & 68944.0 & $11.5^{6 \mathrm{a}}$ \\
\hline China & 1100 & 468691.0 & 651634.0 & 3.6 \\
\hline Guyana & 900 & 677.0 & 770.8 & $9.1^{7}$ \\
\hline India & 540 & 87757.0 & 74043.6 & $9.2^{6 \mathrm{a}}$ \\
\hline Indonesia & 810 & 59505.0 & 48017.3 & 8.1 \\
\hline Iran & 2010 & 24537.0 & 1346.2 & $11.2^{6 \mathrm{a}}$ \\
\hline Jamaica & 2980 & $3768.0^{2,4}$ & $5071.0^{2,4}$ & $15.0^{6 \mathrm{a}}$ \\
\hline Lao & 340 & $500.0^{3,4}$ & $656.0^{3,4}$ & $5.7^{6 \mathrm{~b}}$ \\
\hline Lebanon & 4040 & 2011.0 & 5304.3 & $18.0^{6 \mathrm{~b}}$ \\
\hline Malaysia & 3880 & 121784.0 & 104809.4 & 3.9 \\
\hline Maldives & 2350 & 605.0 & 472.9 & $0.0^{8}$ \\
\hline Mauritius & 4100 & 3402.0 & 3503.8 & 9.2 \\
\hline Mexico & 6230 & 163450.0 & 193598.6 & 1.7 \\
\hline Mongolia & 480 & $785.0^{2,4}$ & $980.0^{2,4}$ & $6.7^{6 \mathrm{c}}$ \\
\hline Nepal & 240 & $1453.0^{2,4}$ & $2080.0^{2,4}$ & $47.0^{6 \mathrm{~d}}$ \\
\hline Philippines & 1080 & 34907.0 & 40672.4 & 9.8 \\
\hline Sri Lanka & 930 & 6667.0 & 9389.4 & 8.2 \\
\hline Thailand & 2190 & 106107.0 & 85083.2 & 2.6 \\
\hline Turkey & 2800 & 68331.0 & 67838.3 & 8.5 \\
\hline Turkmenistan & 1120 & 1326.0 & 1142.3 & $60.0^{6 \mathrm{a}}$ \\
\hline Vietnam & 480 & $20908.0^{2,4}$ & $21685.0^{2,4}$ & $1.9^{6 \mathrm{a}}$ \\
\hline $\begin{array}{l}\text { Notes: } \\
\text { EarthTrends, } 2000 \\
\text { EarthTrends, } 2001 \\
\text { EarthTrends, } 1998 \\
\text { Converted to } 1995 \\
1999 \text { USD } \\
1998 \text { USD }\end{array}$ & $\begin{array}{l}\text { million current } \mathrm{U} \\
\text { million current } \mathrm{U} \\
\text { million current } \mathrm{U} \\
\text { JSD using Econol } \\
=2000 \text { USD / (1-ir } \\
=1999 \text { USD / }(1-\text { ir }\end{array}$ & $\begin{array}{l}\text { dollars. } \\
\text { dollars. } \\
\text { dollars. } \\
\text { c History and the f } \\
\text { ation rate of US in } \\
\text { ation rate of US in }\end{array}$ & $\begin{array}{l}\text { ollowing equations } \\
\text { 2000) } \\
\text { 1999) }\end{array}$ & \\
\hline $\begin{array}{l}\quad \ldots . \\
1995 \text { USD } \\
2.5 \% \text { of EAP as qu } \\
\text { ttp://www.employ } \\
\text { CIA World Factbo } \\
\text { CIA World Factbo } \\
\text { CIA World Factbo }\end{array}$ & $\begin{array}{l}=1996 \text { USD / }(1-\text { ir } \\
\text { ted in } \\
\text { ent.gov.bt/news } \\
\text { k, a }=2004 \text { estima } \\
\text { k, 2000, commen }\end{array}$ & $\begin{array}{l}\text { ion rate of US in } \\
\text { e.php?action=dis } \\
=1997 \text { estimate, } \\
\text { hat this is underst }\end{array}$ & $\begin{array}{l}\text { 1996) } \\
\text { play_news_more\& } \\
\text { c=2003 estimate, } d \\
\text { ated. }\end{array}$ & $\begin{array}{l}\mathrm{d}=71 \text { \&reads }=21 . \\
2001 \text { estimate. }\end{array}$ \\
\hline
\end{tabular}




\section{APPENDIX H}

\section{DEFINITIONS OF SOCIAL, ENVIRONMENTAL, AND ECONOMIC INDICATORS}

This appendix provides all definitions of each indicator for which data were provided in Appendix G. The definitions are group by type of indicator (social, environmental, economic) and follow the same order that the indicators were presented in Appendix G.

\section{Social}

\section{Human Development Index}

The HDI (human development index) is a summary measure of human development. It measures the average achievements in a country in three basic dimensions of human development: - A long and healthy life, as measured by life expectancy at birth. Knowledge, as measured by the adult literacy rate (with two-thirds weight) and the combined primary, secondary and tertiary gross enrolment ratio (with one-third weight). A decent standard of living, as measured by GDP per capita (PPP US\$).

\section{Population Density}

Population density is midyear population divided by land area in square kilometers. Population is based on the de facto definition of population, which counts all residents regardless of legal status or citizenship--except for refugees not permanently settled in the country of asylum, who are generally considered part of the population of their country of origin. Population figures for 1960-2000 are estimates and those for years 2001 and 2002 are projections. Projection data presented are consistent with the medium variant of the 2002 Revision of World Population Prospects at the national level. Land area is a country's total area, excluding area under inland water bodies, national claims to continental shelf, and exclusive economic zones. In most cases the definition of inland water bodies includes major rivers and lakes. Data source for Land Area: FAOSTAT (Data as of August 2002). Data for years 2001 and 2002 are assumed as unvaried from year 2000. 


\section{Life Expectancy}

The average number of years of life expected by a hypothetical cohort of individuals who would be subject during all their lives to the mortality rates of a given period. It is expressed as years.

\section{Population Growth Rate}

The total increase of the population during a given period (usually a year) based on the mean population of that period.

\section{Sex Ratio of the Total Population}

Number of males per 100 females in the population.

\section{Telephone Main Lines in Use per 1000 People}

The number of telephone line connecting the subscriber's terminal equipment to the public switched network and which have a dedicated port in the telephone exchange equipment.

\section{Television Sets per 1000 People}

Apparatus for displaying pictures transmitted by radio transmission, usually with sound. ISIC2 code 383201 .

\section{Government Effectiveness}

One of six dimensions of the Governance Indicators combining responses on the quality of public service provision, the quality of the bureaucracy, the competence of civil servants, the independence of the civil service from political pressures, and the credibility of the government's commitment to policies.

\section{Political Stability}

One of six dimensions of the Governance Indicators combining several indicators which measure perceptions of the likelihood that the government in power will be destabilized or overthrown by possibly unconstitutional and/or violent means, including domestic violence and terrorism.

\section{Regulatory Quality}

One of six dimensions of the Governance Indicators focusing more on the policies themselves, including measures of the incidence of market-unfriendly policies such as price controls or inadequate bank supervision, as well as perceptions of the burdens imposed by excessive regulation in areas such as foreign trade and business development.

\section{Rule of Law}

One of six dimensions of the Governance Indicators that is a measure of the extent of corruption, conventionally defined as the exercise of public power for private gain. It is based on scores of variables from polls of experts and surveys. 


\section{INGOs membership density}

[Environmental Governance and Institutions]

\section{Definition}

This variable is a measurement of the number of international non-governmental organizations that has each member organizations or individuals in each country. If an organization has 1 million members, or only one it is still counted as one membership. Membership density refers to the number of memberships per 1 million population.

According to Resolution 288 of the Economic and Social Council of the United Nations, "any international organization which is not established by intergovernmental agreement shall be considered as a non-governmental organization." Non-governmental organizations (NGOs) can also include "organizations which accept members designated by government authorities, provided that such membership does not interfere with the free expression of views of the organization" (Resolution 1296).

The Union of International Associations (UIA) compiles as complete a list as possible of international non-governmental organizations, based on seven criteria (explained below): aims, membership, structure, officers, finance, activities, and relations with other organizations. The UIA codes organizations by type. The following types of organizations are included in this dataset:

* federations of international organizations

* universal membership organizations

* intercontinental membership organizations

* regionally defined membership organizations

* organizations emanating from places, persons, or other bodies

* organizations having a special form, including foundations and funds.

The following types of organizations are not included in the country and region totals:

* inactive or dissolved organizations

* recently reported or proposed organizations

* subsidiary and internal bodies

* national organizations

* religious orders, fraternities, and secular institutions

* autonomous conference series

* multilateral treaties and agreements

* currently inactive non-conventional bodies

Years Covered and Frequency of Update 
The data reported here were compiled by Anheier et al. for Global Civil Society 2003 and cover the years 1990-1992 and 2000-2002. The Union of International Associations publishes their yearbook annually and has been keeping records on the number of NGOs since 1950; however, their definitions and reporting methods have not remained consistent over that time period.

Methodology

The editors of the Yearbook of International Organizations identify eligible INGOs based on the following seven criteria:

1. Aims: The aim of the organization must be international in character. Societies devoted solely to commemorating individuals are excluded.

2. Members: There must be members from at least three countries. Closed groups are excluded.

3. Structure: There must be a permanent headquarters and some continuity of operation.

4. Officers: Headquarters and officers should be rotated among countries at designated intervals.

5. Finance: Substantial budgetary contributions must come from at least 3 countries, and there must be no attempt to make profits for distribution to members.

6. Relations with other organizations: Organizations must be independent from other organizations and elect their own officers. Internal or subsidiary committees are excluded.

7. Activities: There must be evidence of current activity.

Data Reliability

The compilation of such a massive data set inevitably leads to misreporting and underreporting of organizations. The Union of International Associations frequently lists and categorizes based on an organization's self-description. Users should keep in mind that actual estimates of the number of INGOs vary widely; while the global number of INGOs reported here is about 250,000, some informal estimates put the number of international NGOs at over one million.

Source

Center for the Study of Global Governance.2003. Global Civil Society 2003 (available on-line at http://www.lse.ac.uk/Depts/global/Yearbook/). Oxford: Oxford University Press.

Data were collected from the Union of International Associations' Yearbook of International Organizations by the Center for the Study of Global Governance.

\section{Illiteracy rate (age 15 \& over)}

Adult illiteracy rate is the percentage of people ages 15 and above who cannot, with understanding, read and write a short, simple statement on their everyday life.

Gender Empowerment: Proportion of seats held by women in national parliament 


\section{Population}

\section{DEFINITION}

The proportion of seats held by women in national parliaments is the number of seats held by women expressed as a percentage of all occupied seats.

\section{GOAL AND TARGET ADDRESSED}

Goal 3. Promote gender equality and empower women

Target 4 . Eliminate gender disparity in primary and secondary education preferably by 2005, and in all levels of education no later than 2015

\section{RATIONALE}

Women's representation in parliaments is one aspect of women's opportunities in political and public life, and it is therefore linked to women's empowerment.

\section{METHOD OF COMPUTATION}

The indicator is obtained by dividing the number of parliamentary seats occupied by women by the total number of seats occupied. National parliaments consist of one or two chambers. For international comparisons, generally only the single or lower house is considered in calculating the indicator.

\section{DATA COLLECTION AND SOURCE}

At the national level, the data come from the records of national parliaments. National parliaments also report the total number of parliamentary seats and the number occupied by women and men to the Inter-Parliamentary Union (IPU), which regularly compiles international data series and global and regional aggregates.

\section{PERIODICITY OF MEASUREMENT}

The data are commonly available from national parliaments and updated after an election. National parliaments also transmit their data to the IPU at least once a year and when the numbers change significantly, such as after an election.

\section{GENDER ISSUES}

Women are underrepresented in all decision-making bodies and within political parties, particularly at the higher echelons. Women still face many practical obstacles to the full exercise of their role in political life.

\section{COMMENTS AND LIMITATIONS}

Parliaments vary considerably in their independence and authority, though they generally engage in law-making, oversight of Government and representation of the electorate.

In terms of measuring women's real political decision-making, this indicator may not be sufficient, because women still face many obstacles in fully and efficiently carrying out their parliamentary mandate. Thus, being a member of parliament, especially in 
developing countries and emerging democracies, does not guarantee that a woman has the resources, respect or constituency to exercise significant influence.

\section{REFERENCES AND INTERNATIONAL DATA COMPARISONS}

INTER-PARLIAMENTARY UNION (2003). Women in National Parliaments. Internet site http://www.ipu.org/wmn-e/world.htm. Geneva.

UNITED NATIONS (2003). Millennium Indicators Database. Statistics Division Internet site http://millenniumindicators.un.org.

UNITED NATIONS DEVELOPMENT FUND FOR WOMEN (2000). Progress of the

World's Women. New York. available from

http://www.unifem.undp.org/progressww/2000.

UNITED NATIONS DEVELOPMENT PROGRAMME (2003 and annual). Human

Development Report. New York: Oxford University Press. Available at http://hdr.undp.org.

The IPU regularly compiles international data series and global and regional aggregates.

\section{AGENCIES}

National parliaments \& Inter-Parliamentary Union

\section{Environmental}

\section{MSW Generation rate}

The rate, in terms of kilograms per person per day, of waste generated in households, commercial establishments, institutions, and businesses. Includes used paper, discarded cans and bottles, food scraps, yard trimmings, and other items. Not Included: industrial process wastes, agricultural wastes, mining wastes, and sewage sludge.

\section{Paper and paperboard consumption per capita}

[Energy and Resources — Resource Consumption]

\section{Definition:}

Consumption of paper and paperboard per capita is the average amount of paper and paperboard used per person.

Paper and paperboard includes newsprint, printing and writing paper, packaging paper, household and sanitary paper, and other paper and paperboard. All production data refer to both coniferous and non-coniferous species.

Years Covered and Frequency of Update:

Paper and paperboard data are available for most countries and regions from 1961 to 2002. Data are updated annually by the Food and Agriculture Organization. FAO posted the 2002 updates on-line in December, 2004. 
Population data is updated every two years by the United Nations Population Division. The data used for these calculations were updated in 2004.

Methodology:

Paper consumption per capita is calculated by WRI using FAO data with the crude formula:

Consumption per capita $=($ Production + Imports - Exports $) /$ Population

Therefore, this calculation does not take into account the holdover of paper stocks from year to year. Where production data is unavailable, production is assumed to be zero and consumption is equal to imports minus exports. Paper and paperboard production data are available here.

Per capita calculations use the United Nations Population Division dataset. For information on population Methodology, please see the Earthtrends technical notes for "Population: Total, both sexes."

Production is the amount of primary paper and paperboard produced, even though a portion of it may immediately be consumed in the production of another product. Imports and exports are the amount of paper and paperboard shipped into and out of the country, respectively, for domestic consumption or processing. "In-transit" products are excluded. Some imports and exports for re-export may be included.

FAO compiles forest products data from responses to annual questionnaires sent to national governments. These estimates are reviewed for accuracy and, in cases where the data are questionable, data from other sources such as national statistical yearbooks are used to supplement them. In some cases, FAO prepares its own estimates.

Data Reliability:

The data on paper production and trade reported to FAO are governed by established accounting practices and are therefore generally considered to be reliable. However, the numbers reported here are based on a wide variety of sources of disparate quality.

Source

Trade in Paper: Food and Agriculture Organization of the United Nations (FAO), 2004. FAOSTAT on-line statistical service, Available online at: http://apps.fao.org (FAO: Rome).

Population: Population Division of the Department of Economic and Social Affairs of the United Nations Secretariat, 2003. World Population Prospects: The 2002 Revision. Dataset on CD-ROM. New York: United Nations. Available on-line at http://www.un.org/esa/population/ordering.htm 


\section{Agenda 21: national reporting status}

[Environmental Governance and Institutions]

National Agenda 21 Reporting Status indicates if a country has submitted a report on the status of its implementation of Agenda 21 in relation to the specific themes. Countries with reports "pending" submission are participants in the Agenda 21 process that have not yet submitted reports to in 2002. "Non-reporting" countries are not participating in the Agenda 21 process. Country reports focus on social, economic, and environmental issues, including: combating poverty; energy; health; transport; agriculture; atmosphere; biodiversity; forests; freshwater; hazardous, solid, and radioactive wastes; land management; oceans; and toxic chemicals. Agenda 21 was created as a result of the 1992 Earth Summit and is a comprehensive plan of action to be taken globally, nationally and locally by organizations of the United Nations System, Governments, and Major Groups in every area with human impacts on the environment.

\section{Source}

United Nations Commission on Sustainable Development (UNSD). 2002. National Implementation of Agenda 21: The Report. Available on-line at http://www.un.org/esa/agenda21/natlinfo/wssd/NIA_REPORT.pdf. New York: UNSD

\section{Protected Area Ration to Surface Area}

Millennium Development Indicator (MDG) Ratio of area protected to maintain biological diversity to surface area. Protected land and water area: Area of land and/or sea especially dedicated to the protection and maintenance of biological diversity, and of natural and associated cultural resources, and managed through legal or other effective means. (World Conservation Union, 1994). Reference: World Conservation Union. Guidelines for Protected Area Management Categories, CNPPA with the assistance of the World Conservation Monitoring Centre. Gland, Switzerland and Cambridge, United Kingdom, $1994 . \quad$ Available at www.wcmc.org.uk/protected_areas/categories/eng/index.html

\section{Access to an improved water source}

[Population, Health and Human Well-being — Water and Sanitation]

\section{Definition:}

An improved water source includes any of the following types of drinking water sources: household connections, public standpipes, boreholes, protected dug wells, protected springs, and rainwater collection. At least 20 liters per person per day of this water must be available within one kilometer of a user's dwelling. WHO emphasizes that these data measure access to an improved water supply--access to a safe water supply cannot be adequately measured on a global scale. 
Safe water provides health and economic benefits to households and individuals; nearby access to this water allows women and children to spend less time fetching water and more time on other tasks. A poor water supply and sanitation system can lead to a number of diseases, including diarrhea, intestinal worms, trachoma, schistosomiasis, and cholera. Examples of unimproved water sources include: unprotected wells and springs, vendor-provided water, tanker-provided water, and bottled water. These last examples are considered "unimproved" because they are not consistently available in sufficient quantities.

Years Covered and Frequency of Update:

Data are for 1990 and 2000. These data were collected under the WHO-UNICEF Joint Monitoring Program and published in 2001.

UNICEF publishes water and sanitation data annually in their "State of the World's Children" report, available on-line at www.unicef.org. However, the recent data contained in the report are usually based on studies that are conducted less frequently than every year and based on varying methodologies. The reader should therefore not attempt to conduct a time series by collecting data from multiple copies of State of the World's Children.

Methodology:

WHO and UNICEF substantially revised their data collection methodologies for the Global Water Supply and Sanitation 2000 Report. All countries were instructed to use the same, specific definition of an improved water supply.

Data were collected from assessment questionnaires and household surveys. WHO and UNICEF staff completed the assessment questionnaires by compiling national census reports, Demographic Health Surveys(DHS), and UNICEF Multiple Indicator Cluster Surveys (MICS). The household-level information collected by DHS and MICS shows the facilities that are actually being used, not just the facilities that have been installed. The surveys also measure self-built facilities installed by households and local communities. These facilities were often ignored in previous estimates.

After data collection, survey and census data were plotted on a graph for each country to show coverage in available years (not necessarily 1990 and 2000). A trend line was drawn and reviewed by a panel of experts to determine the amount of safe water available in 1990 and 2000. Particular care was taken with the 40 most populous developing countries. The country-level graphs with trend lines are available on-line at http://www.childinfo.org/eddb/water/database.htm.

For more information, please consult the "Annex A: Methodology" section of the Global Water Supply and Sanitation Assessment 2000 Report, available on-line at http://www.who.int/water_sanitation_health/Globassessment/GlobalTOC.htm . 
Data Reliability:

These data are the result of an intensive and concerted effort to arrive at the best possible estimates of the proportion of the population with an improved water supply. The data has become more reliable as WHO and UNICEF shift from provider-based information (national census estimates) to consumer-based information (survey data).

Nonetheless, users of this data set should keep in mind that the data used to arrive at estimates of an improved water source come from a wide variety of sources of disparate quality. Some countries have numerous sources of data covering the same period, allowing for cross-references, while other estimates are derived from many fewer sources of poor quality. Comparisons among countries should be made with care. The assessment does not account for intermittent or poor quality of water supplies. In addition, regions with higher overall levels of service tend to set stricter requirements for water access.

Source

United Nation's Children's Fund (UNICEF). 2001. State of the World's Children 2002 (available on-line at http://www.unicef.org/sowc02/). New York: UNICEF. Data were originally collected under the UNICEF-World Health Organization (WHO) Joint Monitoring Program.

\section{Access to improved sanitation}

[Population, Health and Human Well-being — Water and Sanitation]

\section{Definition:}

Improved sanitation includes any of the following excreta disposal facilities: connection to a public sewer, connection to a septic tank, pour-flush latrine, simple pit latrine, and ventilated improved pit latrine. WHO emphasizes that these data measure access to an improved excreta disposal system--access to a sanitary system cannot be adequately measured on a global scale.

A poor water supply and sanitation system can lead to a number of diseases, including diarrhea, intestinal worms, and cholera. Examples of an unimproved sanitation system include: open pit latrines, public or shared latrines, and service or bucket latrines (where excreta are manually removed).

Years Covered and Frequency of Update:

Data are for 1990 and 2000. These data were collected under the WHO-UNICEF Joint Monitoring Program and published in 2001.

UNICEF publishes water and sanitation data annually in their "State of the World's Children" report, available on-line at www.unicef.org. However, the recent data contained in the report are usually based on studies that are conducted less frequently 
than every year and based on varying methodologies. The reader should therefore not attempt to conduct a time series by collecting data from multiple copies of State of the World's Children.

Methodology:

WHO and UNICEF substantially revised their data collection methodologies for the Global Water Supply and Sanitation 2000 Report. All countries were instructed to use the same, specific definition of an adequate sanitation system.

Data were collected from assessment questionnaires and household surveys. WHO and UNICEF staff completed the assessment questionnaires by compiling national census reports, Demographic Health Surveys(DHS), and UNICEF Multiple Indicator Cluster Surveys (MICS). The household-level information collected by DHS and MICS shows the facilities that are actually being used, not just the facilities that have been installed. The surveys also measure self-built facilities installed by households and local communities. These facilities were often ignored in previous estimates.

After data collection, survey and census data were plotted on a graph for each country to show coverage in available years (not necessarily 1990 and 2000). A trend line was drawn and reviewed by a panel of experts to determine the amount of safe water available in 1990 and 2000. Particular care was taken with the 40 most populous developing countries. The country-level graphs with trend lines are available on-line at http://www.childinfo.org/eddb/sani/database.htm.

For more information, please consult the "Annex A: Methodology" section of the Global Water Supply and Sanitation Assessment 2000 Report, available on-line at http://www.who.int/water_sanitation_health/Globassessment/GlobalTOC.htm .

Data Reliability:

These data are the result of an intensive and concerted effort to arrive at the best possible estimates of the proportion of the population with an improved excreta disposal system. The data has become more reliable as WHO and UNICEF shift from provider-based information (national census estimates) to consumer-based information (survey data).

Nonetheless, users of this data set should keep in mind that the data come from a wide variety of sources of disparate quality. Some countries have numerous sources of data covering the same period, allowing for cross-references, while other estimates are derived from many fewer sources of poor quality. Comparisons among countries should be made with care. In addition, regions with higher overall levels of service tend to set stricter requirements for adequate sanitation.

\section{Source}


United Nation's Children's Fund (UNICEF). 2001. State of the World's Children 2002 (available on-line at http://www.unicef.org/sowc02/). New York: UNICEF. Data were originally collected under the UNICEF-World Health Organization (WHO) Joint Monitoring Program.

\section{Water Use per capita}

Annual gross quantity of water produced and used for agricultural, industrial and domestic purposes. It does not include other in situ-uses: energy, mining, recreation, navigation, fisheries and the environment, which are typically non consumptive uses of water. The typology of water use is independent from the source of water. Demands are covered by water productions: withdrawals from natural sources, fossil water abstraction ( non-renewable production), non conventional water productions ( reuse, desalination). The use of desalinated and treated wastewater is thus included. There are also referred to as non-conventional sources of water. water use $=$ agricultural water use + domestic water use+ industrial use. Some country, may use 'water withdrawal' when speaking about "water use"; however it is not correct when non conventional waters are used (water withdrawal is then lower than water use).

\section{Water Use as Percentage of Renewable Resources}

Data refer to total water use divided by total natural renewable resources, except for regional totals, where the internal renewable water resource (IRWR) estimates were used to avoid double counting. Data calculation made by UNEP/DEWA/GRID-Geneva. Water Use: Annual gross quantity of water produced and used for agricultural, industrial and domestic purposes. It does not include other in situ-uses: energy, mining, recreation, navigation, fisheries and the environment, which are typically non-consumptive uses of water. The typology of water use is independent from the source of water. Demands are covered by water productions: withdrawals from natural sources, fossil water abstraction (non-renewable production), non-conventional water productions (reuse, desalination). The use of desalinated and treated wastewater is thus included. There are also referred to as non-conventional sources of water. Water use $=$ agricultural water use + domestic water use + industrial use. Some country may use 'water withdrawal' when speaking about "water use"; however it is not correct when non-conventional waters are used (water withdrawal is then lower than water use). Total Natural renewable water resources: The sum of internal and external renewable water resources. It corresponds to the maximum theoretical amount of water available for a country on an average year on a long reference period. Internal renewable water resources (IRWR): That part of the water resources (surface water and groundwater) generated from endogenous precipitation. It is computed by adding up average annual surface runoff and groundwater recharge occurring within the country borders.

\section{Recycling Activity}

Substantial recovery of recyclable materials in municipal solid waste. If quantitative data on recycling activities were provided, then recycling was considered present when five- 
percent or more of the total MSW generated was recovered. When only qualitative data were provided, it was still attempted to assign whether or not a nation recycles. All data were translated to bimodal values of "yes" (1) or "no" (0) for whether a country participates in substantial recycling activity or not, respectively.

\section{Economic}

\section{Household Final Consumption Expenditure - per capita}

Household final consumption expenditure (private consumption) is the market value of all goods and services, including durable products (such as cars, washing machines, and home computers), purchased by households. It excludes purchases of dwellings but includes imputed rent for owner-occupied dwellings. It also includes payments and fees to governments to obtain permits and licenses. Here, household consumption expenditure includes the expenditures of nonprofit institutions serving households, even when reported separately by the country. Household final consumption expenditure per capita is calculated by UNEP / DEWA / GRID-Geneva using Household final consumption expenditure from the World Bank and the total population from the World Population Prospects: The 2000 Revision.

\section{Economically Active Population}

The economically active population comprises all persons of either sex who furnish the supply of labour for the production of economic goods and services as defined by the United Nations systems of national accounts and balances during a specified timereference period. According to these systems the production of economic goods and services includes all production and processing of primary products whether for the market for barter or for own consumption, the production of all other goods and services for the market and, in the case of households which produce such goods and services for the market, the corresponding production for own consumption.

\section{GDP, PPP per capita}

[Economics, Business, and the Environment]

Adapted from the World Bank's World Development Indicators

\section{Definition}

Gross Domestic Product (GDP) per capita, PPP is the total annual output to a country's economy, converted to current international dollars using Purchasing Power Parity (PPP) rates, and divided by the population of the country that year. GDP is the total market value of all final goods and services produced in a country in a given year, equal to total consumer, investment and government spending. Dollar figures for GDP are converted to international dollars using purchasing power parity (PPP) rates. An international dollar adjusted for PPP has the same purchasing power over GDP as a U.S. dollar in the United States and buys an equivalent amount of goods or services irrespective of the country. 
PPP rates provide a standard measure allowing comparisons of real price levels between countries, just as conventional price indexes allow comparison of real values over time. Values are in current dollars and are not adjusted for inflation.

Years Covered and Frequency of Update

The World Bank publishes the World Development Indicators each April. These values, published in 2004, are available for each year from 1975 to 2003.

Methodology

GDP at purchaser values (market prices) is the sum of gross value added by all resident and nonresident producers in the economy plus any taxes and minus any subsidies not included in the value of the products. The gross domestic product estimates at purchaser values (market prices) are in international dollars and are the sum of GDP at purchaser values (value added in the agriculture, industry, and services sectors) and indirect taxes, less subsidies. It is calculated without making deductions for depreciation of fabricated assets or for depletion and degradation of natural resources. Value added is the net output of an industry after adding up all outputs and subtracting intermediate inputs. The industrial origin of value added is determined by the International Standard Industrial Classification (ISIC) revision 3 (ISIC revision 3 is available at: http://unstats.un.org/unsd/cr/registry/regcst.asp?Cl=2\&Lg=1).

The PPP rates for each country are estimated through extrapolation and regression analysis using data from the International Comparison Programme (ICP). Computation of the PPP involves deriving implicit quantities from national accounts expenditure data and specially collected price data and then revaluing the implicit quantities in each country at a single set of average prices. PPP estimates tend to lower per capita GDPs in industrialized countries and raise per capita GDPs in developing countries (more information on ICP available at http://www.worldbank.org/data/).

GDP data for most developing countries are collected from national statistical organizations and central banks by visiting and resident World Bank missions. The data for high-income economies come from OECD data files (see the OECD's National Accounts, 1988-1999, volumes 1 and 2). The United Nations Statistics Division publishes detailed national accounts for United Nations member countries in National Accounts Statistics: Main Aggregates and Detailed Tables and updates in the Monthly Bulletin of Statistics (these can be found at:

http://unstats.un.org/unsd/nationalaccount/nadefault.htm).

Data Reliability

The World Bank produces the most reliable global GDP estimates available. However, many obstacles inhibit data collection. Informal economic activities sometimes pose a measurement problem, especially in developing countries, where much economic activity may go unrecorded. Obtaining a complete picture of the economy requires estimating 
household outputs produced for local sale and home use, barter exchanges, and illicit or deliberately unreported activity. Technical improvements and growth in services sector are both particularly difficult to measure. How consistent and complete such estimates will be depends on the skill and methods of the compiling statisticians and the resources available to them.

\section{Source}

Development Data Group, The World Bank. 2004. World Development Indicators 2004 online (see

http://publications.worldbank.org/ecommerce/catalog/product?item_id=631625)

Washington, D.C.: The World Bank.

\section{Industrialized? Percent of labor force in industry}

Utilized CIA's World Factbook data on "Labor force - by occupation," which is the percentage distribution of the labor force by occupation. The distribution will total less than 100 percent if the data are incomplete. The typical categories include: agriculture, industry, and services.

\section{Exports of Goods \& Services}

Exports of goods and services represent the value of all goods and other market services provided to the rest of the world. They include the value of merchandise, freight, insurance, transport, travel, royalties, license fees, and other services, such as communication, construction, financial, information, business, personal, and government services. They exclude labor and property income (formerly called factor services) as well as transfer payments.

\section{Imports of Goods \& Services}

Imports of goods and services represent the value of all goods and other market services received from the rest of the world. They include the value of merchandise, freight, insurance, transport, travel, royalties, license fees, and other services, such as communication, construction, financial, information, business, personal, and government services. They exclude labor and property income (formerly called factor services) as well as transfer payments.

\section{Total Unemployment - Percent of Total Labor Force}

Unemployment refers to the share of the labor force without work but available for and seeking employment. Definitions of labor force and unemployment differ by country. 